\title{
Prion protein-induced proteome alterations in sporadic Creutzfeldt-Jakob disease and in SH-SY5Y cell culture model
}

\section{PhD Thesis}

\author{
Dissertation \\ for the award of the degree \\ "Doctor of Philosophy" (Ph.D.) \\ in the Molecular Medicine PhD Program \\ at the Georg-August-University, Göttingen
}

submitted by

Joanna Gawinecka

born in

Aleksandrow Kujawski, Poland 


\title{
Members of the Thesis Committee
}

\author{
Prof. Dr. Inga Zerr
}

Department of Neurology

Medical Center Georg August University

Prof. Dr. Mathias Bähr

Department of Neurology

Medical Center Georg August University

Prof. Dr. Thomas Bayer

Department for Psychiatry

Division of Molecular Psychiatry

Medical Center Georg August University

Prof. Dr. Mikael Simons

Department of Neurology

Medical Center Georg August University

Date of the oral examination: 


\section{DECLARATION}

I hereby declare that this submission is my own work and that, to the best of my knowledge and belief, it contains no materials previously published or written by another person nor material which to a substantial extent has been accepted for the award of any other degree of the university or other institute of higher education, except where due acknowledgement has been made in the text.

Joanna Gawinecka

Göttingen, 10 October 2010 


\section{ACKNOWLEDGMENTS}

In the first place I would like to thank Prof. Dr. Inga Zerr for giving me the opportunity to work with her in the Prion Research Group at Neurology Department, Medical Center Georg August University. I am extremely grateful for her supervision and support throughout my $\mathrm{PhD}$ years. Above all, I would like to thank for her wonderful enthusiasm, boundless motivation and her trust.

I sincerely thank Prof. Dr. Mathias Bähr, Prof. Dr. Thomas Bayer and Prof. Dr. Mikael Simons for their supportive contributions as members of my thesis committee.

I owe many thanks to all current and former members of the Prion Research Group. Especially, I am grateful to Barbara Ciesielczyk and Monika Bodemer for introducing me into "Prionlabor" and helping to discover a lack of albumin on my 2D gels. Monika, thanks for your patience with me when I was re-organizing our lab according to my concepts. Barbara, thank you for all these non- and scientific talks which we could lead for hours and common fascination with Murakami. My heartfelt thanks to Dr. Karin Gmitterova and Dr. Uta Heinemann for giving me help at work and after it. Uta, thanks for realizing me that also biologist has to learn about disease and not only focus on the protein causing it. Karin, thanks for being my “dietnij sledz". I also want to thank Dr. Julie Carimalo for giving me hundreds of valuable advices, tolerating my moods, your willingness to help every time I need, and fun which we have after work. Special thanks to Jolanthe Ehrlich and Maja Schneider-Dominco for their effort to deal with all administrative issues as well as to Dr. Matthias Schmitz and Katja Herman for creating a friendly, supporting atmosphere in the lab.

I am thankful to members of Neuropathology Department. Especially, I would like to thanks Tatjana Pfander, Manuela Becker, Dr. Wiebke Wemheuer, Jutta Petschenka, Johanna Breyer, Arne Wrede and Dr. Walter Schluz-Schäffer. Tatjana, thanks for your outstanding technical assistance and providing me brain sections. Manuela, thanks a lot sharing with me all things which I needed and could not find in my own lab. Wiebke, Jutta and Johanna, I really appreciate your patience when I asked thousands times about keys and thanks for creating a friendly atmosphere in "unfriendly" S2 lab. Arne, thanks for giving me a lot of advices and spending time on microscoping in the dark room. 
I am grateful to Jana Dieks, Ruth Lehbrink and Martin Nowak for letting me to train on them my poor teaching skills and also I want to say sorry if I did not spend enough time with you or could not answer your all questions.

I would like to also express gratitude to the workers of Department of Clinical Chemistry: Christa Scholz, Christina Wiese, Saima Zafar and Dr. Abdul R. Asif. I thank Christa and Christina for their excellent technical assistance. Asif, thanks for troubleshooting and inspiration which you gave to me. Saima, it was nice to share bright and dark sides of $\mathrm{PhD}$ research with you and thanks for giving me cells.

I also want to thank Dr. Hassan Dihazi and Dr. Jan-Hendrik Streich for providing me HPLC and fluorescent scanner as well as for many valuable ideas and useful tips.

I would like to thank all the people whose names I did not mention here, but they gave me the necessary help and made it possible for me to write this thesis.

My appreciation for the financial support provided by Deutscher Akademischer Austauch Dienst (DAAD).

I am grateful to all my friends in Göttingen, who made my time here pleasurable and unforgettable. Thanks for being with me in good and bad moments.

I would also like to mention Rafael and thank him for giving me so much love and attention, as well as for sharing with me the same way of thinking and comprehending the world around us.

Finally, my parents and sisters deserve special place in my acknowledgments. My deep and lasting gratitude to them for their unconditional love, faith and support. Without you I would never reach as much as I reached having you always on my side. 


\section{LIST OF ABBREVIATIONS}

$\mathrm{AD}$ - Alzheimer's disease

ALDOA - aldolase A

ANXA5 - annexin A5

CJD - Creutzfeldt-Jakob disease

CSF - cerebrospinal fluid

ER - endoplasmic reticulum

GRB2 - growth factor receptor-bound protein 2

G6PI - glucose-6-phoshate isomerase

$\mathrm{LDH}$ - lactate dehydrogenase

MM - (methionine/methionine) codon 129 genotype in human PrP gene

NDC - non-demented neurological control

PDIA1 - disulfide isomerase precursor

PPID - $40 \mathrm{kDa}$ peptidyl-prolyl cis-trans isomerase

$P R N P$ - gene encoding human PrP

Prnp - gene encoding murine PrP

$\operatorname{PrP}$ - prion protein

$\operatorname{PrP}^{\mathrm{C}}$ - cellular prion protein

$\mathrm{PrP}^{\mathrm{Sc}}-$ scrapie prion protein

PSWC - periodic sharp wave complexes

sCJD - sporadic Creutzfeldt-Jakob disease

TAGL2 - transgelin-2

TCTP - translationally-controlled tumor protein

TSE - transmissible spongiform encephalopathie

VD - vascular dementia

VV - (valine/valine) codon 129 genotype in human PrP gene

$1433 \mathrm{G}-14-3-3$ protein gamma isoform

2D-DIGE - 2D Fluorescence Difference Gel Electrophoresis 


\begin{abstract}
Cellular prion protein $\left(\mathrm{PrP}^{\mathrm{C}}\right)$ is a glycosylated membrane glycoprotein mainly expressed in the central nervous system. Some still undefined molecular events can lead to the conversion of $\operatorname{PrP}^{\mathrm{C}}$ into an abnormal conformer called scrapie prion protein $\left(\mathrm{PrP}^{\mathrm{Sc}}\right) \cdot \operatorname{PrP}^{\mathrm{Sc}}$ is characterized by increased $\beta$-sheet content, detergent insolubility, partial resistance to protease digestion and tendency to aggregate in the brain tissue.

The conversion and subsequent aggregation of $\operatorname{PrP}^{\mathrm{Sc}}$ in the brain tissue underlay pathogenesis of transmissible spongiform encephalopathies. In turn, sporadic Creutzfeldt-Jakob disease is most common form of human transmissible spongiform encephalopathie. The heterogeneous disease phenotype is mainly influenced by the methionine/valine $(\mathrm{M} / \mathrm{V})$ polymorphism at codon 129 in the human prion protein gene (PRNP gene) and by the presence of two major types of pathological, protease-resistant forms of the prion protein $\left(\operatorname{PrP}^{\mathrm{Sc}}\right)$ leading to 2 different profiles in Western blot (type 1 and type 2).

This thesis includes 2 original publications that investigate the physiology and the pathology of the human prion protein.

In our first study, CSF proteome alterations in living, symptomatic sCJD patients with two different codon 129 genotypes (MM and VV) were analyzed using a proteomic approach consisted of 2D Fluorescence Difference Gel Electrophoresis (2D-DIGE) and mass spectrometry analysis.
\end{abstract}

CSF proteome profiling revealed up-regulation of 27 and down-regulation of 3 proteins in the MM-sCJD as well as the up-regulation of 24 proteins in the VV-sCJD when compared to control. Beside proteins showing common regulation for both codon 129 genotypes in SCJD, some proteins seem to be specifically regulated in certain genotype.

Almost $40 \%$ of sCJD specifically regulated proteins in CSF are involved in glucose metabolism, regardless of codon 129 polymorphism. The validation phase of selected glycolytic enzymes using Western blot technique confirmed up-regulation of ALDOA, LDH and G6PI when compared to three different control groups (NDC, AD and VD).

Furthermore, the immunolabeling showed that G6PI is present in reactive astrocytes in SCJD affected brain while it is predominantly localized in neurons in age-matched control brain. Additionally, decreased level of G6PI was found in the brain of MM1-sCJD subtype.

With these data, for the first time the implication of G6PI in prion-induced pathology was demonstrated. 
The identification of SCJD-regulated proteins in CSF proteome alterations in living, symptomatic sCJD- patients will broaden our knowledge about pathological processes occurring in SCJD, as they are still not fully understood. Moreover, they could serve as protein source to identify novel biomarkers for differential sCJD diagnosis.

In our second study, a proteomic approach was applied in order to reveal proteins, and thereby biological processes, affected by stable overexpression of human $\operatorname{PrP}^{\mathrm{C}}$ in human neuroblastoma SH-SY5Y cell line.

Densitometric analysis of silver stained 2D gels showed 18 differentially regulated proteins in SH-SY5Y cells overexpressing human $\operatorname{PrP}^{\mathrm{C}}$. Between them, 13 proteins were up- and 5 down-regulated. The $\mathrm{PrP}^{\mathrm{C}}$ overexpression in SH-SY5Y cells affected mostly few biological processes such as signal transduction, cytoskeleton organization and protein folding.

Proteomics gives a unique opportunity to analyze both physiological and pathological processes at the protein level on a global scale. Proteome analysis of SH-SY5Y human neuroblastoma cells stably overexpressing $\mathrm{PrP}^{\mathrm{C}}$ revealed proteins whose expression is directly modulated through $\operatorname{PrP}^{\mathrm{C}}$ and consequently physiological processes which are influenced by $\mathrm{PrP}^{\mathrm{C}}$ level in cells. On the other hand side, identification of CSF proteome alterations in sCJD provides more information about pathological processes occurring in the brain and caused by presence of $\operatorname{PrP}^{\mathrm{Sc}}$. Both these studies broaden our knowledge about still not fully understood pathobiology of PrP. 


\section{TABLE OF CONTENTS}

\section{INTRODUCTION TO THE SCIENTIFIC PROJECT}

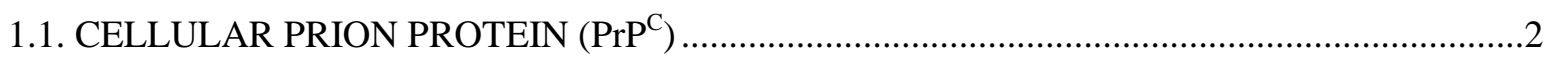

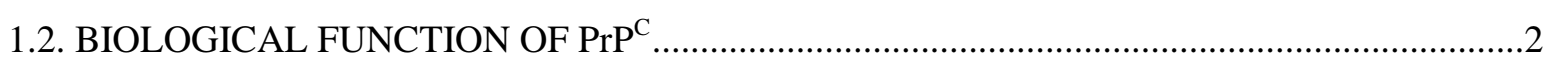

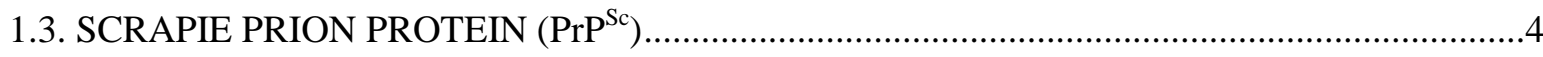

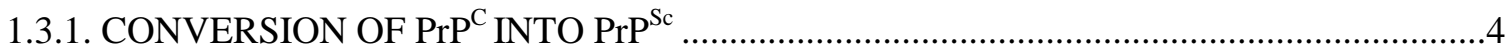

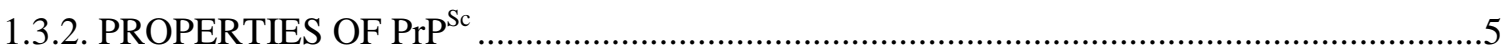

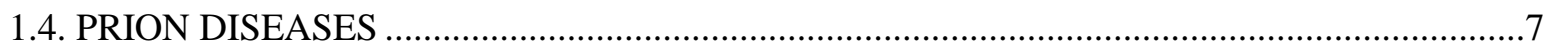

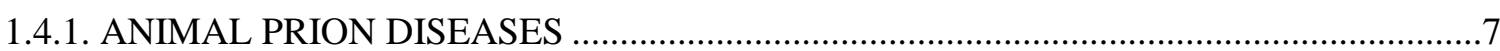

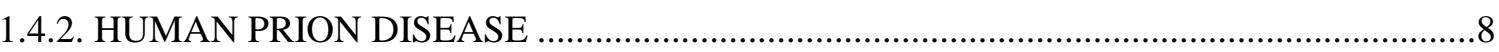

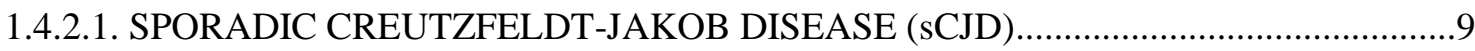

1.5. CSF PROTEOMICS AND BIOMARKER DISCOVERY IN CJD ........................................12

\section{FOCUS OF THE PRESENT WORK}

2.1. CODON 129 POLYMORPHISM SPECIFIC CSF PROTEOME PATTERN IN SPORADIC CREUTZFELDT-JAKOB DISEASE AND THE IMPLICATION OF GLYCOLYTIC ENZYMES

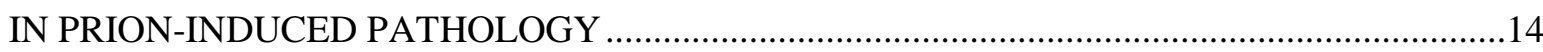

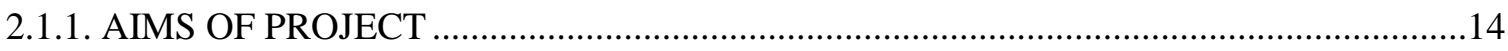

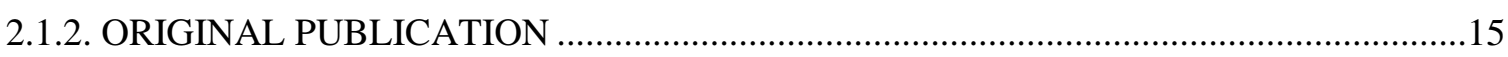

2.2. CELLULAR PRION PROTEIN OVEREXPRESSION DISTRUBS CELLULAR

HOMEOSTATSIS IN SH-SY5Y NEUROBLASTOMA CELLS BUT DOES NOT ALTER p53

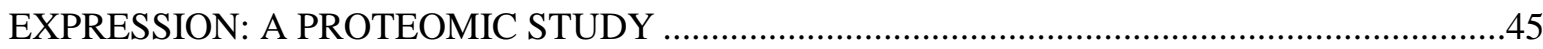

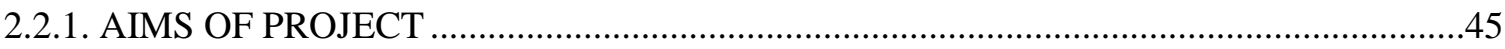

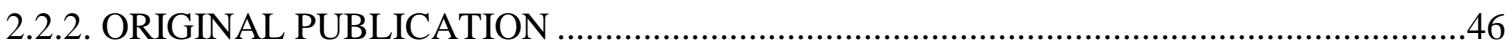

\section{DISCUSSION}

3.1. CODON 129 POLYMORPHISM SPECIFIC CSF PROTEOME PATTERN IN SCJD ............57

3.2. IMPLICATION OF GLYCOLYTIC ENZYMES IN SCJD PATHOLOGY ...........................58

3.3. DISTRUBANCES IN CELLULAR HOMEOSTASIS UPON STABLY PrPC OVERPRODUCTION IN HUMAN NEUROBLASTOME SH-SY5Y CELLS ...........................60

3.4. ANNEXIN A5 AS MOLECULAR PARTNER FOR PrP PATHOBIOLOGY ........................62

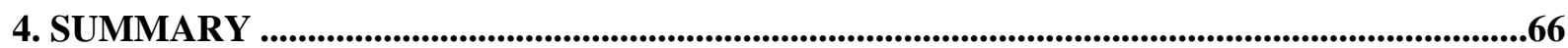

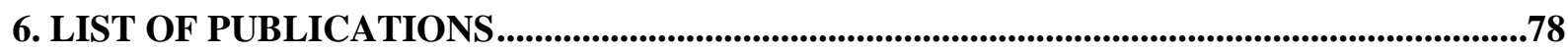

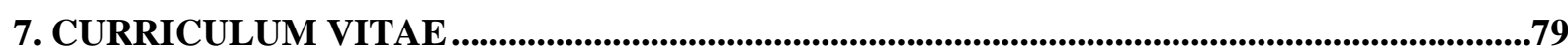




\subsection{Cellular prion protein $\left(\operatorname{PrP}^{\mathrm{C}}\right)$}

Cellular prion protein $\left(\operatorname{PrP}^{\mathrm{C}}\right)$ is a membrane glycoprotein, which has been found in all vertebrates and it is highly conserved in mammals (Wopfner et al., 1999). In humans, $\operatorname{PrP}^{\mathrm{C}}$ is encoded by a single-copy gene (PRNP) on chromosome 20 (Sparkes et al., 1986). It is predominantly expressed in the brain, but also found in the heart and skeletal muscle, in follicular dentritic cells, and in some lymphocytes (Bendheim et al., 1992; Ford et al., 2002; McBride et al., 1992).

$\operatorname{PrP}^{\mathrm{C}}$ is synthesized in the rough endoplasmic reticulum (ER) and transited trough the Golgi apparatus on its way to the plasma membrane. The maturation of the primary translation product consists of the removal of 22 amino acids $\mathrm{N}$-terminal signal sequence, the replacement of 23 amino acids at the C-terminus by a glycosylphosphatidyl inositol (GPI) anchor and the glycolysation of two asparagine residues (181N and 197N). The glycolysation sites are of variable occupancy and PrP exists in di-, mono- and unglycosylated forms, as shown by Western blot analysis (Figure 1).

The structure of $\operatorname{PrP}^{\mathrm{C}}$ comprises a globular domain containing three $\alpha$-helices, one short antiparallel $\beta$-sheet and a single disulfide bond. The $\mathrm{N}$-terminus contains five octapeptide repeats, which have high affinity for copper (II) ions. Moreover, it is highly flexible, thus does not adopt any stable tertiary structure (Riek et al., 1996; Brown et al., 1997a; Riek et al., 1997)

(Figure 1). $\operatorname{PrP}^{\mathrm{C}}$ is attached by the GPI anchor to lipid rafts on the outer cell surface, but it is also localized inside the cells (Knopman et al., 2003). $\operatorname{PrP}^{\mathrm{C}}$ undergoes constitutively internalization and endocytosis which is reversibly stimulated by copper (II) ions (Pauly and Harris, 1998; Prado et al., 2004).

\subsection{Biological function of $\operatorname{PrP}^{\mathrm{C}}$}

The exact biological function of $\operatorname{PrP}^{\mathrm{C}}$ still remains obscure. However, several physiological roles have been proposed, in particular cell adhesion, signaling, regulation of cell death, neuroprotection, protection against oxidative stress and involvement in the metabolic functions related to its copper-binding properties. 

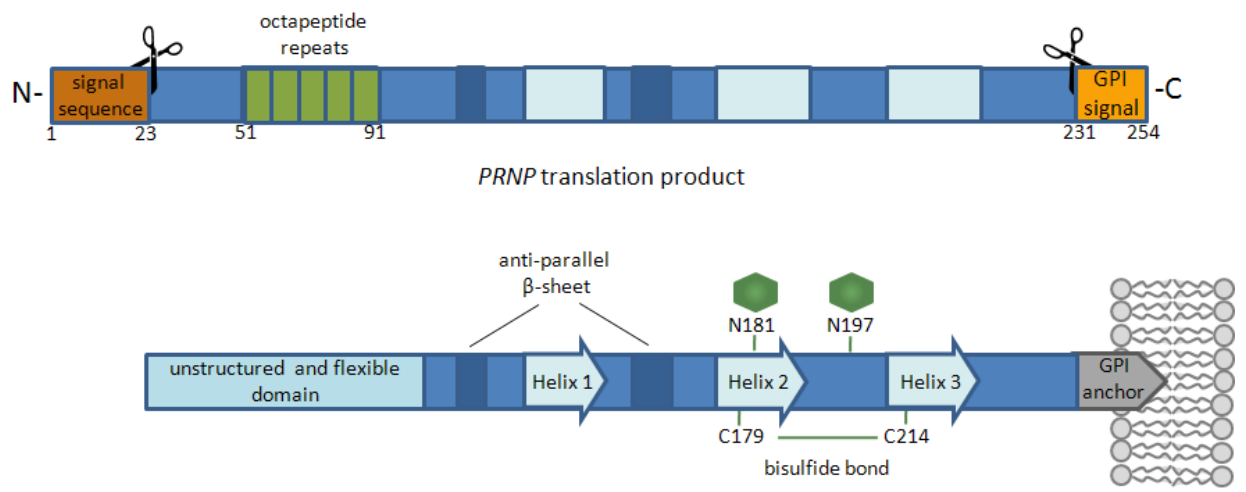

Mature human $\mathrm{PrPC}$
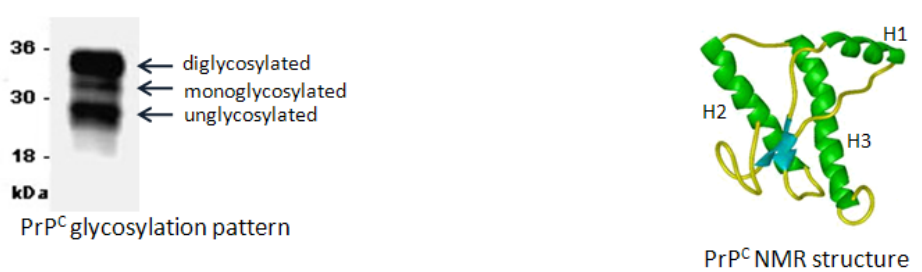

Figure 1. Schematic depiction of the $\operatorname{PrP}^{\mathrm{C}}$ structure and its maturation

The first evidence that $\operatorname{PrP}^{\mathrm{C}}$ protects against cell death was obtained in murine hippocampal neurons exposed to serum deprivation. Under these conditions, cell death in $\operatorname{Prnp}^{0 / 0}$ cells was more prominent than in the control counterpart cells. Moreover, restoring of $\mathrm{PrP}^{\mathrm{C}}$ expression in $\operatorname{Prnp}^{0 / 0}$ hippocampal cells followed by transfection with a Prnp gene protected these cells from serum deprivation-induced cell death in a similar manner to the well-known antiapoptotic protein Bcl-2 (Kuwahara et al., 1999). Moreover, apoptosis induced by microinjection of Bax into human fetal neurons was prevented by co-injection of PRNP gene (Bounhar et al., 2001). In sharp contrast to the data supporting a protective role of $\operatorname{PrP}^{\mathrm{C}}$ is observation that overexpression of $\mathrm{PrP}^{\mathrm{C}}$ leads to a gene dose-dependent unprovoked neurodegenerative genotype of transgenic mice (Westaway et al., 1994). Furthermore, ectopic $\mathrm{PrP}^{\mathrm{C}}$ expression potentiated staurosporine-stimulated caspase 3-dependent apoptosis in both HEK 293 cells and inducible $\operatorname{PrP}^{\mathrm{C}}$-transfected rabbit kidney epithelial cells (Paitel et al., 2002). On the other hand side, increased cellular content of $\operatorname{PrP}^{\mathrm{C}}$ in breast carcinoma MCF7 cells did not affect staurosporine-induced cell death (Roucou et al., 2003). It is very likely that the role of $\operatorname{PrP}^{\mathrm{C}}$ in cellular sensitivity to the cell death may differ among cell lines and depend on the availability of its interaction partners.

The localization of $\mathrm{PrP}^{\mathrm{C}}$ at the plasma membrane implies its function as a receptor triggering signals. In fact, $\operatorname{PrP}^{\mathrm{C}}$ mediates activation of the cAMP/ protein kinase A (PKA) pathway 
leading to neuroprotection in the retinal tissue (Chiarini et al., 2002; Martins et al., 1997). Furthermore, the activity of PI 3-kinase (PI3-K) was found to be higher in the brain of wild type than PrP-null mice and in neural cell lines transfected with Prnp gene when compared to parental cell lines. In Prnp-transfected cells, the activity of PI3-K as well as $\operatorname{PrP}^{\mathrm{C}}$-induced cytoprotection against oxidative stress was revoked by either copper chelation or deletion of the octarepeat domain. This suggests a major role that $\operatorname{PrP}^{\mathrm{C}}$ copper-binding domain in $\operatorname{PrP}^{\mathrm{C}}$ mediated/induced upregulation of PI3-K (Vassallo et al., 2005). Moreover, $\operatorname{PrP}^{\mathrm{C}}$-mediation of other signal transduction pathways involving mitogen-activated protein kinase/ extracellular signal-regulated kinase (MAPK/ERK), Fyn and Src kinases has been also reported (Chiarini et al., 2002; Schneider et al., 2003; Stuermer et al., 2004).

An increasing number of studies support $\mathrm{PrP}^{\mathrm{C}}$ role in protection cells from oxidative stress. Certainly, the most compelling observation confirming this is the fact that cerebellar granular and neocortical cultured neurons from PrP-null mice are more susceptible than wild type counterpart neurons to treatment with oxidative stress inducing agents such as hydrogen peroxide, xanthine oxidase and copper ions (Brown et al., 1997b; Brown et al., 2002). In line with these cell culture results are in vivo studies showing that brain tissue from PrP-null mice exhibits biochemical changes indicating presence of oxidative stress (Wong et al., 2001). Moreover, brain lesions induced by hypoxia and ischemia are significantly larger in PrP-null mice when compared to wild type mice (Mclennan et al., 2004; Sakurai-Yamashita et al., 2005; Spudich et al., 2005). Since both these pathological conditions probably cause neuronal cell death via oxidative damage, it can tie $\operatorname{PrP}^{\mathrm{C}}$ to a neuroprotective function against oxidative stress.

\subsection{Scrapie prion protein $\left(\mathrm{PrP}^{\mathrm{Sc}}\right)$}

\subsubsection{Conversion of $\operatorname{PrP}^{\mathrm{C}}$ into $\operatorname{PrP}^{\mathrm{Sc}}$}

The precise molecular events leading to the conversion of $\operatorname{PrP}^{\mathrm{C}}$ into the scrapie agent $\left(\operatorname{PrP}^{\mathrm{Sc}}\right)$ are still not well defined. It is known that this conversion involves a conformational change in which the $\alpha$-helical content diminishes and $\beta$-sheet content increases (Pan et al., 1993). The most coherent and general model to date proposes that PrP fluctuates between a dominant native state, $\operatorname{PrP}^{\mathrm{C}}$, and a series of minor conformations, one or a set of which can self-associate in an ordered manner to produce a stable structure, $\mathrm{PrP}^{\mathrm{Sc}}$, composed of misfolded $\operatorname{PrP}$ 
monomers. Once a stable "seed" structure is formed, PrP is then recruited leading to explosive autocatalytic $\operatorname{PrP}^{\mathrm{Sc}}$ formation (Collinge et al., 2001) (Figure 2). This model would be extremely sensitive to three factors: 1) the total PrP concentration, 2) the equilibrium of the distribution between the native and self-associating conformation, and 3) the complementarity between conformers in aggregation step. These three theoretical predictions are manifest in the etiology of prion diseases. First, an inversely proportional relationship between $\operatorname{PrP}^{\mathrm{C}}$ expression and disease incubation period in transgenic mice was described in several studies (Prusiner et al., 1990; Büeler et al., 1993; Collinge et al., 1995; Telling et al., 1995). Second, the predisposition of PrP to adopt a misfolded form induced by rather subtle mutations in the protein sequence was found (Collinge et al., 1997). Finally, molecular homogeneity is required for efficient $\mathrm{PrP}^{\mathrm{Sc}}$ propagation (Prusiner et al., 1990; Palmer et al., 1991).

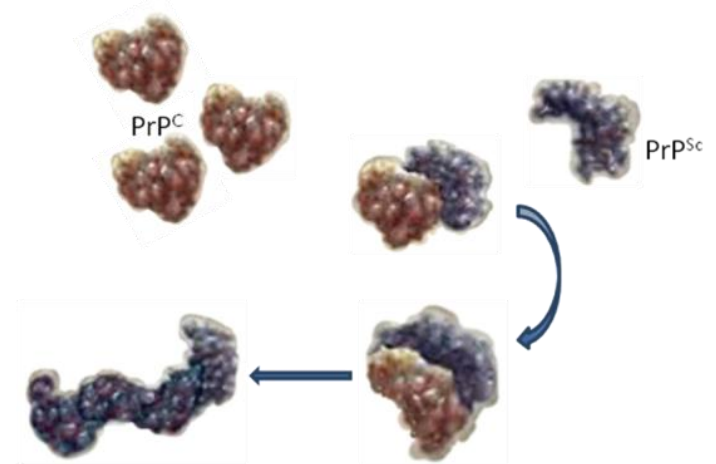

Figure 2. Schematic representation of $\mathrm{PrP}^{\mathrm{C}}$ conversion into $\mathrm{PrP}^{\mathrm{Sc}}$

\subsubsection{Properties of $\operatorname{PrP}^{\mathrm{Sc}}$}

$\operatorname{PrP}^{\mathrm{Sc}}$ is a $\beta$-sheet- rich protease resistant aggregating and infectious form of $\operatorname{PrP}^{\mathrm{C}}$. Its tertiary conformation is still unresolved, mainly because of its tendency to form large heterogeneous aggregates which are recalcitrant to analysis by high-resolution techniques. The greatest infectivity of $\mathrm{PrP}^{\mathrm{Sc}}$ is associated with $300-600 \mathrm{kDa}$ particles consisting of 14-28 $\operatorname{PrP}$ molecules. Much less specific infectivity was detected for monomeric PrP or large fibrils (Silveira et al., 2005). Many evidences suggest that the infectious form(s) of PrP may not be the proximate cause of neuronal dysfunction and degeneration in prion diseases. It has been shown that mutant forms of $\operatorname{PrP}$ (nine octapeptide insertion or GGS mutations) associated with familial prion disease are pathogenic, but not infectious (Chiesa et al., 2003; Nazor et al., 
2005). Furthermore, heterozygous transgenic mice expressing anchorless PrP inoculated with scrapie prions failed to develop typical clinical signs of scrapie infection. However, they were shown to replicate prion infectivity, albeit on lower level than wild type mice. Moreover, histopathological examination of brain tissue revealed a striking accumulation of extracellular protease-resistant PrP deposits with the characteristics of amyloid (Chesebro et al., 2005). Then again, homozygous transgenic mice, which express 2-fold more anchorless PrP than heterozygous transgenic mice, developed a fatal clinical disease upon scrapie infection. However, this disease differed markedly in incubation time, clinical signs and neuropathology from typical scrapie disease observed in wild type mice (Chesebro et al., 2010).

Cellular mechanism which underlies prion neurotoxicity still remains obscure. Different hypotheses are postulated: 1) loss, 2) subversion or 3) gain of PrP function. If the main function of $\mathrm{PrP}^{\mathrm{C}}$ is neuroprotection then loss of it upon conversion into or with $\mathrm{PrP}^{\mathrm{Sc}}$ would lead to prion-induced neurodegeneration. Incompatible with a loss-of-function mechanism of $\operatorname{PrP}$ toxicity is the observation that genetic ablation of $\operatorname{PrP}^{\mathrm{C}}$ expression has relatively little phenotypic effect and does not contribute to the development of any prion diseases features (Büeler et al., 1992; Manson et al., 1994; Mallucci et al., 2002). On the other hand, a dispensable biological activity of $\operatorname{PrP}^{\mathrm{C}}$ under physiological conditions may become essential in pathological state due to cellular or organismal stress. The subversion-of-function hypothesis presumes that interaction with $\operatorname{PrP}^{\mathrm{Sc}}$ converts $\operatorname{PrP}^{\mathrm{C}}$ from a neuroprotective signal transducer into a neurotoxic signal transducer. Consistent with this hypothesis is the observation that cross-linking of $\operatorname{PrP}^{\mathrm{C}}$ with anti-PrP antibodies induces apoptotic processes in neurons in vivo (Solforosi et al., 2004). Alternatively, $\operatorname{PrP}^{\mathrm{Sc}}$ may bind to and block specific regions of $\mathrm{PrP}^{\mathrm{C}}$, thereby altering the neuroprotective signaling properties. The neurodegenerative phenotype of transgenic mice expressing $\operatorname{PrP} \Delta 32-121 / 134$ suggests that specific domains of PrP are essential for its protective role and that deletion of these domains unmasks a neurotoxic activity, perhaps by altering interaction with critical signaling molecules (Behrens et al., 2002). These two above mentioned hypothesis stand in contrast to a toxic gainof-function mechanism, which is usually evoked to explain dominantly inherited neurodegenerative disorders including Alzheimer's, Huntington's, and Parkinson's disease. In these cases, the protein aggregates accumulating in the brain are presumed to possess a novel neurotoxic activity that is independent of the normal physiological function of the parent 
protein. Similarly, $\mathrm{PrP}^{\mathrm{Sc}}$ aggregates may have a neurotoxic effect by blocking axonal transport or interfering with synaptic transmission. Moreover, $\operatorname{PrP}^{\mathrm{Sc}}$ may disturb function of lysosomes and proteasome, where it accumulates, and/or increased ER stress.

\subsection{Prion diseases}

Prion diseases or transmissible spongiform encephalopathies (TSEs) are unique fatal neurodegenerative disorders of diverse phenotypes and forms affecting both humans and animals. The prototypic prion disease is scrapie, a naturally occurring disease affecting sheep and goats. More recently defined animal prion diseases include transmissible mink encephalopathy, chronic wasting diseases and bovine spongiform encephalopathy. Human prion diseases have been classified in three forms sporadic (sporadic Creutzfeldt-Jakob disease), familial (genetic Creutzfeldt-Jakob disease, Gerstmann-Sträussler-Scheinker syndrome, fatal familial insomnia and genetic TSEs) and acquired by infection (iatrogenic CJD, variant CJD and Kuru).

\subsubsection{Animal prion diseases}

Scrapie occurring in sheep and goats was the first prion disease being recognized in Europe for over 200 years ago. However, only little is known about its natural routes of transmission. Scrapie is also the first TSE experimentally transmitted to primates, rodents, and other species (Wharton et al., 2005).

To date chronic wasting disease (CWD) and transmissible mink encephalopathy of wild as well as captive deer and mink appear only in North America. Some evidences suggest that these prion diseases can spread through contamination of feed and water sources with urine, saliva and faeces. Moreover, soil and soil minerals can serve as a reservoir of TSE infectivity (Petersen et al., 2006). This brings a potential risk to cattle and also to humans although no evidence of natural transmission of CWD to non-cervids has been reported so far (Belay et al., 2004).

The first case of bovine spongiform encephalopathy (BSE) was recognized in 1986 in UK and spread next decade as a massive epidemic infecting about 1 million cows (Anderson et al., 1996). Export of cattle and feed scattered BSE to countries around the world. The source of disease outbreak was evidently the contamination of meat-and-bone meal supplements with 
scrapie-infected sheep carcasses. Thanks to the prohibition of feeding cattle with ruminant carcasses, the incidence of BSE diminished.

\subsubsection{Human prion diseases}

Sporadic Creutzfeldt-Jakob disease (CJD) is the most common form of human TSEs and accounts for about $85 \%$ of all cases. The annual incidence rate is 1-2 cases per million people worldwide. Unfortunately, the etiology of sporadic CJD remains unclear. The hypothesis favours either a spontaneous change of PrP structure or a somatic mutation in the PRNP gene leading to an abnormal form of the protein. Familial prion diseases are associated with autosomal dominant inheritance of mutations in the PRNP gene (Knight et al., 2006).

Over 30 different mutations in the PRNP gene have been already reported, but only four point mutations, at codon 102, 178, 200 and 210, as well as insertions of five or six octapeptide repeats account for $95 \%$ of all familial cases (Mead et al., 2006) (Figure 3).

\section{positions of mutations}

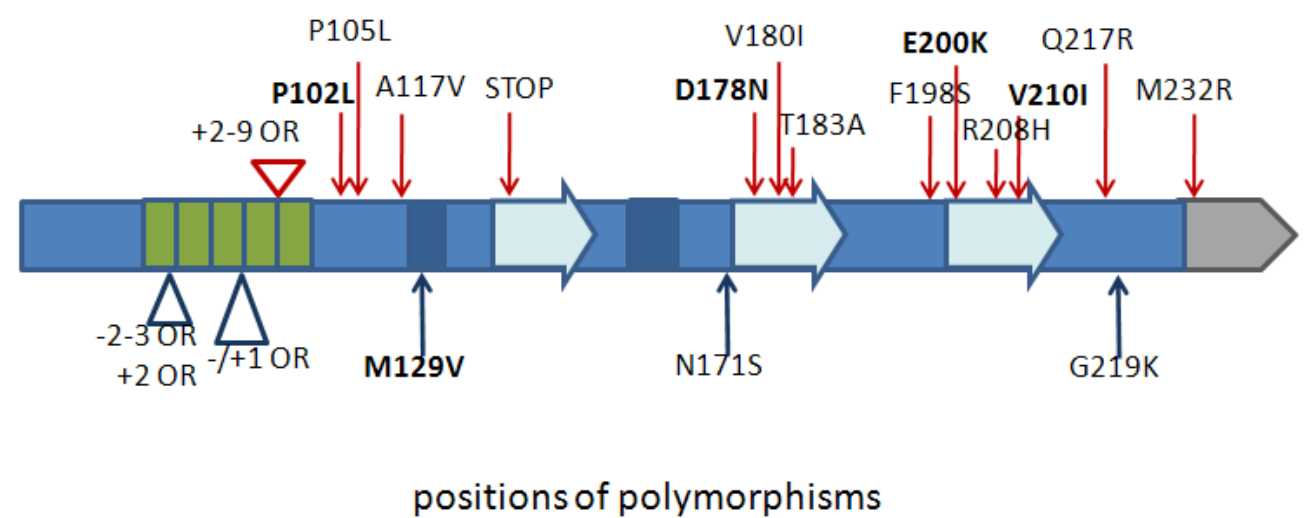

Figure 3. The most common polymorphism and mutation sides in human PRNP gene

In general, familial prion diseases are characterized by earlier age of onset and longer clinical course when compared to sporadic CJD. Patients affected by Gerstmann-Sträussler-Scheinker (GSS) syndrome, caused by the point mutation either at codon 102 (P102L) or at codon 105 (P105L), developed progressive cerebellar ataxia and spastic paraparesis between $20-40^{\text {th }}$ year of life. Moreover, the presence of PrP-amyloid plaques in the brain is unique for this syndrome (Bugiani et al., 2000). Both, genetic CJD forms linked to E200K-129M and V210I- 
129M mutations show similar clinical and pathological features like sporadic CJD (Gambetti et al., 2003). The disease phenotype associated with the mutation at codon 178 is determined by the polymorphism at codon 129; D178N-129M causes fatal familial insomnia (FFI), while D178N-129V causes typical genetic CJD (Goldfarb et al., 1992). The clinical course of FFI is dominated by progressive insomnia, autonomic dysfunction and dementia.

To the acquired forms of human prion diseases belong iatrogenic CJD (iCJD), variant CJD (vCJD) and Kuru. Transmission of iCJD from one person to another has occurred via medical or surgical treatment such as corneal transplants, dural grafts, growth hormone extracted from human pituitary glands and contaminated neurosurgical instruments (Gibbs et al., 1994; Lang et al., 1998; Will, 2003). Moreover, the increased susceptibility to iCJD has been found for methionine or valine homozygosity at codon 129 in the PRNP gene (Brown et al., 2000). vCJD is considered to be a result of BSE infectious agent entering human food chain. Biochemical analysis and transmission studies confirmed that vCJD and BSE are caused by the same scrapie prion strain (Collinge et al., 1996; Hill et al., 1997). The risk period in the UK fell approximately on 1980-1996, when the most of cases appeared (Knigt et al., 1999). The young age at onset, the prominence of psychiatric and sensory symptoms and the long disease duration distinguish vCJD from sporadic form. Furthermore, all vCJD cases tested to date have been homozygous for methionine at codon 129 (Will et al., 2000). Kuru had been transmitted through a ritual cannibalism. However, after abolition of a bereavement ceremony, in which highly infectious organs from dead relatives were primarily eaten by women and children, the spread of this disease has been greatly limited (Huillard d'Aignaux et al., 2002).

\subsubsection{Sporadic Creutzfeldt-Jakob disease}

Sporadic Creutzfeldt-Jakob disease (sCJD) is characterized by wide clinical and pathological variability. The disease phenotype is mainly influenced by the methionine/valine (M/V) polymorphism at codon 129 in the PRNP gene and by the presence of two major types of protease-resistant form of the $\operatorname{PrP}$ (type 1 and type 2). These two $\operatorname{PrP}^{\mathrm{Sc}}$ types are distinguishable based on the molecular weight of unglycosylated form of $\mathrm{PrP}^{\mathrm{Sc}}$ after proteinase $\mathrm{K}(\mathrm{PK})$ digestion. In $\mathrm{PrP}^{\mathrm{Sc}}$ type 1 , the unglycosylated form migrates at $21 \mathrm{kDa}$, while in $\operatorname{PrP}^{\mathrm{Sc}}$ type 2 it migrates at $19 \mathrm{kDa}$ (Parchi et al., 1996). Different PK cleavage occurs probably due to existence of two major conformational states of $\operatorname{PrP}^{\mathrm{Sc}}$. 
The major subtypes of SCJD are homozygous for methionine at codon 129 in PRNP gene with $\mathrm{PrP}^{\mathrm{Sc}}$ type 1 (MM1-sCJD), homozygous for valine at codon 129 in PRNP gene with $\operatorname{PrP}^{\mathrm{Sc}}$ type 2 (VV2-sCJD) and heterozygous with $\mathrm{PrP}^{\mathrm{Sc}}$ type 2 (MV2-sCJD), representing about 67\%, $15 \%$ and $9 \%$ of all sCJD cases, respectively (Figure 4 ).

The most important differential diagnoses of sCJD include Alzheimer's disease (AD), vascular dementia (VD), dementia with Lewy body, brain tumors and cerebellar degeneration (WHO, 1998).

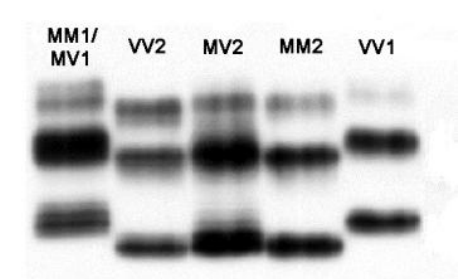

Figure 4. $\operatorname{PrP}^{\mathrm{Sc}}$ types in sCJD [adapted from (Gambetti et al., 2003)]

The MM1-sCJD subtype was previously described as myoclonic or "classic" CJD. The typical clinical features of this subtype are short disease duration of 4 months with cognitive impairment, mental and visual signs. For MV1 subtype, which is usually grouped together with MM1-sCJD, ataxia rather than cognitive decline is present at onset. Within the first 3 months of disease course in about $80 \%$ of the MM1 and MV1-sCJD cases, periodic sharp wave complexes (PSWC) are detected in EEG (Parchi et al., 1999). MRI examination revealed the presence of basal ganglia hyperintensities in about 70\% of MM1-sCJD cases (Meissner et al., 2009). Furthermore, the diagnostic test based on the presence of 14-3-3 protein in the cerebrospinal fluid (CSF) is positive in about 95\% cases (Castellani et al., 2004; Sanchez-Juan et al., 2006). Similarly to other CJD forms, the histopathological features of these subtypes are spongiform degeneration, astrogliosis and neuronal loss. The spongiform degeneration is made of fine vacuoles and is fairly homogeneously distributed within the affected regions. The topography of the lesions shows that the cerebral neocortex, especially in the occipital lobe, is more severely affected than basal ganglia, thalamus and cerebellum while the brain stem is spared. $\mathrm{PrP}^{\mathrm{Sc}}$ immunodetection shows a characteric punctate pattern of staining (synaptic) with a degree of intensity that is overall directly related to the severity of the affected brain regions. The immunostaining is often homogenous, but relatively large regions may remain either unstained or with variable staining intensities (Gambetti et al., 2003). 
The VV2-sCJD subtype represents the cerebellar or ataxic variant, because ataxia is the most prominent presenting sign. With disease progression, dementia, myoclonus and pyramidal signs are developed. In contrast, cortical signs such as aphasia or apraxia are very rarely observed in this subtype. In the great majority of VV2-sCJD cases, EEG shows non-specific slowing while in less than $10 \%$ of cases PSWC are present (Gambetti et al., 2003). The basal ganglia hyperintensities occur in 77\% of VV2-sCJD cases (Meissner et al., 2009). Moreover, the sensitivity of 14-3-3 is about $85 \%$ (Castellani et al., 2004; Sanchez-Juan et al., 2006). The lesion triad composed of fine spongiform degeneration, astrogliosis and neuronal loss is also present in VV2-sCJD subtype. Similarly to MM1-sCJD, the spongiform changes are made of fine vacuoles, but deeper cortical layers are preferentially affected. The topography of the lesions shows that the cerebral neocortex is usually more severely affected in the frontal than in the occipital lobe. The severity of the lesions depends on the disease duration so that the cerebral cortex is often spared in cases with rapid course. Overall, the cerebral neocortex is less affected than basal ganglia and thalamus, moreover, lesions are present in the brain stem, the dorsal regions and the substantia nigra. $\operatorname{PrP}^{S c}$ immunohistochemistry displays the presence of focal aggregates looking like plaques. Moreover, the intense immunostaining is found along cell processes and is especially prominent in basal ganglia and thalamus. The hallmark of VV2-sCJD subtype is the immunostaining pattern of the cerebellum showing intense immunostaining of the Purkinje cells and the upper granule cell layers (Gambetti et al., 2003). The MV2-sCJD is phenotypically and histopathologically similar to the VV2-sCJD subtype, but easily distinguishable due to significantly longer disease duration with a mean duration of 17 months and the presence of Kuru plaques in the cerebellum. However, cognitive, mental or pyramidal signs and myoclonus are often present in MV2-sCJD while they are absent in VV2sCJD subtype. The sensitivity of 14-3-3 test is about $60 \%$, thus significantly lower than for other sCJD subtypes (Castellani et al., 2004; Sanchez-Juan et al., 2006). The hyperintensity of basal ganglia has been found in $77 \%$ of cases (Meissner et al., 2009). In contrast to VV2SCJD, MV2-sCJD subtype is characterized by the lack of any significant cerebellar cortical atrophy.

The presentation of MM2-sCJD subtype is dominated by cognitive decline observed in all cases. The disease duration for this subtype is 3-4 times longer when compared to disease duration of MM1-sCJD subtype. The EEG shows non-specific slowing and 14-3-3 test is 
positive in about 75\% of MM2-sCJD cases (Gambetti et al., 2003; Castellani et al., 2004; Sanchez-Juan et al., 2006). The typical feature of this subtypes is the spongiform degeneration with large vacuoles which was previously identified as status spongiosis and more recently as coarse spongiosis (Parchi et al., 1996). The vacuoles are several times larger than vacuoles found in MM1-sCJD and widespread in the cerebral cortex, basal ganglia and thalamus. They are often confluent resulting in the formation of tissue islands surrounded by vacuoles. The $\mathrm{PrP}^{\mathrm{Sc}}$ immunostaining shows two basic patterns: an intense staining of the large vacuoles rim and a spotted staining with loose plaque formations (Budka et al., 1995).

The VV1-sCJD subtype is the most uncommon one with characteristic features of early onset and dementia of frontotemporal type (Parchi et al., 1999). The EEG shows slowing, but not PSWC and 14-3-3 test are positive in all cases (Gambetti et al., 2003; Castellani et al., 2004; Sanchez-Juan et al., 2006). The basal ganglia hyperintensity was not detected in VV1-CJD subtype (Meissner et al., 2009). The hallmark of this subtype is dissociation between the histopathological lesions (severe fine spongiform degeneration, gliosis and occasionally neuronal loss) and synaptic pattern of $\mathrm{PrP}^{\mathrm{Sc}}$ staining. The hippocampal cortex is more affected while thalamus and cerebellum are less affected when compared to MM1-sCJD (Gambetti et al., 2003).

\subsection{CSF proteomics and biomarker discovery in CJD}

Proteomic approach has been already applied for the investigation of CSF proteome changes in CJD and the searching for novel biomarkers. Interestingly, First reported biomarkers in CJD were proteins 130 and 131, later identified as proteins belonging to 14-3-3 family (Harrington et al., 1986; Hsich et al., 1996).

Analyzing native CSF from MM1-sCJD, Piubelli and colleagues (Piubelli et al., 2006) detected 7 up-regulated and 6 down-regulated proteins. Besides SCJD-associated dysregulation in CSF, levels of ubiquitin, gelsolin and $\alpha$-1-antichymotrypsin were also altered in CSF or/and blood of AD patients (Iqbal et al., 1997; Demeester et al., 2000; DeKosky et al., 2003; Puchades et al., 2003). This might suggest their role in general neurodegenerative processes caused by the presence of misfolded proteins in the brain. Similarly to the studies of Sanchez and colleagues (Sanchez et al., 2004) very high up-regulation of cystatin C, a inhibitor of cysteine proteinases, was found in CSF, thus this protein was proposed as a novel CJD 
biomarker. Interestingly, gene encoding cystatin $\mathrm{C}$ was found be up-regulated in global expression profiling of sCJD affected brain (Xiang et al., 2005).

In other studies, comparison of CSF patterns between CJD, AD and controls revealed 5 protein spots present only in CJD. However, no further characterisation of these proteins was performed. Finally, Brechlin and colleagues (Brechlin et al., 2008) applied DIGE technology to investigate CSF in CJD, using fluorescent labelling, depleting albumin and $\operatorname{IgG}$ as well as including other dementia as controls significantly increased specificity of obtained results. Unfortunately, neither specific nor promising candidate for biomarker was detected in these studies.

Furthermore, native CSF from sCJD and vCJD to CSF from other dementia was also already compared and 7 proteins with different abundance were found in two CJD forms. Between them, apolipoprotein E showed significantly higher level in vCJD comparing to SCJD (Choe et al., 2002). Apolipoprotein A1, apolipoprotein E and prostaglandin-H2-D-isomerase showed different levels in both schizophrenia and CJD (Choe et al., 2002; Piubelli et al., 2006; Martins-De-Souza et al., 2010). These proteins are involved in cholesterol and phosholipid metabolism, thus the maintenance of cell membrane could be potentially altered in mental brain disorder as well as in fatal neurodegenerative brain disorder. In fact, one hypothesis postulates that schizophrenia is associated with disordered membrane lipid metabolism (Horrobin et al., 1994; Mahadik et al., 1994). Additionally, alterations in cholesterol metabolism in scrapie mice infected with ME7 strain have been also reported (Xiang et al., 2007).

Taken all together, emerging proteomics field give us tools to explore CSF proteome and reveal protein that may be involved in disease pathogenesis as well as give us a unique possibility to discover novel biomarkers of neurodegenerative disorders including human prion diseases. 


\section{FOCUS OF THE PRESENT WORK}

\subsection{Codon 129 polymorphism specific CSF proteome pattern in sporadic Creutzfeldt- Jakob disease and the implication of glycolytic enzymes in prion-induced pathology}

\subsubsection{Aims of the project}

In this project, we determined CSF proteome alterations in living, symptomatic sCJD patients with two different codon 129 genotypes (MM and VV). This was acquired by applying a proteomic approach consisted of 2D Fluorescence Difference Gel Electrophoresis (2D-DIGE) and mass spectrometry.

At the molecular level, TSEs are caused by the conversion of a host cellular glycoprotein, the prion protein $\left(\mathrm{PrP}^{\mathrm{C}}\right)$ into a pathological conformer called scrapie prion protein $\left(\mathrm{PrP}^{\mathrm{Sc}}\right)$, which tends to aggregate and accumulate in the brain tissue. The presence of pathological form of PrP induces brain proteome changes, which might be different in particular disease subtypes. We hypothesize that these alterations may also be reflected in CSF from symptomatic SCJD patients.

A deep insight in prion-induced CSF proteome alterations in living symptomatic sCJDpatients will broaden our knowledge about pathological processes occurring in SCJD, as they are still not fully understood. Moreover, they could serve as protein source to identify novel biomarkers for a differential sCJD diagnosis. 


\subsubsection{Orginal publication}

The results described below are published in:

Joanna Gawinecka, Jana Dieks, Abdul R. Asif, Julie Carimalo, Uta Heinemann, Jan-Hendrik Streich, Hassan Dihazi, Walter Schulz-Schaeffer, Inga Zerr. Codon 129 polymorphism specific CSF proteome pattern in sporadic Creutzfeldt-Jakob disease and the implication of glycolytic enzymes in prion-induced pathology. Journal of Proteome Research 2010 Sep 27. [Epub ahead of print]

Author contribution:

This study was designed, performed and interpreted by Joanna Gawinecka. Jana Dieks was involved in preparatory phase and sample collection. Julie Carimalo gave valuable advices for immunohistochemical analysis. Abdul R. Asif performed mass spectrometry analysis. Uta Heinemann helped with the patient selection. Jan-Hendrik Streich optimized conditions of the CSF fractionation. Hassan Dihazi provided fluorescent scanner used to obtain images of 2D gel. Walter Schulz-Schaeffer provided brain samples. The publication was written by Joanna Gawinecka and Inga Zerr. 


\section{prouralofteome \\ research}

\section{Article}

Subscriber access provided by Niedersächsische Staats- und Universitätsbibliothek Göttingen

\section{Codon 129 polymorphism specific CSF proteome pattern \\ in sporadic Creutzfeldt-Jakob disease and the implication \\ of glycolytic enzymes in prion-induced pathology}

Joanna Gawinecka, Jana Dieks, Abdul R. Asif, Julie Carimalo, Uta Heinemann,

Jan-Hendrik Streich, Hassan Dihazi, Walter J. Schulz-Schaeffer, and Inga Zerr

J. Proteome Res., Just Accepted Manuscript • DOI: 10.1021/pr1004604 • Publication Date (Web): 27 September 2010

Downloaded from http://pubs.acs.org on September 29, 2010

\section{Just Accepted}

"Just Accepted" manuscripts have been peer-reviewed and accepted for publication. They are posted online prior to technical editing, formatting for publication and author proofing. The American Chemical Society provides "Just Accepted" as a free service to the research community to expedite the dissemination of scientific material as soon as possible after acceptance. "Just Accepted" manuscripts appear in full in PDF format accompanied by an HTML abstract. "Just Accepted" manuscripts have been fully peer reviewed, but should not be considered the official version of record. They are accessible to all readers and citable by the Digital Object Identifier (DOI@). "Just Accepted" is an optional service offered to authors. Therefore, the "Just Accepted" Web site may not include all articles that will be published in the journal. After a manuscript is technically edited and formatted, it will be removed from the "Just Accepted" Web site and published as an ASAP article. Note that technical editing may introduce minor changes to the manuscript text and/or graphics which could affect content, and all legal disclaimers and ethical guidelines that apply to the journal pertain. ACS cannot be held responsible for errors or consequences arising from the use of information contained in these "Just Accepted" manuscripts.

\section{ACS Publications}




\begin{abstract}
Cerebrospinal fluid (CSF) contains a dynamic and complex mixture of proteins, which can reflect a physiological and pathological state of the central nervous system. In our present study we show CSF protein patterns from patients with the two most frequent subtypes of sporadic Creutzfeldt-Jakob disease (sCJD) defined by the codon 129 genotype (MM, MV and $\mathrm{VV}$ ) and the protease-resistant form of prion protein (type1 and type 2).

The densitometric analysis of 2D gels showed up-regulation of 27 and down-regulation of 3 proteins in the MM-sCJD as well as the up-regulation of 24 proteins in the VV-sCJD as compared to non-demented control. Almost $40 \%$ of sCJD specific regulated proteins in CSF are involved in glucose metabolism, regardless of the codon 129 polymorphism. The increase in CSF levels of lactate dehydrogenase (LDH), glucose-6-phosphate isomerase (G6PI) and fructose-bisphosphate aldolase A (ALDOA) were validated on a larger group of sCJD patients including three possible codon 129 polymorphisms carriers and three control groups consisting of non-demented, neurological cases as well as patients suffering from Alzheimer's disease or vascular dementia. Subsequently, the abundance of these glycolytic enzymes in the brain as well as their cellular localization were determined.

This study demonstrates for the first time the implication of G6PI in prion-induced pathology as well as its cellular translocalization in SCJD. The identification of sCJD-regulated proteins in CSF of living symptomatic patients in our study can broaden our knowledge about pathological processes occurring in SCJD, as they are still not fully understood.
\end{abstract}

Keywords:

CJD, CSF, proteome, 2D DIGE, Creutzfeldt-Jakob disease, cerebrospinal fluid, 2-D Fluorescence Difference Gel Electrophoresis 


\section{Introduction}

Sporadic Creutzfeldt-Jakob disease (sCJD), the most common form of human transmissible spongiform encephalopathies (TSEs), is characterized by wide clinical and pathological variability. Disease phenotype is mainly influenced by the methionine/valine (M/V) polymorphism at codon 129 in the human prion protein gene (PRNP gene) and by the presence of two major types of pathological, protease-resistant form of prion protein $\left(\mathrm{PrP}^{\mathrm{Sc}}\right)$ leading to 2 different profiles in Western blot (type 1 and type 2$)^{1}$. The major subtypes of sCJD are homozygous for methionine at codon 129 in PRNP gene with PrP ${ }^{\mathrm{Sc}}$ type 1 (MM1sCJD), homozygous for valine at codon 129 in PRNP gene with $\operatorname{PrP}^{\mathrm{Sc}}$ type 2 (VV2-sCJD) and heterozygous for $\mathrm{PrP}^{\mathrm{Sc}}$ type 2 (MV2-sCJD), representing about $67 \%, 15 \%$ and $9 \%$ of all sCJD cases, respectively. The clinical and pathological characteristics of these 6 molecular disease subtypes differ markedly with respect to symptoms at onset, localisation and type of the pathological changes as well as $\mathrm{PrP}^{\mathrm{Sc}}$ deposition pattern ${ }^{1,}{ }^{2}$. This might suggest the involvement of different molecular pathways in SCJD pathogenesis.

At the molecular level, TSEs are caused by the conversion of a host cellular glycoprotein, the prion protein $\left(\mathrm{PrP}^{\mathrm{C}}\right)$ into an abnormal conformer called scrapie prion protein $\left(\operatorname{PrP}^{\mathrm{Sc}}\right) \cdot \operatorname{PrP}^{\mathrm{Sc}}$ is characterized by increased $\beta$-sheet content, detergent insolubility, partial resistance to protease digestion and tendency to aggregate in the brain tissue. $\operatorname{PrP}^{\mathrm{Sc}}$ accumulation and aggregation may induce proteome changes in the central nervous system. Furthermore, these prion-induced alterations of the brain proteome may also be reflected in the CSF of SCJD patients. However, due to high dynamic range of protein abundance in CSF spanning twelve orders of magnitude ${ }^{3}$ and the fact that around 10 very well known proteins (e.g. albumin, immunoglobulins, transferrin and haptoglobin) comprise up to $90-95 \%$ of the total protein content, depletion of the high abundant proteins is indispensible for in-depth exploration of sCJD-associated alterations in the CSF proteome. The brain proteome alterations found in CSF can serve as a source of potential CJD biomarkers. The first identified diagnostic biomarker by applying proteomic approach was the 14-3-3 protein, which was introduced for CJD diagnosis ${ }^{4-7}$ later on.

In this study, we show CSF proteome patterns specific for MM and VV codon 129 genotype in SCJD acquired by the application of 2D Fluorescence Difference Gel Electrophoresis (2D- 
DIGE) approach. Moreover, the depletion of 12 high abundant proteins allowed a detailed view on proteome alterations induced by $\operatorname{PrP}^{\mathrm{Sc}}$ in CSF in living, symptomatic patients. The identification of sCJD-regulated proteins broadens our knowledge about pathological processes occurring in SCJD which are still not fully understood.

\section{Patients, Materials and Methods}

\section{Patients}

For 2D Fluorescence Difference Gel Electrophoresis (2D-DIGE) analysis 8 CSF samples from SCJD cases and 8 non-demented individuals were used. The SCJD group consisted of 4 patients homozygous for the methionine (MM) at codon 129 and 4 patients homozygous for the valine (VV) with a mean age of $69 \pm 3$ years and $68 \pm 4$ years, respectively. According to the WHO criteria, 5 patients were classified as having "probable" sCJD and 3 others as having "definite" sCJD (two MM1 and one VV2 type in Parchi's classification) ${ }^{1}$. The CSF samples were taken for diagnostic purposes. However, due to very rapid progress of SCJD and unspecific symptoms at the onset, at the time of lumbar puncture the disease was progressed to either the middle or late stage. The control group consisted of 8 individuals with a mean age of $69 \pm 4$ years and no signs of cognitive decline, which underwent lumbar puncture for various differential diagnostic purposes (Tab. 1). For both groups, CSF parameters did not show any evidence of blood-CSF barrier dysfunction, acute or chronic inflammation or intrathecal immuno response (Tab. 2). Furthermore, none of the sCJD and control patients was a heavy smoker, drug- or alcohol-abused.

To confirm up-regulation of selected proteins by Western blot, CSF samples from 8 nondemented controls (NDC), 8 patients suffering from vascular dementia (VD), 10 Alzheimer's disease patients $(\mathrm{AD})$ and 30 probable or definite sCJD patients (11 homozygous for MM, 9 homozygous for VV and 10 heterozygous at codon 129) were analyzed. The diagnosis of VD and $\mathrm{AD}$ was determined according to diagnostic criteria of the National Institute of Neurological Disorders and Stroke and the Association Internationale pour la Recherché et l'Enseignement en Neurosciences (NINDS-AIREN), and the National Institute of Neurological and Communicative Disorders and the Stroke and the Alzheimer's Disease and Related Disorders Association (NINCDS-ADRDA), respectively. 


\begin{tabular}{|c|c|c|c|c|c|c|c|c|c|}
\hline $\mathbf{N r}$ & Case & $\begin{array}{c}\text { Age } \\
\text { [years] }\end{array}$ & Sex & $\begin{array}{c}\text { Disease } \\
\text { duration } \\
\text { [month] }\end{array}$ & $\begin{array}{l}\text { Time point } \\
\text { of lumbar } \\
\text { puncture }{ }^{\pi}\end{array}$ & MRI $^{¥}$ & EEG* & $14-3-3^{\#}$ & $\begin{array}{c}\mathrm{Tau}^{\S} \\
{[\mathrm{pg} / \mathrm{ml}]}\end{array}$ \\
\hline 1 & definite MM1-sCJD & 67 & $\bar{F}$ & 4.5 & middle stage & + & + & + & 2282 \\
\hline 2 & definite MM1-sCJD & 72 & M & 3.5 & late stage & - & + & + & 24000 \\
\hline 3 & probable MM-sCJD & 65 & M & 3.5 & middle stage & - & + & + & 14550 \\
\hline 4 & probable MM-sCJD & 70 & M & 8.5 & late stage & + & - & + & 8351 \\
\hline 5 & definite VV2-sCJD & 66 & $\mathrm{~F}$ & 3.5 & middle stage & + & - & + & 18014 \\
\hline 6 & probable VV-sCJD & 67 & $\mathrm{~F}$ & 7 & middle stage & + & - & + & 24020 \\
\hline 7 & probable VV-sCJD & 64 & M & 11 & late stage & + & - & + & 20000 \\
\hline 8 & probable VV-sCJD & 75 & M & 7 & late stage & - & + & + & 1997 \\
\hline 9 & lumbago & 73 & M & n.d. & n.d. & n.d. & n.d. & n.d. & n.d. \\
\hline 10 & polyneuropathy & 71 & M & n.d. & n.d. & n.d. & n.d. & n.d. & n.d. \\
\hline 11 & pseudodementia & 68 & $\mathrm{~F}$ & n.d. & n.d. & n.d. & n.d. & n.d. & n.d. \\
\hline 12 & polyneuropathy & 72 & $\mathrm{~F}$ & n.d. & n.d. & n.d. & n.d. & n.d. & n.d. \\
\hline 13 & depression & 73 & $\mathrm{~F}$ & n.d. & n.d. & n.d. & n.d. & n.d. & n.d. \\
\hline 14 & polyneuropathy & 62 & $\mathrm{~F}$ & n.d. & n.d. & n.d. & n.d. & n.d. & n.d. \\
\hline 15 & polyneuropathy & 67 & M & n.d. & n.d. & n.d. & n.d. & n.d. & n.d. \\
\hline 16 & polyneuropathy & 68 & $\mathrm{~F}$ & n.d. & n.d. & n.d. & n.d. & n.d. & n.d. \\
\hline
\end{tabular}

Table 1. Detailed characteristics of SCJD and control patients in 2D-DIGE approach All sCJD patients fulfilled WHO criteria for diagnosis of either probable or definite SCJD, neurological controls did not show any cognitive decline and were age-matched with the sCJD patients. The mean age of MM-sCJD, VV-sCJD and NDC group was $69 \pm 3,68 \pm 4$ and $69 \pm 4$ years, respectively. The sCJD patients were characterized by the presence of 14-3-3 protein and elevated level of tau protein in CSF. ( [ $\pi^{\pi}$ - disease stage when lumbar puncture for diagnostic purposes was performed; ${ }^{¥}$ - presence of hyperintensities in basal ganglia;* presence of periodic sharp wave complexes (PSWC); ${ }^{\#}$ - presence of $14-3-3$ protein in CSF; ${ }^{\S}$ tau level above 1300 pg/ml; F - female; $\mathrm{M}$ - male; n.d. - not determined] 
To perform Western blot analyses, samples of frontal cortex from 6 pathologically confirmed sCJD cases as well as 6 non-neurological controls with only age-related changes in brain tissue were used. The post-mortem delay was around $24 \mathrm{~h}$ for analyzed cases. For colocalization studies, samples of frontal cortex from 3 pathologically confirmed SCJD cases, 3 $\mathrm{AD}$ as well as 3 age-matched, non-neurological controls with only age-related changes in brain tissue were used.

\begin{tabular}{ccccc}
\hline Cases & $\begin{array}{c}\text { protein concentration } \\
{[\mathbf{m g} / \mathbf{l}]}\end{array}$ & $\begin{array}{c}\text { lactate } \\
{[\mathbf{m m o l} / \mathbf{L}]}\end{array}$ & QAlb x 10 $^{\mathbf{3}}$ & cells/ $\boldsymbol{\mu l}$ \\
\hline MM-sCJD & $448 \pm 125$ & $1,8 \pm 0,4$ & $7,6 \pm 2$ & $4 \pm 2$ \\
& & & & \\
VV-sCJD & $275 \pm 59$ & $1,6 \pm 0,1$ & $4,2 \pm 0,2$ & $1 \pm 1$ \\
& & & & \\
Controls & $351 \pm 110$ & $1,4 \pm 0,2$ & $4,8 \pm 1,6$ & $1 \pm 1$ \\
\hline
\end{tabular}

Table 2.CSF parameters of sCJD and control patients in 2D-DIGE approach For both, sCJD and control group CSF parameters were within normal, physiological range.

\section{2D Fluorescence Difference Gel Electrophoresis (2D-DIGE)}

\subsection{Sample Preparation}

Immediately after lumbar puncture, CSF samples were centrifuged at 1300x $g$ for 10 min, snap frozen and stored at $-80^{\circ} \mathrm{C}$ until analysis was performed. $2 \mathrm{ml}$ of CSF were subjected to the depletion of 12 high abundant proteins (Albumin, IgG Total, IgM, IgA, Transferrin, Apo A-I, Apo A-II, $\alpha 1$-Acid Glycoprotein, $\alpha 2$-Microglobulin, $\alpha 1$-Antitrypsin, Haptoglobin and Fibrinogen) using ProteomeLab IgY-12 LC2 Proteome Partitioning Kit (Beckman Coulter). The procedure was performed according to manufacturer's instruction. 


\subsection{D-DIGE and Image Analysis}

$25 \mu \mathrm{g}$ of protein was precipitated overnight with acetone-methanol (8:1; vol:vol) at $-20^{\circ} \mathrm{C}$ and centrifuged at $16000 \mathrm{x} g$ for $15 \mathrm{~min}$. The pellet was resuspended in lysis buffer containing $7 \mathrm{M}$ Urea, 2.5 M Thiourea, 4\% CHAPS, $30 \mathrm{mM}$ TRIS and $5 \mathrm{mM}$ magnesium acetate and subsequently labeled with $100 \mathrm{pmol}$ of CyDye (GE Healthcare) as follows: pooled samples as internal standard with Cy2 as well as individual control and SCJD samples with Cy3 or Cy5. The dye-switch between control and sCJD samples was done in order to avoid dye-to-protein preferences.

Labeling reaction was performed on ice in the dark for $30 \mathrm{~min}$ and terminated by adding 10 $\mathrm{mM}$ Lysine before incubating for further $10 \mathrm{~min}$. Equal volume of lysis buffer containing additionally $130 \mathrm{mM}$ DTT and 0.4\% 3-10 Bio-Lyte (Bio-rad) was added to the labeling mixture. After that samples were mixed together, diluted up to $350 \mu$ with rehydration buffer composed of $7 \mathrm{M}$ Urea, 2.5 M Thiourea, 4\% CHAPS, 0.2\% 3-10 Bio-Lyte and 65 mM DTT and loaded on ReadyStrip IPG nonlinear pH 3-10, $17 \mathrm{~cm}$ strip (Bio-rad). After $12 \mathrm{~h}$ of active rehydration at $50 \mathrm{~V}$, isoelectric focusing was initiated at $500 \mathrm{~V}$ for $1 \mathrm{~h}$, followed by ramping at $1000 \mathrm{~V}$ for $1 \mathrm{~h}$ and $5000 \mathrm{~V}$ for $2 \mathrm{~h}$. The final focusing was carried out at $8000 \mathrm{~V}$ reaching the total of $60000 \mathrm{Vh}$ (PROTEAN IEF CELL, Bio-rad).

Then the strips were equilibrated 2 times for $20 \mathrm{~min}$ in buffer containing $6 \mathrm{M}$ Urea, $2 \%$ SDS, $30 \%$ Glycerin and $150 \mathrm{mM}$ Tris, $\mathrm{pH} 8.8$, supplemented with $2 \%$ DTT in the first and with $2.5 \%$ Iodoacetamide in the second equilibration step. SDS-PAGE was performed overnight with homogenous $12 \%$ polyacrylamide gel using PROTEAN II XL Vertical Electrophoresis Cell (Bio-rad). CyDye-labeled protein gels were scanned by three different lasers with band pass filtered emission wavelengths of $510 \mathrm{~nm}$ (Cy2), $575 \mathrm{~nm}(\mathrm{Cy} 3)$ and $665 \mathrm{~nm}$ (Cy5) using FLA-5100 imaging system (Fujifilm).

Protein spot abundances within 20 CSF proteome patterns (4 MM-sCJD, 4 VV-sCJD, 8 NDC and 4 IS) were analyzed using the Delta2D software (v. 3.6) (DECODON). Differences in spot abundance detected by densitometric analysis were statistically evaluated using unpaired Student's $t$ test. Means and standard deviations were calculated from 4 sets of experiments. A protein spot was considered as differentially regulated when its densitometric analyses showed at least 2-fold change in abundance and when $p$-value was $<0.05$ in unpaired Student's $t$ test. 


\subsection{Protein identification}

Gel plugs containing proteins of interest were manually excised from silver- or Coomassiestained gels and subjected to in-gel digestion. The detailed protocol of this procedure is given by Ramljak et al. ${ }^{8}$. In-gel digested peptides were chromatographically separated peptides (C18 pepMap100 nano Series analytical column, LC Packings) and analyzed by ESI-Q-TOF Ultima Global mass spectrometer (Micromass). Data acquisition was performed using the MassLynx (v. 4.0) software and further processed on Protein- Lynx-Global-Server (v 2.1), (Micromass). The acquired data were searched against MSDB and SwissProt 2010_08 databases through the Mascot search engine using a peptide mass and MS/MS fragment mass tolerance of 0.5 Da. The searching criteria were set with one missed cleavage by trypsin allowed and protein modifications set to methionine oxidation and carbamidomethylcysteine when appropriate.

\section{Western blotting}

\subsection{Brain homogenate}

Samples of frontal cortex were homogenized in 5 volumes of buffer containing $20 \mathrm{mM}$ HEPES (pH 7.4), 320 mM sucrose, 1 mM Sodium Orthovanadate, 1 mM EDTA and Complete Protease Inhibitor Cocktail (Roche). Brain homogenates were centrifuged at 15000 rpm for 10 min. Supernatants were collected and protein concentration was determined by BCA assay (Sigma).

\subsection{Western blotting}

$30 \mu \mathrm{g}$ of CSF protein or $20 \mu \mathrm{g}$ of brain protein was separated on $12 \%$ SDS-PAGE gels and transferred to PVDF membranes. Membranes were blocked with 5\% skimmed milk in phosphate buffer saline with $0.2 \%$ Triton X-100 (PBST) for $1 \mathrm{~h}$ at RT. Subsequently, the membranes were incubated overnight at $4{ }^{\circ} \mathrm{C}$ with the following primary antibodies: mouse anti-G6PI (1:2000, Abcam), mouse anti-ALDOA (1:1000, Abcam), mouse anti- $\beta$-actin (1:2000, Abcam) or goat anti-LDH (1:500, Abcam). Thereafter, membranes were washed with PBST and incubated for $1 \mathrm{~h}$ at RT with corresponding horseradish peroxide-conjugated secondary antibodies: donkey anti-goat (1:5000, Santa Cruz Biotechnology), goat anti-mouse 
(1:7500, Abcam). The immunoreactivity was detected after immersing the membranes into enhanced chemiluminescence (ECL) solution and expositing to ECL-Hyperfilm (Amersham Biosciences). Films were scanned, densitometric and statistic analysis was performed with both ImageJ (Image Processing and Data Analysis free software) and Sigmaplot (Exact Graphs and Data Analysis software, Systat), respectively. The protein-regulation was considered as specific for SCJD when $p$-value was lower than 0.05 in Kruskal-Wallis ANOVA test.

\section{Immunofluorescent staining}

Formalin-fixed and paraffin-embedded brain tissue sections were deparaffinized and rehydrated by washing three times for $3 \mathrm{~min}$ in xylol and for $2 \mathrm{~min}$ in 100\%, 95\%, 70\% and $50 \%$ isopropanol. Heat-induced antigen retrieval was performed by cooking in a microwave for $18 \mathrm{~min}$ in Tris/EDTA buffer at $\mathrm{pH}$ 9. Then brain sections were blocked with buffer containing $2 \%$ gelatin, $0.25 \%$ Triton- $\mathrm{X}$ and $1 \mathrm{mM}$ Lysine for $1 \mathrm{~h}$ and lipofuscin-like autofluorescence was reduced with $0.5 \%$ Sudan black for $15 \mathrm{~min}$. Subsequently, brain sections were incubated for $2 \mathrm{~h}$ with the following primary antibodies: goat anti-LDH (1:500, Abcam), mouse anti-G6PI (1:200, Abcam), mouse anti-ALDOA (1:150, Abcam), rabbit anti-GFAP (1:1000, DAKO), mouse anti-Neurofilament (1:100, DAKO) or rabbit anti-Neurofilament

Light (1:200, Millipore). Brain sections were incubated for $1.5 \mathrm{~h}$ with the corresponding secondary antibodies: Cy3-labeled sheep anti-mouse (1:1000, Sigma), FITC-labeled goat antirabbit (1:500, Sigma) or Cy3-labeled donkey anti-goat (1:500, J. Research). Nuclei labeling was performed with $2 \mu \mathrm{g} / \mathrm{ml}$ Hoechst 33342 solution for $10 \mathrm{~min}$. Finally, brain sections were mounted with Mowiol and stored at $4{ }^{\circ} \mathrm{C}$ in a dark box. All steps were carried out in a humid dark chamber at RT and each incubation step was followed by rinsing four times with Tris buffer saline with $0.05 \%$ Tween 20 (TBST). Microscopic examination of brain sections was performed with the Olympus BX51 microscope using a fluorescence unit. Images were acquired using Olympus XM 10 camera and processed using the Cell F-software (Olympus). 


\section{Results}

\section{General observations}

In order to achieve better coverage of low abundant proteins, the immunodepletion of 12 of the most abundant CSF proteins (albumin, IgG, IgM, IgA, transferrin, Apo A-I, Apo A-II, $\alpha 1$ Acid glycoprotein, $\alpha 2$-microglobulin, $\alpha 1$-antitrypsin, haptoglobin and fibrinogen) was performed. Then the fractions of low abundant CSF proteins were then subjected into labeling with CyDyes and separated by 2D-DIGE.

Using Delta2D's 100\% spot matching approach, 539 protein spots were detected on CSF 2D patterns. Densitometric and statistical analysis revealed that 51 protein spots showed significantly different expression level in sCJD comparing to non-demented, neurological controls, which comprises $9.5 \%$ of all detected protein spots. These protein spots corresponded to 33 different proteins (Fig. 1). In MM-sCJD, 27 up-regulated and 3 downregulated proteins were found, whereas 24 up-regulated proteins were identified in the VVsCJD cases (Tab. 3). Twenty one proteins were commonly up-regulated in both codon 129 polymorphisms. The group of MM-sCJD specific regulated proteins included: leucine-rich alpha-2-glycoprotein (LRG), actin, truncated form of complement C4-A, superoxide dismutase $[\mathrm{Cu}-\mathrm{Zn}]$ (SOD-1), insulin-like growth factor-binding protein 6 (IGFBP-6), tetranectin, semaphorin-7A (Sema7A), protein FAM3C and transaldolase. The group of VVSCJD specific regulated proteins included: DJ-1 protein, fibrinogen alpha chain (FGA) and angiotensinogen (ANGT).

When biological function was taken into consideration, the major alteration in CSF proteome was observed in proteins belonging to the glycolysis pathway or being involved in glucose

metabolism. The remaining proteins fell into five functional groups: apoptosis / oxidative stress, signal transduction, amino acid / protein metabolism, immuno response / acute phase response signaling (APRS) and cell structure / transport (Fig. 2). 


\begin{tabular}{|c|c|c|c|c|c|c|c|c|c|c|c|}
\hline \multirow[b]{2}{*}{$\mathrm{Nr}$} & \multirow[b]{2}{*}{ Protein name } & \multicolumn{2}{|c|}{ MM genotype } & \multicolumn{2}{|c|}{ VV genotype } & \multirow[b]{2}{*}{$\begin{array}{l}\text { UniProt } \\
\text { Accession }\end{array}$} & \multirow{2}{*}{$\begin{array}{c}\text { MW } \\
{[\mathrm{kDa}]}\end{array}$} & \multirow[b]{2}{*}{ pI } & \multirow[b]{2}{*}{ Score } & \multirow[b]{2}{*}{$\begin{array}{l}\text { Queries } \\
\text { matched }\end{array}$} & \multirow[b]{2}{*}{$\begin{array}{c}\text { Coverage } \\
{[\%]}\end{array}$} \\
\hline & & $\begin{array}{l}\text { fold of } \\
\text { change }\end{array}$ & $p$-value & $\begin{array}{l}\text { fold of } \\
\text { change }\end{array}$ & $p$-value & & & & & & \\
\hline 1 & 14-3-3 protein zeta/delta & 2.4 & 0.033 & 1.2 & 0.714 & P63104 & 28 & 4.7 & 362 & 9 & 36 \\
\hline 2 & & 4.8 & 0.055 & 3.1 & 0.003 & & & & 194 & 7 & 25 \\
\hline 3 & Leucine-rich alpha-2-glycoprotein & 3.8 & 0.008 & 1.7 & 0.074 & P02750 & 38 & 5.7 & 103 & 3 & 7 \\
\hline 4 & & 2.2 & 0.038 & 1.5 & 0.46 & & & & 70 & 4 & 10 \\
\hline 5 & Actin, aortic smooth muscle & 4.7 & 0.036 & 2.3 & 0.267 & P62736 & 42 & 5.2 & 70 & 4 & 11 \\
\hline 6 & Gamma-enolase (NSE) & 5.3 & 0.006 & 5.4 & 0.003 & P09104 & 47 & 4.9 & 440 & 7 & 19 \\
\hline 7 & $\begin{array}{l}\mathrm{N}(\mathrm{G}), \mathrm{N}(\mathrm{G}) \text {-dimethylarginine } \\
\text { dimethylaminohydrolase } 1\end{array}$ & 3.2 & $5.7 \mathrm{E}-04$ & 2,2 & 0.009 & O94760 & 31 & 5.5 & 193 & 5 & 15 \\
\hline 8 & L-lactate dehydrogenase B chain & 2.7 & 0.005 & 2.9 & 0.006 & P07195 & 37 & 5.7 & 376 & 9 & 27 \\
\hline 9 & Malate dehydrogenase & 18 & 0.001 & 6.5 & 0.016 & P40925 & 36 & 6.9 & 118 & 4 & 13 \\
\hline 10 & & 3.4 & 0.036 & 4.6 & 0.06 & & & & 480 & 10 & 33 \\
\hline 11 & & 5.6 & 0.001 & 3.2 & 0.003 & & & & 333 & 9 & 32 \\
\hline 12 & Phosphatidylethanolamine-binding & 2.8 & $6.4 \mathrm{E}-05$ & 2 & 0.008 & P30086 & 21 & 7.4 & 340 & 7 & 49 \\
\hline 13 & protein 1 & 1.9 & 0.088 & 2.4 & 0.005 & & & & 265 & 7 & 45 \\
\hline 14 & & 4.1 & 0.043 & 2.4 & 0.045 & & & & 431 & 10 & 52 \\
\hline 15 & Triosephosphate isomerase & 2.1 & 0.012 & 2.5 & 0.022 & P60174 & 66 & 6.5 & 89 & 3 & 14 \\
\hline 16 & & 3.2 & 0.001 & 2 & 0.004 & & & & 75 & 2 & 10 \\
\hline 17 & $\begin{array}{l}\text { Insulin-like growth factor-binding } \\
\text { protein } 6\end{array}$ & 2 & 0.044 & 1.8 & 0.2 & P24592 & 27 & 7.9 & 70 & 1 & 4 \\
\hline 18 & Fructose-bisphosphate aldolase A & 10.4 & $1 \mathrm{E}-07$ & 10.7 & 9E-04 & P04075 & 39 & 8.4 & 472 & 9 & 24 \\
\hline 19 & & 15 & $4.8 \mathrm{E}-06$ & 11.7 & $2.3-06$ & & & & 350 & 8 & 21 \\
\hline 20 & & 4.7 & $1.2 \mathrm{E}-04$ & 4.3 & 0.001 & & & & 94 & 3 & 10 \\
\hline 21 & Aspartate aminotransferase, & 4.7 & 0.002 & 3.3 & $9.5 \mathrm{E}-04$ & P17174 & 46 & 6.6 & 440 & 15 & 34 \\
\hline 22 & cytoplasmic & 3.3 & 0.007 & 2.5 & 0.003 & & & & 63 & 5 & 10 \\
\hline 23 & Fructose-bisphosphate aldolase C & 3.3 & $3.6 \mathrm{E}-04$ & 3.1 & 0.018 & P09972 & 39 & 6.6 & 60 & 3 & 8 \\
\hline 24 & & 5.2 & 0.002 & 3.6 & 0.007 & & & & 111 & 4 & 13 \\
\hline 25 & & 3.2 & 0.044 & 3.2 & 0.049 & & & & 57 & 3 & 10 \\
\hline 26 & Alpha-enolase & 13.1 & $9.4 \mathrm{E}-05$ & 15.9 & 0.021 & P06733 & 47 & 7.0 & 175 & 6 & 16 \\
\hline 27 & & 5.3 & 0.008 & 6.9 & 0.005 & & & & 143 & 5 & 13 \\
\hline 28 & Glucose-6-phosphate isomerase & 6.9 & 0.028 & 6.7 & 0.004 & P06744 & 63 & 8.4 & 129 & 5 & 7 \\
\hline
\end{tabular}




\begin{tabular}{|c|c|c|c|c|c|c|c|c|c|c|c|}
\hline \multirow[b]{2}{*}{$\mathrm{Nr}$} & \multirow[b]{2}{*}{ Protein name } & \multicolumn{2}{|c|}{ MM genotype } & \multicolumn{2}{|c|}{ VV genotype } & \multirow[b]{2}{*}{$\begin{array}{c}\text { UniProt } \\
\text { Accession }\end{array}$} & \multirow{2}{*}{$\begin{array}{c}\text { MW } \\
{[\mathrm{kDa}]}\end{array}$} & \multirow[b]{2}{*}{ pI } & \multirow[b]{2}{*}{ Score } & \multirow[b]{2}{*}{$\begin{array}{c}\text { Queries } \\
\text { matched }\end{array}$} & \multirow[b]{2}{*}{$\begin{array}{c}\text { Coverage } \\
{[\%]}\end{array}$} \\
\hline & & $\begin{array}{l}\text { fold of } \\
\text { change }\end{array}$ & $p$-value & $\begin{array}{l}\text { fold of } \\
\text { change }\end{array}$ & $p$-value & & & & & & \\
\hline 29 & Pyruvate kinase isozymes M1/M2 & 7.4 & 0.001 & 4.1 & 0.01 & P14618 & 58 & 7.9 & 556 & 17 & 30 \\
\hline 30 & & 3.6 & 0.034 & 2.3 & 0.062 & & & & 55 & 3 & 5 \\
\hline 31 & Gelsolin & 2.3 & 0.007 & 2.6 & 0.031 & P06396 & 86 & 5.7 & 102 & 4 & 5 \\
\hline 32 & Truncated form of Complement C4-A & 4.8 & 2.7E-04 & 1.5 & 0.068 & P0C0L4 & 33 & 6.2 & 115 & 5 & 3 \\
\hline 33 & (gamma and beta chain) & 2.4 & 0.028 & 1.1 & 0.731 & & 76 & 9.2 & 867 & 23 & 11 \\
\hline 34 & L-lactate dehydrogenase A chain & 7 & $9.2 \mathrm{E}-04$ & 4.1 & 0.004 & P00338 & 37 & 8.5 & 151 & 4 & 12 \\
\hline 35 & & 4.4 & 0.041 & 1.9 & 0.053 & & & & 49 & 3 & 8 \\
\hline 36 & Tetranectin & 0.4 & 0.043 & 0.6 & 0.339 & P05452 & 22 & 5.8 & 96 & 2 & 11 \\
\hline 37 & Retinol-binding protein 4 & 3.9 & 0.011 & 3.2 & 0.212 & P02753 & 23 & 5.3 & 161 & 6 & 29 \\
\hline 38 & Protein DJ-1 & 13 & 0.076 & 25.9 & 0.001 & Q99497 & 20 & 6.3 & 109 & 6 & 33 \\
\hline 39 & Truncated form of Desmoplakin & 62 & 0.02 & 78.9 & $1 \mathrm{E}-04$ & P15924 & 331 & 6.4 & 63 & 2 & $<1$ \\
\hline 40 & Angiotensinogen & 1.3 & 0.062 & 2.2 & 0.001 & P01019 & 53 & 5.9 & 326 & 13 & 31 \\
\hline 41 & Fibrinogen alpha chain & 2.9 & 0.11 & 3.8 & 0.004 & P02671 & 95 & 5.7 & 186 & 7 & 9 \\
\hline 42 & $\begin{array}{c}\text { Aspartate aminotransferase, } \\
\text { mitochondrial }\end{array}$ & 6.2 & $3.5 \mathrm{E}-04$ & 3.1 & 0.006 & P00505 & 47 & 9.1 & 63 & 5 & 13 \\
\hline 43 & Phosphoglycerate kinase 1 & 12 & $1.8 \mathrm{E}-04$ & 11.2 & 0.002 & P00558 & 45 & 8.3 & 403 & 14 & 39 \\
\hline 44 & Transketolase & 3.2 & 0.02 & 7.4 & 0.01 & P29401 & 68 & 7.6 & 156 & 7 & 13 \\
\hline 45 & Superoxide dismutase $[\mathrm{Cu}-\mathrm{Zn}]$ & 2.8 & 0.037 & 3.2 & 0.128 & P00441 & 16 & 5.7 & 192 & 2 & 16 \\
\hline 46 & Protein FAM3C & 0.3 & 0.048 & 0.5 & 0.213 & Q92520 & 25 & 8.5 & 107 & 4 & 21 \\
\hline 47 & Chitinase-3-like protein 1 & 3 & 0.002 & 2.7 & 0.056 & P36222 & 43 & 8.6 & 50 & 3 & 9 \\
\hline 48 & & 3.8 & 0.011 & 3.2 & 8.1E-04 & & & & 95 & 4 & 10 \\
\hline 49 & & 0.4 & 0.044 & 0.5 & 0.325 & & & & 57 & 3 & 9 \\
\hline 50 & Transaldolase & 2 & 0.023 & 2.6 & 0.214 & P37837 & 37 & 6.4 & 43 & 1 & 3 \\
\hline 51 & Semaphorin-7A & 2.6 & 0.02 & 1.3 & 0.1 & O75326 & 75 & 7.6 & 98 & 6 & 10 \\
\hline
\end{tabular}

Table 3. List of sCJD-regulated proteins in CSF

Protein spot was considered as SCJD-regulated when its densitometric analyses showed at least -fold change in abundance and when $p$ -

value $<0.05$ in unpaired Student's $t$ test 

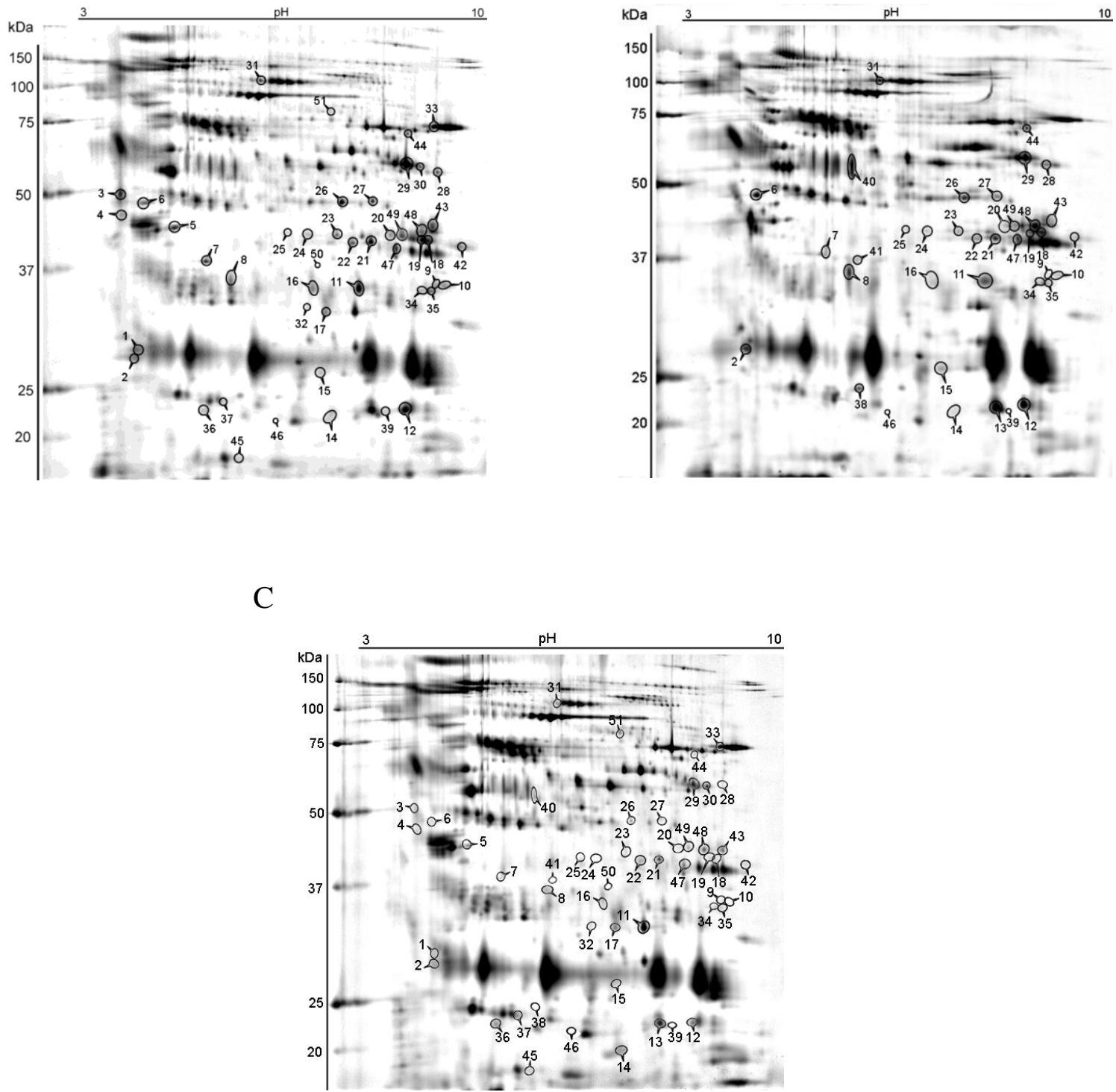

Figure 1. 2D maps of depleted CSF from codon 129 genotype in MM-sCJD (panel A), VVsCJD (panel B), and NDC (panel C) patients acquired by the application of 2-D Fluorescence Difference Gel Electrophoresis (2-D DIGE)

The densitometric and statistical analysis of CSF 2D maps revealed significantly different expression levels of 51 protein spots, which corresponded with to 33 different proteins. 


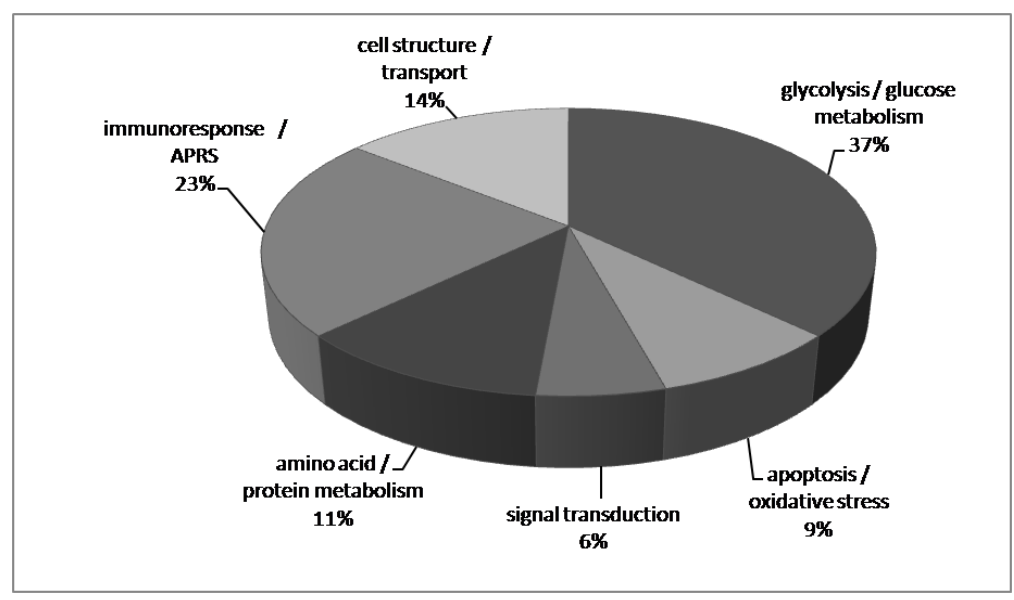

Figure 2. The biological function of sCJD-regulated proteins in CSF

The major alteration in CSF proteome was observed in proteins involved in the glycolysis pathway or involved in glucose metabolism. The remaining proteins fell into five functional groups: apoptosis / oxidative stress, signal transduction, amino acid / protein metabolism, immunoresponse / acute phase response signaling (APRS) and cell structure / transport.

\section{CSF level of enzymes involved in glucose metabolism}

Since we believe, that energy metabolism is strongly linked with cell death and survival, we focused particularly on three proteins related to glucose metabolism: glucose-6-phosphate isomerase (G6PI), lactate dehydrogenase ( $\mathrm{LDH})$ and fructose-bisphosphate aldolase A (ALDOA) in the following experiments.

In order to validate our findings from 2D-DIGE experiments, we performed Western blot analysis using a larger group of sCJD and control patients. Control patients included nondemented, neurological patients (NDC), patients suffering from vascular dementia (VD) and patients affected by Alzheimer's disease (AD).

An increase of G6PI level in CSF was observed for all three codon 129 genotypes in sCJD (MM-sCJD, MV-sCJD and VV-sCJD) compared to all control groups The observed mean fold of change in protein abundance was 3 for VV-sCJD and 2 for other codon 129 genotypes in SCJD (Fig 3A).

The Western blot analysis revealed presence of two ALDOA isoforms slightly different in molecular weight. The isoform with lower molecular weight was predominant in NDC, VD and $\mathrm{AD}$, whereas the dominance of the isoform with higher molecular weight was characteristic for SCJD. More than 3-fold of change in total ALDOA level were detected in MM-sCJD, MV-sCJD and VV-sCJD in comparison to NDC. Moreover, decreased ALDOA 
concentration was found in VD, whereas its concentration in $\mathrm{AD}$ was found to be increased comparing to NDC (Fig 3B).

Finally, an enormous increase in LDH abundance was detected in the CSF of sCJD patients in comparison to all three control groups. The mean fold of change was 20 times higher for MMsCJD and 40 times higher for VV-sCJD (Fig 3C).

Using Kruskal-Wallis ANOVA test all above-mentioned changes of protein abundance in CSF were found to be statistically significant.

A

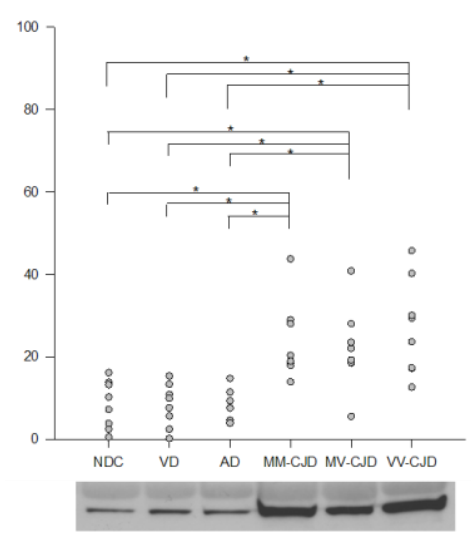

$\mathrm{B}$

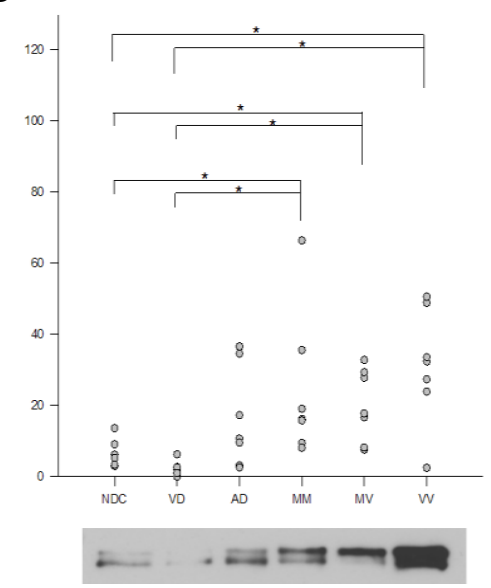

$\mathrm{C}$

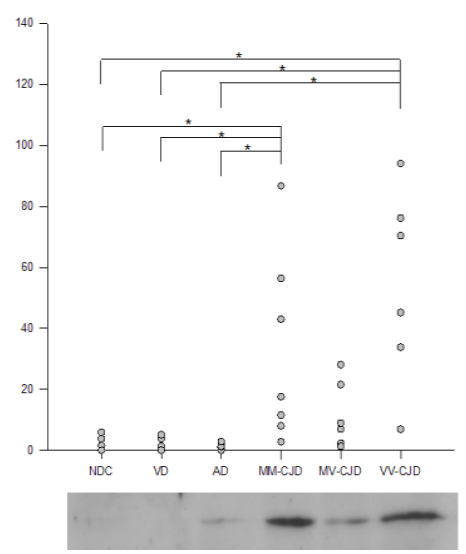

Figure 3.Levels of G6PI (Panel A), ALDOA (Panel B) and LDH (Panel C) in CSF

\section{Brain level of enzymes involved in glucose metabolism}

Subsequently, levels of G6PI, ALDOA and LDH were determined in the frontal cortex of the MM1-sCJD and the VV2-sCJD patients. Both ALDOA and LDH showed no significant alterations in protein abundance in both SCJD subtypes comparing to the age-matched, nondemented controls (NDC) (Fig. 4A and 4B). The G6PI level was decreased by 2-fold in MM1-sCJD and it remained unchanged in VV2-sCJD comparing to NDC (Fig. 4C).

The above-mentioned change of protein abundance in brain was statistical significant using Kruskal-Wallis ANOVA test. 
A

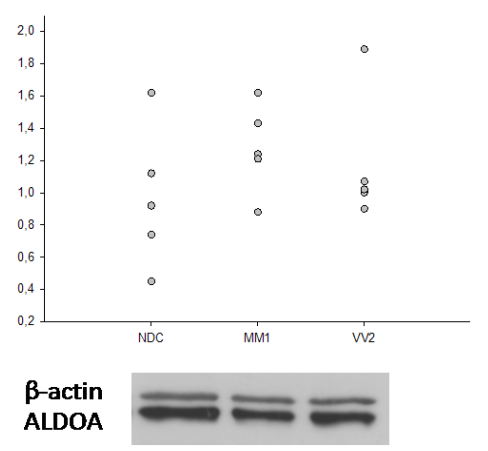

B

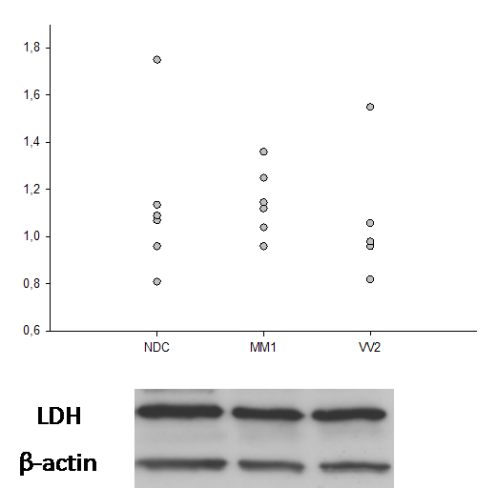

$\mathrm{C}$

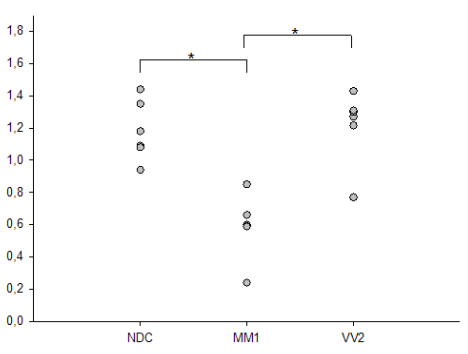

G6PI

B-actin

Figure 4. Levels of ALDOA (Panel A), LDH (Panel B) and G6PI (Panel C) in brain

\section{Cellular localization of enzymes involved in glucose metabolism}

Pathological processes occurring in SCJD affect both neural populations of cells: glial cells (astrogliosis) and neurons (neuronal loss). Therefore, the next step of this study was the investigation of the cellular distribution of sCJD-regulated glycolytic enzymes. This was determined in paraffin-embedded sections of human frontal cortex by co-labeling of proteins of interest either with neuronal marker (Neurofilament - NF or NF-L) or astrocytic maker (Glial fibrillary acidic protein - GFAP).

The intensive LDH immunoreactivity was found in the cytoplasm of astrocytes in SCJD, AD, and in NDC (Fig. 5A). In NDC and AD, G6PI immunostaining was present in both cell bodies and processes of all cortical layers, whereas in SCJD, the G6PI intense immunoreactivity was predominantly observed in reactive astrocytes (Fig. 5B and Fig. 6). Diffuse ALDOA immunostaining was predominantly found in neurons in the gray matter and in astrocytes in the white matter of NDC and AD. This stands in contrast to the distribution in SCJD where ALDOA immunoreactivity was mostly detected in neuronal cell bodies (Fig. $5 \mathrm{C})$. 


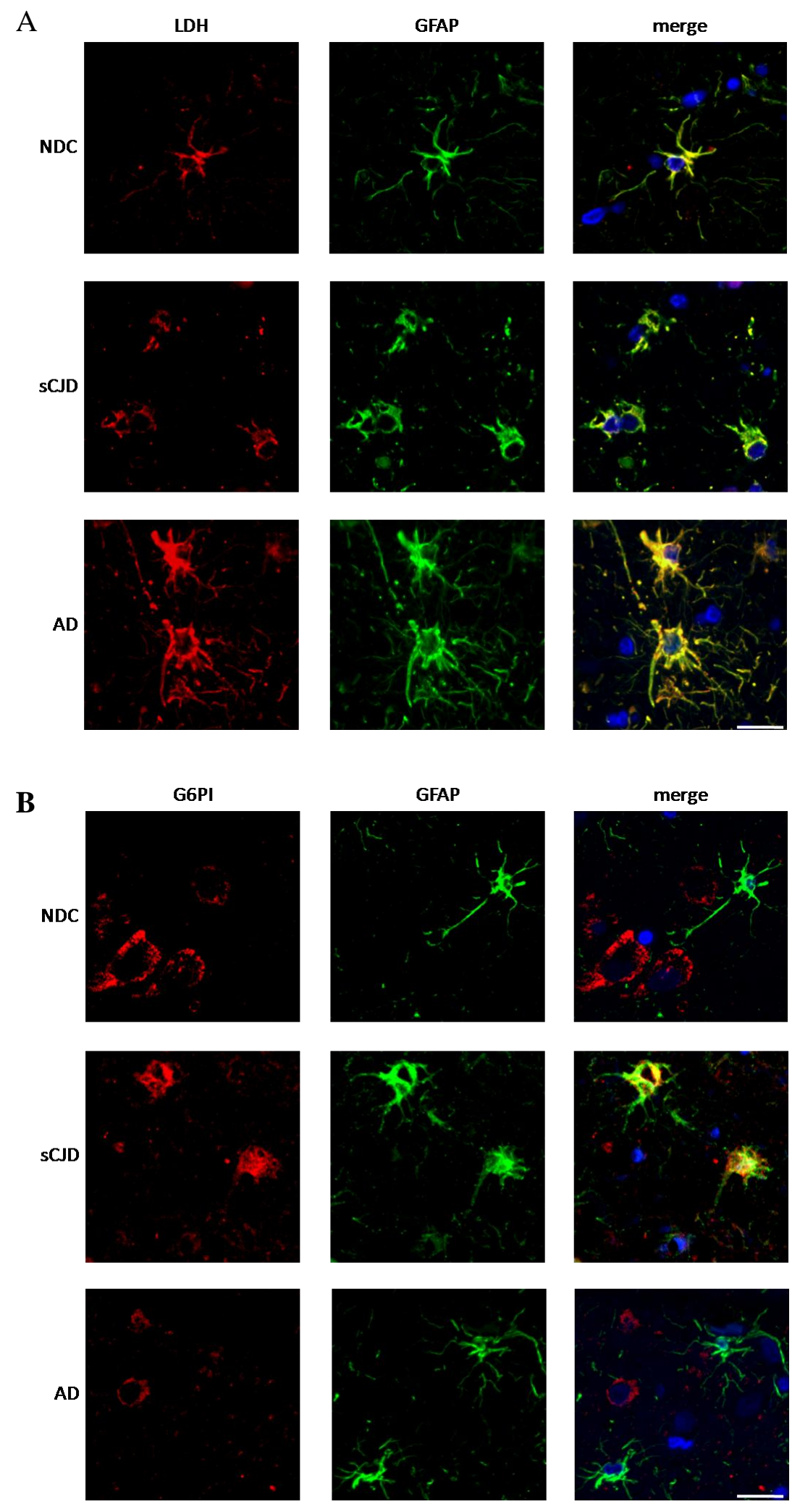


C
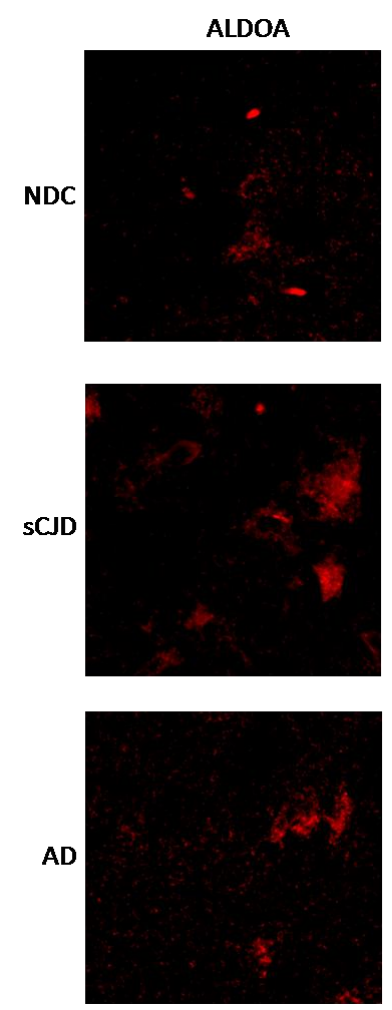

GFAP
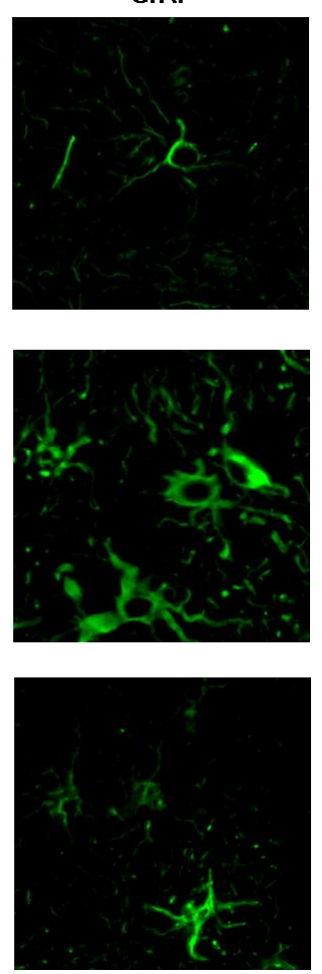

merge
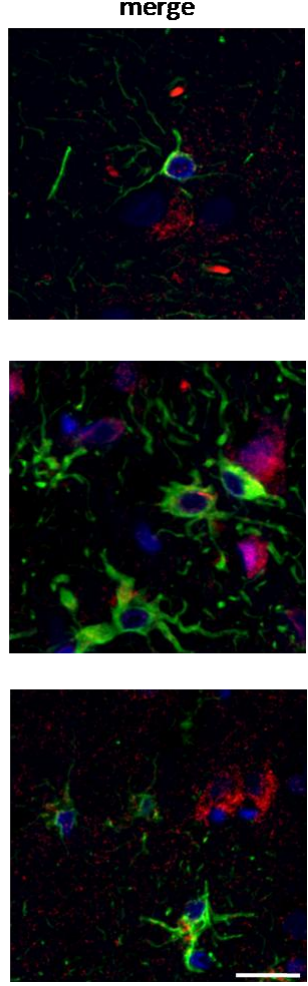

Figure 5. Cellular localization of LDH (Panel A), G6PI (Panel B) and ALDOA (Panel C) in human frontal cortex

LDH intensive immunoreactivity was found in cytoplasm of astrocytes in SCJD, AD, and in NDC (Panel A). The G6PI staining was co-localized with GFAP-positive cells only in sCJD (Panel B). ALDOA diffuse immunostaining was predominantly found in neurons in the gray matter and in astrocytes in the white matter of NDC, sCJD and AD (Panel C). DAPI-labeling was used to visualize nuclei. Scale bar: $20 \mu \mathrm{m}$. [NDC - non-demented, neurological patients; SCJD - sporadic CJD; AD - Alzheimer's disease] 

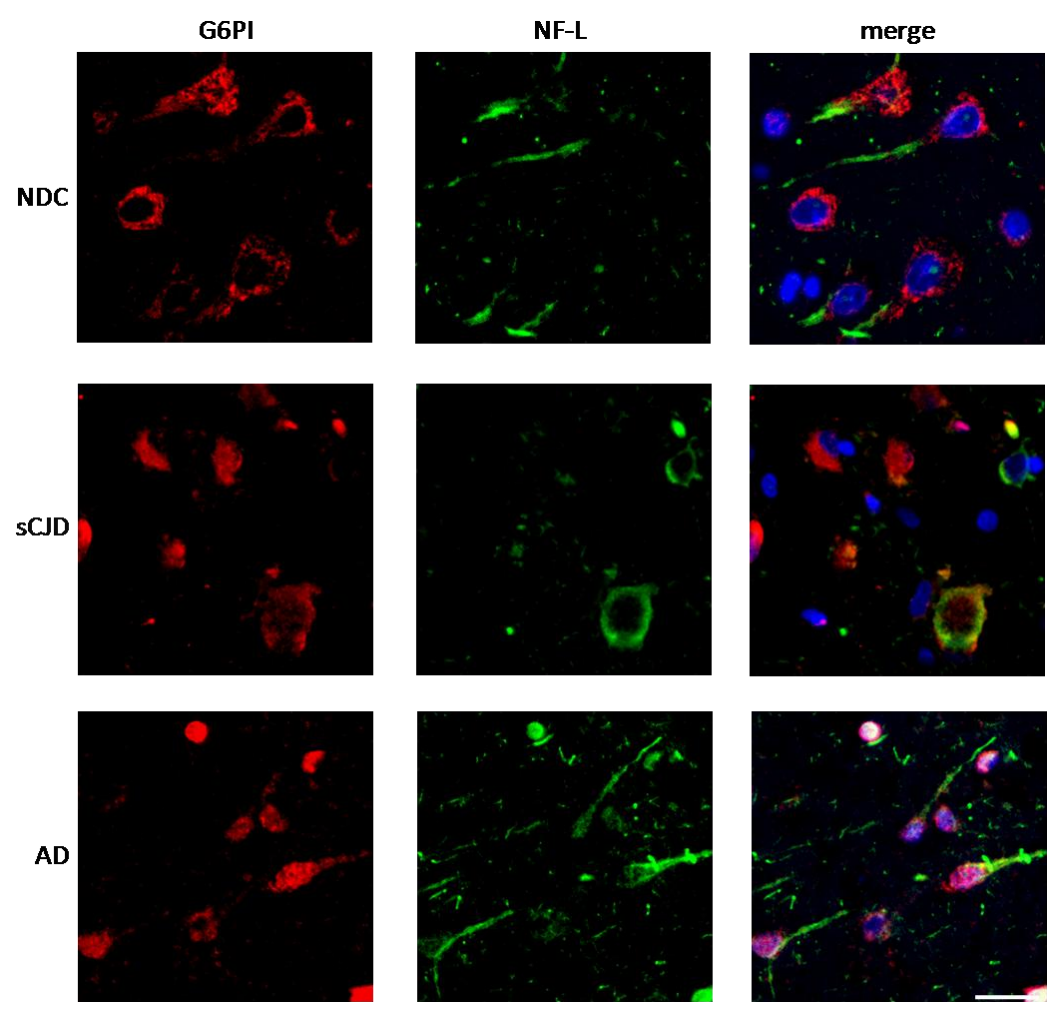

Figure 6. Cellular distribution of G6PI in human frontal cortex

Although G6PI-positive neurons were indentified in SCJD brain, but the G6PI was mainly localized in reactive astrocytes. DAPI-labeling was used to visualize nuclei. Scale bar: $20 \mu \mathrm{m}$. [NDC - non-demented, neurological patients; sCJD - sporadic CJD;

$\mathrm{AD}$ - Alzheimer's disease]

\section{Discussion}

Analysis of CSF is challenging in terms of the high dynamic range of protein concentration. The dominance of particular proteins like albumin or immunoglobulins leads to many low abundant proteins remaining undetected by conventional techniques such as 2D gel electrophoresis and mass spectrometry. Therefore, for a more effective coverage of low abundance proteins, the immunodepletion of 12 of the most abundant CSF proteins (albumin, IgG, IgM, IgA, transferrin, Apo A-I, Apo A-II, $\alpha 1$-Acid glycoprotein, $\alpha 2$-microglobulin, $\alpha 1$ antitrypsin, haptoglobin and fibrinogen) was performed. The fractions of low abundant CSF proteins were then subjected to labeling with CyDyes and separated by 2D-DIGE. The densitometric and statistical analysis of CSF 2D maps showed up-regulation of 27 and downregulation of 3 proteins in MM-sCJD as well as up-regulation of 24 proteins in VV-sCJD in comparison to non-demented neurological controls. Twenty one proteins showed common upregulation for both codon 129 polymorphisms in SCJD. 
The leucine-rich alpha-2-glycoprotein (LRG), complement $\mathrm{C} 4$ and superoxide dismutase $[\mathrm{Cu}$ $\mathrm{Zn}$ ] (SOD-1), which belong to the group of MM-sCJD differentially regulated proteins, were previously shown to be implicated in the PrP pathobiology.

The exact biological function of LRG still remains unclear. However, recent studies have shown that LRG can bind cytochrome $\mathrm{C}$, which displays a neurotoxic effect when released from cells during apoptotic death processes. Thus LRG may have neuroprotective properties and promote cell survival ${ }^{9-11}$. Furthermore, it has been shown that PrP106-126, a synthetic peptide corresponding to residues 106-126 of the human PrP sequence, which is used to mimic $\mathrm{PrP}^{\mathrm{Sc}}$ neurotoxicity, induces an endoplasmic reticulum (ER) stress in primary culture of rat cortical neurons leading to mitochondrial cytochrome $\mathrm{C}$ release, caspase 3 activation and subsequent apoptotic neuronal death ${ }^{12}$. The increased expression level of the gene encoding LRG was found in mice intracerebrally infected with the Rocky Mountain Laboratory (RML) scrapie strain. However, no difference in expression level was found when mice were infected with the ME7 scrapie strain ${ }^{13}$. Taking altogether, these data suggest that LRG may play a role in prion-induced pathological processes in a scrapie strain-dependent manner.

The C4 protein is essential for the activation of the complement system. Interestingly, active components of complement were detected in amyloid plaques in SCJD and GSS ${ }^{14}$. Existing evidences suggest that prion-induced neurodegenerative processes may not be mediated by complement and that it is very unlikely that it plays a protective role in the CNS during prion infection ${ }^{15}$. Nevertheless, expression profile studies performed in mice infected either with the ME7 or the RML scrapie strains revealed an up-regulation of genes encoding proteins involved in immuno response and participating in complement activation including C3 and C4. These findings might indicate that the enhancement of complement proteins and inflammatory factors may be important pathogenic events in prion disease ${ }^{13}$.

The SOD-1 is a protein involved in protection against oxidative stress and cell death. The presence of oxidative stress events during prion infection was well proven by many studies. Moreover, the perturbation in SOD-1 level and activity as well as its involvement in $\operatorname{PrP}^{\mathrm{Sc}}$ induced pathological processes have already been well described ${ }^{16-18}$.

VV-sCJD specific regulated proteins include DJ-1 protein, fibrinogen alpha chain (FGA) and angiotensinogen (ANGT).

The DJ-1 protein is abundantly expressed throughout the body and its biological implications are extremely diverse including fertility ${ }^{19}$, oncogenesis ${ }^{20}$ and protection against oxidative stress $^{21}$. Moreover, mutations in the PARK7 gene encoding DJ-1 protein cause autosomal- 
recessive early-onset Parkinson's disease ${ }^{22}$. It has also been reported that DJ-1 is required for the activity of the nuclear erythroid 2-related factor, a key player in the regulation of response to oxidative stress $^{23}$. This could suggest a potential protective role of DJ-1 in VV-sCJD pathophysiology.

The major role attributed to fibrinogen (FG) is the involvement in blood coagulation. However, it also displays a chaperone-like activity and is able to interact and suppress aggregation of a wide spectrum of stressed proteins. More interestingly, FG has been shown to inhibit fibril formation of yeast prion protein Sup35, which is known to share key features with the mammalian prion or amyloid proteins, suggesting a potential role of FG in protein misfolding diseases such as $\mathrm{sCJD}^{24}$. Supporting this idea, it has been also shown that FG fractioned from murine blood can bind $\mathrm{PrP}^{\mathrm{Sc}}$ isolated from scrapie mice ${ }^{25}$.

The angiotensinogen is a precursor molecule for angiotensins I, II and III belonging to reninangiotensin system (RAS). Beside classical functions of RAS such as regulation of water and salt homeostasis or blood pressure, RAS has been implied in memory and learning processes. Recently, many evidences have shown that brain RAS may be involved in Alzheimer's disease, stroke, depression or emotional stress ${ }^{26}$. Moreover, an elevated level of ANGT in CSF has been found in multiple sclerosis indicating that it could be a potential biomarker of disease progression ${ }^{27}$. However, no relationship between ANGT and prion disease is known so far.

The detection of regulated proteins specific for codon 129 genotype may confirm the hypothesis which assumes the involvement of different molecular pathways in sCJD pathogenesis depending on $\mathrm{PrP}^{\mathrm{Sc}}$ strain.

Some of the SCJD-altered proteins, which are found in these studies, are also previously reported as being associated either with prion protein or CJD. For instance, gelsolin, 14-3-3 protein, gamma enolase (NSE), and L-lactate dehydrogenase B chain (LDH-B) have been described to be differentially regulated in CSF of SCJD patients ${ }^{28,}{ }^{29}$. Moreover, proteins related to glucose metabolism such as malate dehydrogenase, alpha and gamma enolase, glucose-6-phosphate isomerase (G6PI), pyruvate kinase isozymes M1/M2 as well as LDH-B were identified as interaction partners of fully functional myc-tagged PrP in supramolecular complex studies $^{30}$. In neuroblastoma cell-based disease model studies of PrP molecular network, 14-3-3 zeta protein and LDH-A were recognized as specific interactors of FLAGtagged PrP. Further proteins such as actin, N(G),N(G)-dimethylarginine dimethylaminohydrolase 1 , malate dehydrogenase, triosephosphate isomerase, fructosebisphosphate aldolase A, alpha enolase, pyruvate kinase isozymes M1/M2 were also 
indentified. However, they have been classified as unspecific interactors of PrP or its homologs, Shadoo and Doppel ${ }^{31}$.

Global studies of cerebral gene expression profile revealed that the expression of genes encoding 14-3-3 protein (beta, eta and zeta isoform), NSE, malate dehydrogenase, cytoplasmic aspartate aminotransferase and retinol-binding protein 4 were down-regulated whereas expression of encoding gene actin was up-regulated ${ }^{32}$ in brains of sCJD patients. In these studies, CSF level of all above mentioned proteins were increased. It may occur due to release or secretion mechanism of protein content from impaired neural cells into the extracellular space and then eventually into CSF. Moreover, this hypothesis could explain dominant up-regulation of proteins in CSF from SCJD affected patients. However, this farreaching theory has to be proven by further investigations.

\section{Glycolytic enzymes in CJD}

Almost $40 \%$ of sCJD specific regulated proteins in CSF are involved in glucose metabolism, thus in energy metabolism. All these enzymes displayed up-regulation in SCJD regardless the codon 129 polymorphism. The increase in CSF level of glucose-6-phosphate isomerase (G6PI), lactate dehydrogenase (LDH) and fructose-bisphosphate aldolase A (ALDOA) was validated with further tests on a larger group of sCJD patients including three possible codon 129 polymorphisms as well as on three different types of controls consisting of nondemented, neurological controls (NDC), patients with vascular dementia (VD) and Alzheimer's disease (AD). Subsequently, their abundance in the brain as well as their cellular localization was determined.

The G6PI catalyzes the conversion of glucose-6-phosphate into fructose 6-phosphate, whereas ALDOA catalyzes hydrolysis of fructose 1,6-bisphospate into glyceraldehyde-3-phospate and dihydroxyacetone phosphate. Both enzymes belong to the second and fourth step of glycolysis, respectively. The LDH catalyzes the interconversion of lactate and pyruvate, which is formed in the final step of the glycolysis pathway.

The G6PI level showed 2-3-fold increase in CSF for all three codon 129 polymorphisms in the sCJD. However, its level in brain was 2-fold decreased specifically in the MM1-sCJD subtype and remained unchanged in the VV2-sCJD. This could suggest that G6PI expression and/or secretion may be modulated in a $\mathrm{PrP}^{\mathrm{Sc}}$ strain-dependent manner. Moreover, a shift in cellular distribution of G6PI was observed in sCJD. The intense immunoreactivity was predominantly localized in reactive astrocytes in SCJD, whereas in both control groups, NDC 
and $\mathrm{AD}$, it was mainly found in neurons. With this data we demonstrated for the first time the involvement of G6PI in prion-induced pathological process occurring in human brain.

Besides its glycolytic function, G6PI shows an activity of extracellular cytokine and acts as a growth factor promoting the survival and neurite outgrowth of motor and sensory neurons ${ }^{33}$, as an autocrine motility factor inducing cell motility ${ }^{34,35}$, and as a maturation factor to mediate the differentiation of myeloid precursor cells to mature monocytes ${ }^{36}$. The inhibition of G6PI expression caused an increased susceptibility to caspase-dependent apoptosis in PC12 neuronal cells ${ }^{37}$. Furthermore, overexpression and subsequent secretion of G6PI protected NIH-3T3 fibroblasts against PI3K/Akt mediated apoptosis ${ }^{38}$.

The positive G6PI immunostaining in astrocytes occurred two weeks after mechanical injury of murine cerebral cortex ${ }^{39}$ and its expression was shown to be elevated in the later stage of brain infection with rabies virus in $\mathrm{C} 3 \mathrm{H}$ mice model ${ }^{40}$. This may suggest that detectable expression of G6PI in astrocytes is a response to signals coming from impaired neurons to increase their metabolism and prolong survival. The same motion of G6PI action might occur in sCJD-affected brain, but it is differentially modulated by different $\operatorname{PrP}^{\mathrm{Sc}}$ strains.

The enormous increase in LDH level in CSF did not correlate with its unchanged level in the brain. This discrepancy could be explained by LDH release in extracellular space, which always accompanies cell death. However, LDH in CSF from SCJD patients exhibited significantly higher level than those determined in other dementias and proposed as a potential CSF marker for sCJD differential diagnosis ${ }^{41}$. Moreover, as mentioned above, LDH is the interaction partner of cellular $\operatorname{Pr}^{30,31}$ and its expression was found to be up-regulated when $\operatorname{PrP}^{\mathrm{C}}$ was introduced into $\operatorname{Prnp}^{0 / 0}$ cells ${ }^{8}$. Therefore, the role of LDH in prion-induced pathological processes may not be restricted only to being the marker of cellular damage.

According to an astrocyte-neuron lactate shuttle hypothesis (ANLSH), lactate is generated in an activity-dependent and glutamate-mediated manner by astrocytes and it is subsequently transported to active neurons, which are the target of the lactate use ${ }^{42,43}$. In more details, this hypothesis postulates that neuronal activation increases the extracellular concentration of glutamate, which is then taken up via $\mathrm{Na}^{+}$-dependent transporters by astrocytes. Subsequently, elevated levels of glutamate and $\mathrm{Na}^{+}$in astrocytes activate glutamine synthetase and $\mathrm{Na}^{+} / \mathrm{K}^{+}$ ATPase, respectively. This triggers astrocytic ATP consumption leading to activation of glycolysis and lactate production. As the next step, the lactate is released from astrocytes and taken up by neurons, where it serves as a fuel for activity-related neuronal energy needs ${ }^{44-48}$. The cellular PrP regulates astrocytic $\alpha 2 / \beta 2-\mathrm{Na}^{+} / \mathrm{K}^{+}$ATPase activity and glutamate-triggered, basigin-associated lactate transport in primary culture of astrocytes. The $\mathrm{Na}^{+} / \mathrm{K}^{+}$ATPase 
activity was found to be reduced in PrP-deficient astrocytes or by binding of a monoclonal PrP antibody to its octarepeat, which further leads to regulation of MCT1-mediated lactate transport and the glutamate-independent elevation of lactate transport. Moreover, the CSF level of lactate is elevated in PrP-deficient mice compared to wild-type mice ${ }^{49}$. The loss of PrP function in astrocytes of CJD-affected brain may result in elevated levels of extracellular lactate, thus neuronal damage followed by lactate-induced acidosis.

The ALDOA displayed 3-fold increased CSF concentration for all three codon 129 polymorphisms in SCJD. However, the elevated level of ALDOA was also found in AD. It suggests that ALDOA might also be implicated in pathological processes occurring in AD. The ALDOA abundance in the brain remained unchanged in MM1-sCJD and VV2-sCJD in comparison to the age-matched controls. Moreover, partial shift in its cellular distribution was observed in the SCJD. Diffuse ALDOA immunostaining was predominantly found in neurons in the gray matter and in astrocytes in the white matter of NDC and AD, whereas the ALDOA immunoreactivity in SCJD was only detected in neuronal cell bodies.

It has been shown, that glyceraldehyde-3-phospahte (G-3-P), an enzymatic product of ALDOA, is implied in the protection of cells against apoptosis via the inhibition of caspase-3 activity $^{50}$. Moreover, neurotoxicity of doppel (Dpl), the $\operatorname{PrP}^{\mathrm{C}}$ homolog, in Purkinje cells of the Ngsk $\operatorname{Prnp}^{0 / 0}$ mouse model varies according to aldolase $\mathrm{C}$ expression. The higher sensitivity to Dpl-induced neurotoxicity, thus increased cell loss, is characteristic for Purkinje cells from aldolase C-negative compartments of the cerebellum ${ }^{51}$. Summarizing, the presence of ALDOA in impaired neurons and its secretion may play an anti-apoptotic role in SCJD.

It is very likely that immuno-positive neural cells are origin of glycolytic enzymes which were found in elevated levels in CSF. Nevertheless, based on our experiments, a conclusive correlation between cellular localization of investigated glycolytic enzymes and their elevated level in CSF cannot be demonstrated. This hypothesis should be addressed in future studies.

Both, glycolysis and apoptosis are highly conserved and finely regulated multi-step processes maintaining cellular homeostasis. The activation of apoptotic pathway is dependent on energy status and, hence, apoptosis might be dependent on glucose metabolism. Based on numerous studies demonstrating that glucose metabolism is involved in cell death and survival, it is reasonable to speculate that these two crucial processes are linked. However, precise mechanisms underlying the regulation of glucose metabolism and the implication of glycolytic enzymes in apoptosis remain to be elucidated. 


\section{Concluding remarks}

In summary, this study shows that 2D-DIGE approach can be successfully applied to explore in depth alterations in CSF proteome caused by CNS disorders. Furthermore, the identification of SCJD-regulated proteins in CSF provided a new insight into prion-induced pathological processes occurring in the brain of living, symptomatic patients. Moreover, revealed proteins could serve as a source of novel potential, diagnostic marker(s) for sCJD. Therefore, it would be of great interest to test utility of selected proteins in early diagnosis of sCJD. Another appealing aspect of our study, which would require further investigation concern the role of G6PI as well as its cellular translocalization in SCJD. 


\section{Bibliography}

1. Parchi, P.; Giese, A.; Capellari, S.; Brown, P.; Schulz-Schaeffer, W.; Windl, O.; Zerr, I.; Budka, H.; Kopp, N.; Piccardo, P.; Poser, S.; Rojiani, A.; Streichemberger, N.; Julien, J.; Vital, C.; Ghetti, B.; Gambetti, P.; Kretzschmar, H. A., Classification of sporadic Creutzfeldt-Jakob disease based on molecular and phenotypic analysis of 300 subjects. Ann Neurol 1999, 46, 224-33.

2. Gambetti,; P.; Kong, Q.; Zou, W.; Parchi P.; Chen, S.G., Sporadic and familial CJD: classification and characterisation. Br Med Bull 2003, 66, 213-39.

3. Anderson NL, Anderson, N.G., Proteome and proteomics: new technologies, new concepts, and new words. Electrophoresis 1998, 19, (11), 1853-61.

4. Harrington, M. G.; Merril, C. R.; Asher, D. M.; Gajdusek, D. C., Abnormal proteins in the cerebrospinal fluid of patients with Creutzfeldt-Jakob disease. N Engl J Med 1986, 315, (5), 279-83.

5. Hsich, G.; Kenney, K.; Gibbs Jr., C. J.; Lee, K. H.; Harrington, M. G., The 14-3-3 brain protein in cerebrospinal fluid as a marker for transmissible spongifrom encephalopathies. N Engl J Med 1996, 335, (13), 924-30.

6. Zerr, I.; Bodemer, M.; Gefeller, O.; Otto, M.; Poser, S.; Wiltfang, J.; Windl, O.; Kretzschmar, H. A.; Weber, T., Detection of 14-3-3 protein in the cerebrospinal fluid supports the diagnosis of Creutzfeldt-Jakob disease. Ann Neurol 1998, 43, (1), 32-40.

7. WHO, WHO manual for strengthening diagnosis and surveillance of Creutzfeldt-Jakob disease. World Health Organisation Communicable Disease Surveillance and Response 1999.

8. $\quad$ Ramljak, S.; Asif, A.R.; Armstrong, V.W.; Wrede, A.; Groschup, M.H.; Buschmann, A.; SchulzSchaeffer, W.; Bodemer, W.; Zerr, I., Physiological role of the cellular prion protein (PrPc): protein profiling study in two cell culture systems. J Proteome Res 2008, 7, (7), 2681-95.

9. $\quad$ Codina, R.; Vanasse, A.; Kelekar, A.; Vezys, V.; Jemmerson, R., Cytochrome c-induced lymphocyte death from the outside in: inhibition by serum leucine-rich alpha-2-glycoprotein-1. Apoptosis 2010, 15, (2), 13952.

10. Jemmerson. R.; LaPlante, B.; Treeful, A., Release of intact, monomeric cytochrome c from apoptotic and necrotic cells. Cell Death Differ 2002, 9, (5), 538-48.

11. Renz, A.; Burek, C.; Mier, W.; Mozoluk, M.; Schulze-Osthoff, K.; Los, M., Cytochrome c is rapidly extruded from apoptotic cells and detectable in serum of anticancer-drug treated tumor patients. Adv Exp Med Biol 2001, 495, 331-4.

12. Agostinho, P.; Oliveria, C.R., Involvement of calcineurin in the neurotoxic effects induced by amyloidbeta and prion peptides. Eur J Neurosci 2003, 17, (6), 1189-96.

13. Xiang, W.; Windl, O.; Wünsch, G.; Dugas, M.; Kohlmann, A.; Dierkes, N., Westner, I.M.; Kretzschmar, H.A., Identification of differentially expressed genes in scrapie-infected mouse brains by using global gene expression technology. J Virol 2004, 78, (20), 11051-60.

14. Ishii, T.; Haga, S.; Yagishita, S.; Tateishi, J., The presence of complements in amyloid plaques of Creutzfeldt-Jakob disease and Gerstmann-Straussler-Scheinker disease. Appl Pathol 1984, 2, (6), 370-9.

15. Mabbott, N.A., Burce, M.R., Complement component C5 is not involved in scrapie pathogenesis. Immunobiology 2004, 209, (7), 545-9. 
16. Kim, H. C.; Chang, K. H.; Song, I. C.; Lee, S. H.; Kwon, B. J.; Han, M. H.; Kim, S. Y., Diffusionweighted MR imaging in biopsy-proven Creutzfeldt-Jakob disease. Korean J Radiol 2001, 2, (4), 192-6.

17. Milhavet, O.; McMahon H.E.; Rachidi, W.; Nishida, N.; Katamine, S.; Mangé, A.; Arlotto, M.; Casanova, D.; Riondel, J.; Favier, A., Lehmann S, Prion infection impairs the cellular response to oxidative stress. Proc Natl Acad Sci U S A 2000, 5, (97), 13937-42.

18. Milhavet, O.; Lehmann, S., Oxidative stress and the prion protein in transmissible spongiform encephalopathies. Brain Res Brain Res Rev 2002, 38, (3), 328-39.

19. Okada, M.; Matsumoto, K.; Niki, T.; Taira, T.; Iguchi-Ariga, S.M.; Ariga, H., DJ-1, a target protein for an endocrine disrupter, participates in the fertilization in mice. Biol Pharm Bull 2002, 25, (7), 853-6.

20. Nagakubo, D.; Taira, T.; Kitaura, H.; Ikeda, M.; Tamai, K.; Iguchi-Ariga, S.M.; Ariga, H., DJ-1, a novel oncogene which transforms mouse NIH3T3 cells in cooperation with ras. Biochem Biophys Res Commun 1997, 231, (2), 509-13.

21. Taira, T.; Saito, Y.; Niki, T.; Iguchi-Ariga, S.M.; Takahashi, K.; Ariga, H., DJ-1 has a role in antioxidative stress to prevent cell death. EMBO Rep 2004, 5, (2), 213-8.

22. van Duijn C.M.; Dekker, M.C.; Bonifati, V.; Galjaard, R.J.; Houwing-Duistermaat, J.J.; Snijders, P.J.; Testers, L.; Breedveld, G.J.; Horstink, M.; Sandkuijl, L.A.; van Swieten, J.C.; Oostra, B.A.; Heutink, P., Park7, a novel locus for autosomal recessive early-onset parkinsonism, on chromosome 1p36. Am J Hum Genet 2001, 69, (3), 629-34.

23. Clements, C.M.; McNally, R.S.; Conti, B.J.; Mak, T.W.; Ting, J.P., DJ-1, a cancer- and Parkinson's disease-associated protein, stabilizes the antioxidant transcriptional master regulator Nrf2. Proc Natl Acad Sci U $S$ A 2006, 103, (41), 15091-6.

24. Tang, H.; Fu, Y.; Cui, Y.; He, Y.; Zeng, X.; Ploplis, V.A.; Castellino, F.J.; Luo, Y., Fibrinogen has chaperone-like activity. Biochem Biophys Res Commun 2009, 378, (3), 662-7.

25. Fischer, M. B.; Roeckl, C.; Parizek, P.; Schwarz, H. P.; Aguzzi, A., Binding of disease-associated prion protein to plasminogen. Nature 2000, 408, 479-83.

26. Phillips, M.I.; de Oliveria, E.M., Brain renin angiotensin in disease. J Mol Med 2008, 86, (6), 715-22.

27. Ottervald, J.; Franzen, B.; Nilsson, K.; Andersson, L.I.; Khademi, M.; Eriksson, B.; Kjellström, S.; Marko-Varga, G.; Végvári, A.; Harris, R.A.; Laurell, T.; Miliotis, T.; Matusevicius, D.; Salter, H.; Ferm, M.; Olsson, T., Multiple sclerosis: Identification and clinical evaluation of novel CSF biomarkers. J Proteomics 2010, 73, (6), 1117-32.

28. Piubelli, C.; Fiorini, M.; Zanusso, G.; Milli, A.; Fasoli, E.; Monaco, S.; Righetti, P. G., Searching for markers of Creutzfeldt-Jakob disease in cerebrospinal fluid by two-dimensional mapping. Proteomics 2006, 6 Suppl 1 256-261.

29. Brechlin, P.; Jahn, O.; Steinacker, P.; Cepek, L.; Kratzin, H.; Lehnert, S.; Jesse, S.; Mollenhauer, B.; Kretzschmar, H.A.; Wiltfang, J.; Otto, M., Cerebrospinal fluid-optimized two-dimensional difference gel electrophoresis (2-D DIGE) facilitates the differential diagnosis of Creutzfeldt-Jakob disease. Proteomics 2008 , $8,(20), 4357-66$.

30. Rutishauser, D., Mertz, K.; Moos, R.; Brunner, E,; Rülicke, T.; Calella, A.M.; Aguzzi, A., The comprehensive native interactome of a fully functional tagged prion protein. PLoS One 2009, 4, (2), e4446.

31. Watts, J.C.; Huo, H.; Bai, Y.; Ehsani, S.; Jeon, A.H.; Shi, T.; Daude, N.; Lau, A.; Young, R.; Xu, L.; Carlson, G.A.; Williams, D.; Westaway, D.; Schmitt-Ulms, G., Interactome analyses identify ties of PrP and its 
mammalian paralogs to oligomannosidic N-glycans and endoplasmic reticulum-derived chaperones. PLoS Pathog 2009, 5, (10), 1000608.

32. Xiang, W.; Windl, O.; Westner, I. M.; Neumann, M.; Zerr, I.; Lederer, R. M.; Kretzschmar, H. A., Cerebral gene expression profiles in sporadic Creutzfeldt-Jakob disease. Ann Neurol 2005, 58, (2), $242-57$. 33. Gurney, M.E.; Heinrich, S.P.; Lee, M.R.; Yin, H.S., Molecular cloning and expression of neuroleukin, a neurotrophic factor for spinal and sensory neurons. Science 1986, 234, (4776), 566-74.

34. Liotta, L. A.; Mandler, R.; Murano, G.; Katz, D. A.; Gordon, R. K.; Chiang, P. K.; Schiffmann, E. Tumor cell autocrine motility factor. Proc Natl Acad Sci U S A 1986, 83, (10), 236-41.

35. Niinaka, Y.; Paku, S.; Haga, A.; Watanabe, H.; Raz, A., Expression and secretion of neuroleukin/phosphohexose isomerase/maturation factor as autocrine motility factor by tumor cells. Cancer Res 1998, 58, (12), 2667-74.

36. Xu, W.; Chiao, J.W., Biochemical characteristics of a human myeloid leukemia cell differentiation factor. Prep Biochem Biotechnol 1996, 26, (1), 21-30.

37. Romagnoli, A.; Oliveiro, S.; Evangelisti, C.; Iannicola, C.; Ippolito, G.; Piacentini, M., Neuroleukin inhibition sensitises neuronal cells to caspase-dependent apoptosis. Biochem Biophys Res Commun 2003, 302, (3), 448-53.

38. Tsutsumi, S.; Hogan, V.; Nabi, I.R.; Raz, A., Overexpression of the autocrine motility factor/phosphoglucose isomerase induces transformation and survival of NIH-3T3 fibroblasts. Cancer Res 2003, 63, (1), 242-9.

39. Decourt, B.; Bouleau, Y.; Dulon, D.; Hafidi, A., Expression analysis of neuroleukin, calmodulin, cortactin, and Rho7/Rnd2 in the intact and injured mouse brain. Brain Res Dev Brain Res 2005, 159, (1), 36-54.

40. Prosniak, M.; Zborek, A.; Scott, G.S.; Roy, A.; Phares, T.W.; Koprowski, H.; Hooper, D.C.,

Differential expression of growth factors at the cellular level in virus-infected brain. Proc Natl Acad Sci U S A 2003, 100, (11), 6765-70.

41. Schmidt, H.; Otto, M.; Niedmann, P.; Cepek, L.; Schroter, A.; Kretzschmar, H. A.; Poser, S., CSF lactate dehydrogenase activity in patients with Creutzfeldt-Jakob disease exceeds that in other dementias. Dement Geriatr Cogn Disord 2004, 17, 204-6.

42. Pellerin, L.; Pellegri, G.; Bittar, P. G.; Charnay, Y.; Bouras, C.; Martin, J. L.; Stella, N.; Magistretti, P. J., Evidence supporting the existence of an activity-dependent astrocyte-neuron lactate shuttle. Dev Neurosci 1998, 20, (4-5), 291-9.

43. Pellerin, L.; Pellegri, G.; Martin, J.L.; Magistretti, P.J., Expression of monocarboxylate transporter mRNAs in mouse brain: support for a distinct role of lactate as an energy substrate for the neonatal vs. adult brain. Proc Natl Acad Sci U S A 1998, 95, (7), 3990-5.

44. Bouzier-Sore A.K.; Merle, M.; Magistretti, P.J.; Pellerin, L., Feeding active neurons: (re)emergence of a nursing role for astrocytes. $J$ Physiol Paris 2002, 96, (3-4), 273-82.

45. Magistretti, P.J.; Pellerin, L., Astrocytes Couple Synaptic Activity to Glucose Utilization in the Brain. News Physiol Sci 1999, 14, 177-182.

46. Magistretti, P.J., M., Cellular bases of functional brain imaging: insights from neuron-glia metabolic coupling. Brain Res 2000, 886, (1-2), 108-112.

47. Magistretti, P.J.; Pellerin, L.; Rothman, D.L.; Shulman, R.G., Energy on demand. Science 1999, 283, (5401), 496-7. 
48. Magistretti, P.J.; Pellerin, L., Cellular mechanisms of brain energy metabolism and their relevance to functional brain imaging. Philos Trans R Soc Lond B Biol Sci 1999, 354, (1397), 1155-63.

49. Kleene, R.; Loers, G.; Langer, J.; Frobert, Y.; Buck, F.; Schachner, M., Prion protein regulates glutamate-dependent lactate transport of astrocytes. J Neurosci 2007, 27, (45), 12331-40.

50. Jang, M.; Kang, H.J.; Lee, S.Y.; Chung, S.J.; Kang, S.; Chi, S.W.; Cho, S.; Lee, S.C.; Lee, C.K.; Park, B.C.; Bae, K.H.; Park, S.G., Glyceraldehyde-3-phosphate, a glycolytic intermediate, plays a key role in controlling cell fate via inhibition of caspase activity. Mol Cells 2009, 28, 559-63.

51. Heitz, S.; Gautheron, V.; Lutz, Y.; Rodeau, J.L.; Zanjani, H.S.; Sugihara, I.; Bombarde, G.; Richard, F.; Fuchs, J.P.; Vogel, M.W.; Mariani, J.; Bailly Y, BCL-2 counteracts Doppel-induced apoptosis of prion-proteindeficient Purkinje cells in the Ngsk Prnp(0/0) mouse. Dev Neurobiol 2008, 15, (68), 332-48.

\section{Acknowledgments}

The authors thank Barbara Ciesielczyk, Monika Bodemer, Anja Schütz, Tatjana Pfander, Christa Scholz, Christina Wiese and Arne Wrede for their outstanding technical help and valuable advices.

Providing of $\mathrm{Cy} 3$ anti-goat secondary antibody by Prof. Reinhard Schuh (Molecular

Organogenesis Group, Max Planck Institute for Biophysical Chemistry, Goettingen) is greatly appreciated.

The work was supported by a grant from European Commission Prionscreen SP5A-CT-2007044438 "Development of a blood screening assay for diagnosis of prion disease in humans". 
2.2. Cellular prion protein overexpression disturbs cellular homeostasis in SH-SY5Y neuroblastoma cells but does not alter p53 expression: a proteomic study

\subsubsection{Aims of the project}

The aim of this study was to examine proteome and thereby biological processes affected by stable overexpression of human $\operatorname{PrP}^{\mathrm{C}}$ in human neuroblastoma SH-SY5Y cell line.

Many evidences indicate that $\operatorname{PrP}^{\mathrm{C}}$-overexpression in different cells line leads to increased sensitivity to apoptotic stimuli or triggers neurodegeneration and myopathy. The observed pro-apoptotic properties of $\operatorname{PrP}^{\mathrm{C}}$ seem to be related to the p53-dependent apoptotic pathway. Therefore, we applied a proteomic approach to reveal proteins which contribute to $\operatorname{PrP}^{\mathrm{C}}$ overexpression-mediated disturbances in cellular homeostasis as well as to investigate involvement of p53-dependent pathway in this pathological process. 


\subsubsection{Orginal publication}

The results described below are published in:

Weiss E, Ramljak S, Asif AR, Ciesielczyk B, Schmitz M, Gawinecka J, Schulz-Schaeffer W, Behrens C, Zerr I. Cellular prion protein overexpression disturbs cellular homeostasis in SHSY5Y neuroblastoma cells but does not alter p53 expression: a proteomic study. Neuroscience 2010 Sep 15;169(4):1640-50

Author contribution:

The study was designed, conducted and interpreted by Sanja Ramljak. Eva Weiss performed cell culture and partially Western blot analysis. Eva Weiss and Joanna Gawinecka performed 2D gel electrophoresis and densitometric analysis of gel images. Abdul R. Asif performed mass spectrometry analysis. Matthias Schmitz helped in review process by performing transient transfection of mouse neuroblastoma N2a cells and human neuroblastoma SK-N-LO cells. Christina Behrens generated stable $\mathrm{PrP}^{\mathrm{C}}$-overexpressing SH-SY5Y human neuroblastoma cells. Walter Schulz-Schaeffer provided cell culture facilities and partially cell culture materials. Sanja Ramljak and Inga Zerr wrote manuscript. 


\section{CELLULAR PRION PROTEIN OVEREXPRESSION DISTURBS CELLULAR HOMEOSTASIS IN SH-SY5Y NEUROBLASTOMA CELLS BUT DOES NOT ALTER p53 EXPRESSION: A PROTEOMIC STUDY}

\author{
E. WEISS, ${ }^{a 2}$ S. RAMLJAK, ${ }^{a 1,2 *}$ A. R. ASIF, \\ B. CIESIELCZYK, ${ }^{a}$ M. SCHMITZ, ${ }^{a}$ J. GAWINECKA, ${ }^{a}$ \\ W. SCHULZ-SCHAEFFER, ${ }^{c}$ C. BEHRENS ${ }^{c}$ AND I. ZERR ${ }^{a}$ \\ ${ }^{a}$ Department of Neurology, Georg-August University, Robert-Koch- \\ Strasse 40, 37075 Göttingen, Germany \\ ${ }^{b}$ Department of Clinical Chemistry, Georg-August University, Robert- \\ Koch-Strasse 40, 37075 Göttingen, Germany \\ 'Department of Neuropathology, Georg-August University, Robert- \\ Koch-Strasse 40, 37075 Göttingen, Germany
}

\begin{abstract}
The definite physiological role of the cellular prion protein $\left(\mathrm{PrP}^{\mathrm{c}}\right)$ remains elusive. There is ample in vitro and in vivo evidence suggesting a neuroprotective role for $\operatorname{PrP}^{c}$. On the other hand, several in vitro and in vivo studies demonstrated detrimental effects of $\operatorname{PrP}^{c}$ overexpression through activation of a p53 pathway. Recently, we reported that transient overexpression of $\mathrm{PrP}^{\mathrm{c}}$ in human embryonic kidney 293 cells elicits proteome expression changes which point to deregulation of proteins involved in energy metabolism and cellular homeostasis. Here we report proteome expression changes following stable $\operatorname{PrP}^{\mathrm{c}}$ overexpression in human neuronal SH-SY5Y cells. In total 18 proteins that are involved in diverse biological processes were identified as differentially regulated. The majority of these proteins is involved in cell signaling, cytoskeletal organization and protein folding. Annexin $V$ exhibited a several fold up-regulation following stable $\mathrm{PrP}^{\mathrm{c}}$ overexpression in SH-SY5Y cells. This finding has been reproduced in alternative, mouse N2a and human SK$\mathrm{N}-\mathrm{LO}$ neuroblastoma cell lines transiently overexpressing $\mathrm{PrP}^{\mathrm{c}}$. Annexin $\mathrm{V}$ plays an important role in maintenance of calcium homeostasis which when disturbed can activate a p53-dependent cell death. Although we did not detect changes in $\mathrm{p} 53$ expression between $\mathrm{PrP}^{\mathrm{c}}$ overexpressing $\mathrm{SH}$ SY5Y and control cells, deregulation of several proteins including annexin $\mathrm{V}$, polyglutamine tract-binding protein-1,
\end{abstract}

${ }^{1}$ Present address: S. Ramljak, German Primate Center, Department of Infectious Biology, Kellnerweg 4, 37077 Göttingen, Germany.

${ }^{2}$ The first two authors equally contributed to this study.

*Corresponding author. Tel: +49-551-38-51151; fax: +49-551-3851184.

E-mail address: sramljak@dpz.eu (S. Ramljak).

Abbreviations: ADHX, alcohol dehydrogenase class III; ANXA5, annexin V; CV028, UPF0027 protein; DMEM, Dulbecco's modified Eagle medium; FCS, fetal calf serum; FKBP4, FK506-binding protein 4; FUMH, fumarate hydratase; GRB2, growth factor receptor bound protein 2; GSTO1, glutathione S-transferase omega-1; MTDC, bifunctional methylenetetrahydrofolate dehydogenase/cyclohydrolase; PA1B3, platelet-activating factor acetylhydrolase IB subunit gamma; PDIA1, protein disulfide isomerase precursor; PPID, $40 \mathrm{kDa}$ peptidyl-prolyl cis-trans isomerase; PQBP1, polyglutamine tract-binding protein-1; PRNP, human prion protein gene; $\mathrm{PrP}^{\mathrm{c}}$, cellular prion protein; $\mathrm{P} / \mathrm{S}$, penicillin/streptomycin; RD23B, UV excision repair protein RAD23 homolog B; RHG01, Rho GTP-ase activating protein 1; SCJD, sporadic Creutzfeldt-Jakob disease; SPSY, spermine synthase; TAGL2, transgelin; TCTP, translationally-controlled tumor protein; 2-DE, two dimensional gel electrophoresis; 14-3-3G, 14-3-3 gamma. spermine synthase and transgelin 2 indicates disrupted cellular equilibrium. We conclude that stable $\mathrm{PrP}^{\mathrm{c}}$ overexpression in SH-SY5Y cells is sufficient to perturb cellular balance but insufficient to affect p53 expression. () 2010 IBRO. Published by Elsevier Ltd. All rights reserved.

Key words: prion protein, signal transduction, cytoskeleton, protein folding, annexin $\mathrm{V}$, transgelin 2.

In recent years numerous studies have focused on revealing the physiological function(s) of $\mathrm{PrP}^{\mathrm{c}}$. Recognizing cellular processes governed by $\mathrm{PrP}^{\mathrm{c}}$ might promote our understanding of molecular dysfunctions underlying the pathogenesis of transmissible spongiform encephalopathies mediated by the pathological isoform of $\mathrm{PrP}^{\mathrm{c}}$. Strong evidence suggests $\mathrm{PrP}^{\mathrm{c}}$ entailment in activation of distinct signal transduction pathways (Mouillet-Richard et al., 2000; Chen et al., 2003; Vassallo et al., 2005), copper metabolism (Pauly and Harris, 1998; Kramer et al., 2001), anti-oxidant activities (Brown and Besinger, 1998; Wong et al., 2001), synaptic transmission (Collinge et al., 1994) and modulation of cell death (Kuwahara et al., 1999; Bounhar et al., 2001). Despite PrP's involvement in diverse cellular activities its exact physiological role is still not defined.

Various studies investigating the control of cell death by $\operatorname{PrP}^{\mathrm{c}}$ have led to somewhat opposite conclusions. Extensive data documented anti-apoptotic, neuroprotective properties of $\mathrm{PrP}^{\mathrm{c}}$. Kuwahara and colleagues (1999) demonstrated that serum-deprivation induced cell death was more prominent in mouse prion protein knock-out $\left(\mathrm{Prnp}^{\circ{ }^{\circ}}\right)$ hippocampal neurons than in the control Prnp ${ }^{+/+}$cells. Furthermore, $\mathrm{PrP}^{\mathrm{C}}$ protected human neurons from apoptosis triggered by an overexpression of pro-apoptotic Bax protein (Bounhar et al., 2001). In vivo studies confirmed $\mathrm{PrP}^{\mathrm{c}}$-mediated neuroprotection. $\mathrm{PrP}^{\mathrm{c}}$-deficient mice are more susceptible to acute seizures (Walz et al., 1999) and exhibit significantly increased infarction volumes following transient focal cerebral ischemia as compared to their wild-type counterparts (Weise et al., 2004). These data are apparently in contrast to other reports indicating that overexpression of $\mathrm{PrP}^{\mathrm{c}}$ in different cell lines results in increased sensitivity to apoptotic stimuli (Paitel et al., 2002, 2003). The observed $\mathrm{PrP}^{\mathrm{c}}$-mediated hypersensitivity to apoptotic agents appears to be controlled via a p53-dependent pathway (Paitel et al., 2004; Sunyach et al., 2007). In vivo findings showed that $\mathrm{PrP}^{\mathrm{c}}$ overexpression triggers severe degeneration in the central and peripheral nervous system and causes primary myopathy in skeletal muscles (Westaway et al., 1994; Huang et al., 2007; Chiesa et al.,

0306-4522/10 \$ - see front matter @ 2010 IBRO. Published by Elsevier Ltd. All rights reserved.

doi:10.1016/j.neuroscience.2010.06.013 
2008). The primary myopathy observed in $\operatorname{PrP}^{\mathrm{c}}$-overexpressing mice appears to be related to a p53-dependent pathway, too (Liang et al., 2009).

Using a proteome approach we demonstrated that transient overexpression of human $\mathrm{PrP}^{\mathrm{c}}$ in human embryonic kidney (HEK) 293 cells evokes perturbed expression of proteins involved in energy production and maintenance of cellular homeostasis (Ramljak et al., 2008). The present study employs proteomics techniques to examine proteome and thereby biological processes affected by stable overexpression of human $\operatorname{PrP}^{\mathrm{C}}$ in human neuroblastoma SH-SY5Y cell line. The SH-SY5Y cell line is well characterized and was previously used either as a model system for studying the physiological role of $\operatorname{PrP}^{\mathrm{c}}$ (Watt et al., 2007) or prion-induced neuronal death (Dupiereux et al., 2006; Martínez and Pascual, 2007). We show that the majority of differentially regulated proteins can be either directly or indirectly associated with cell signaling, cytoskeletal organization or protein folding. Although the proteome patterns of HEK 293 cells transiently overexpressing $\operatorname{PrP}^{\mathrm{c}}$ (Ramljak et al., 2008) and SH-SY5Y cells stably overexpressing $\mathrm{PrP}^{\mathrm{C}}$ were largely non-intersecting with regard to affected protein groups, our results support the view that sole overexpression of $\operatorname{PrP}^{\mathrm{c}}$ is sufficient to subvert the cellular balance regardless of the cell type used (HEK 293 vs. SH-SY5Y) or transfection procedure (transient vs. stable).

\section{EXPERIMENTAL PROCEDURES}

\section{Plasmid construction and generation of stable PrPc-overexpressing cells}

SH-SY5Y human neuroblastoma cells were purchased from the American Type Culture Collection (ATCC, USA). To generate SH-SY5Y cells that constitutively and stably express full length human $\mathrm{PrP}^{\mathrm{c}}$, wild-type human prion protein gene (PRNP) was cloned into the Xhol/Xbal site of the pCIneo vector (Promega, Mannheim, Germany). The construct was verified by sequencing. Consequently, SH-SY5Y cells were transfected with pCIneoPRNP using Lipofectamin (Invitrogen, Karlsruhe, Germany) according to the manufacturer's instructions. Forty-eight hours after transfection cells were grown in Dulbecco's modified Eagle medium (DMEM; Biochrom, Berlin, Germany) supplemented with $10 \%$ fetal calf serum (FCS, Biochrom), 1\% penicillin/streptomycin (P/S, Biochrom) and $1 \%$ L-glutamine (Biochrom) at $37{ }^{\circ} \mathrm{C}, 5 \% \mathrm{CO}_{2}$ supply and $95 \%$ humidity. Six weeks after addition of $400 \mu \mathrm{g} / \mathrm{mL}$ Geneticin (Gibco/Invitrogen, Karlsruhe, Germany) stably transfected SH-SY5Y cells were selected and further maintained in the same medium with a lower concentration of Geneticin $(200 \mu \mathrm{g} /$ $\mathrm{ml})$. Medium was exchanged every 4 days. An overexpression of PRNP was checked by Western blot analysis. Parental SH-SY5Y cells were grown without Geneticin in DMEM containing $10 \%$ FCS, $1 \% \mathrm{P} / \mathrm{S}, 1 \%$ L-glutamine at $37{ }^{\circ} \mathrm{C}, 5 \% \mathrm{CO}_{2}$ supply and $95 \%$ humidity. The morphological features of transfected and nontransfected $\mathrm{SH}-\mathrm{SY} 5 \mathrm{Y}$ cells were identical as shown by light microscopy (Fig. 1A, B).

\section{Transient overexpression of $\operatorname{PrP}^{c}$ in human neuroblastoma SK-N-LO and mouse neuroblastoma N2a cells}

SK-N-LO human neuroblastoma (Cell lines service, Eppelheim, Germany) and N2a mouse neuroblastoma cells (ATCC, USA) were both transiently transfected with the pCMS-PRNP-EFGP vector, bearing human PRNP (Ramljak et al., 2008). In parallel, an empty pCMS-EGFP vector was used as a control. For the transfection of $1-1.5 \times 10^{6}$ cells in a six well plate $2 \mu \mathrm{g}$ of plasmid DNA and 4-5 $\mu$ l of Lipofectamine (Invitrogen) were dissolved in $250 \mu \mathrm{l}$ OptiMEM (Gibco/Invitrogen, Karlsruhe, Germany) for 5 min. Stable DNA complexes were formed after 15-20 min and added to the transfection medium (Gibco OptiMEM containing 2\% FCS). After $6-8 \mathrm{~h}$ the transfection medium was replaced by fresh culture medium. SK-N-LO cells were cultured in Alpha-MEM (Stem Cell technologies, Grenoble, France) supplemented with 10\% FCS and $1 \% \mathrm{P} / \mathrm{S}$ (Biochrom). N2a cells were maintained under same culture conditions as previously described for SH-SY5Y cell line. Cells were collected $48 \mathrm{~h}$ post-transfection.

\section{Sample preparation for two-dimensional electrophoresis and Western blotting}

Cell medium was removed from tissue culture flasks, cells were washed twice with cold phosphate-buffered saline (PBS), scraped and centrifuged at $+4{ }^{\circ} \mathrm{C}, \sim 4,000 \times g$ for $20 \mathrm{~min}$. The supernatant was decanted and the pellet was resuspended in cold PBS and centrifuged once more at $+4{ }^{\circ} \mathrm{C}, \sim 4,000 \times g$ for $10 \mathrm{~min}$. After discarding the supernatant, the pellet was lysed in $7 \mathrm{M}$ urea, $2 \mathrm{M}$ thiourea, $4 \%$ CHAPS, $2 \%$ ampholytes, $1 \%$ dithiothreitol (DTT) and a protease inhibitor mixture $(0.1 \mathrm{mM}$ phenylmethylsulfonylfluoride, $10 \mu \mathrm{M} \mathrm{N}$-tosyl-L-phenylalanyl-chloromethylketone and $10 \mu \mathrm{M}$ $\mathrm{N}$ - $\alpha$-tosyl-L-lysinyl-chloromethylketone) was added. The lysate was centrifuged in a microcentrifuge at $14000 \mathrm{rpm}$ for $10 \mathrm{~min}$ at $+4{ }^{\circ} \mathrm{C}$ to remove cell debris. Proteins were quantified by the Bradford assay (Bio-Rad, Munich, Germany).

\section{Western blotting}

For immunoblotting analysis, equal amounts of protein were diluted in $4 \times$ sample buffer, boiled for $5 \mathrm{~min}$ and loaded onto $12 \%$ polyacrylamide gels. Following separation by gel electrophoresis, proteins were electrophoretically transferred to polyvinylidene difluoride membranes (AppliChem, Darmstadt, Germany) and subsequently blocked with $5 \%(\mathrm{v} / \mathrm{v})$ non-fat dry milk in PBS and $0.1 \%$ Tween 20 (PBST) for $1 \mathrm{~h}$ at RT. Membranes were then incubated with different primary antibodies anti-PrP 12F10 monoclonal antibody (Krasemann et al., 1999; 1:1000), anti-annexin $\mathrm{V}$ polyclonal antibody (Abcam, Cambridge, UK; 1:500), anti-14-3-3 gamma polyclonal antibody (Santa Cruz Biotechnology, Santa Cruz, CA, USA; 1:4000), anti-transgelin monoclonal antibody (Abcam, $1: 625)$ and anti- $\beta$ actin monoclonal antibody (Abcam, 1:10 000) overnight at $4{ }^{\circ} \mathrm{C}$, with gentle rocking. After extensive rinsing in PBST, membranes were incubated with a peroxidase-conjugated goat anti-mouse or anti-rabbit secondary antibody (Jackson ImmunoResearch Laboratories Inc., West Grove, PA, USA; 1:2000; 1:5000) for $1 \mathrm{~h}$ at RT. Immunolabeled proteins were detected after immersion of the membranes into enhanced chemiluminescence $(E C L)$ solution and exposition to ECL-Hyperfilm (Amersham Biosciences, Buckinghamshire, UK). Densitometric measurements were performed using the ArcSoft photo Studio 5 (ArcSoft Inc.) and Lablmage $V$ 2.52a software. For each condition analyzed, minimum three Western blots were prepared from three different protein extractions.

\section{Two dimensional electrophoresis}

Protein samples were diluted with rehydration buffer containing 7 $\mathrm{M}$ urea, $2 \mathrm{M}$ thiourea, $15 \mathrm{mM}$ DTT, 4\% CHAPS and 2\% ampholytes for first-dimension isoelectric focusing. One-hundred and thirty micrograms of protein were loaded on a $17 \mathrm{~cm}, \mathrm{pH} 3-10$ linear, immobilized pH gradient (IPG) strip (Bio-Rad). IPG strips were focused until $32000 \mathrm{Vh}$ were reached and were first reduced for $25 \mathrm{~min}$ in the buffer containing $6 \mathrm{M}$ urea, $2 \%$ sodium dodecyl 

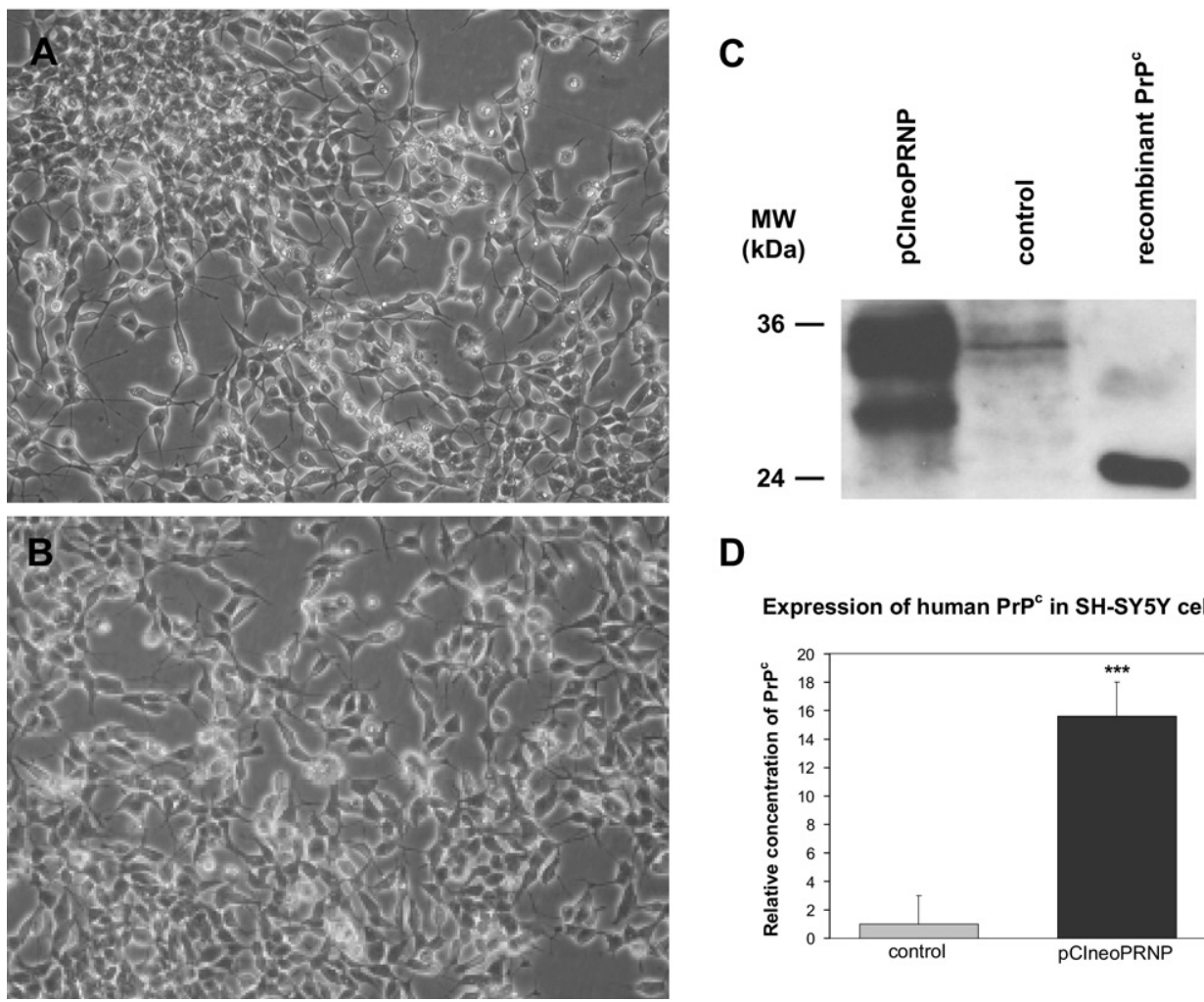

D

Expression of human $\mathrm{PrP}^{\mathrm{c}}$ in SH-SY5Y cells

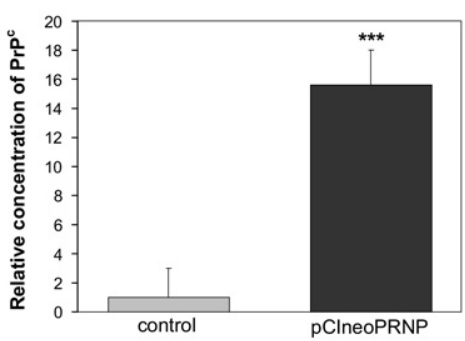

Fig. 1. (A, B) PrPc-overexpressing and parental SH-SY5Y cells. No morphological changes were observed (light microscope $10 \times m a g n i f i c a t i o n)$ between $\mathrm{PrP}^{\mathrm{c}}$-overexpressing $(\mathrm{A})$ and parental SH-SY5Y cells (B). (C) Western blot analysis of $\mathrm{PrP}^{\mathrm{c}}$ expression in $\mathrm{SH}^{-S Y} 5 \mathrm{Y}$ cells. PrPc expression was determined in $40 \mu \mathrm{g}$ of proteins from the total cell lysates of SH-SY5Y cells stably overexpressing PrPc (pClneoPRNP) and SH-SY5Y cells expressing endogenous $\mathrm{PrP}^{\mathrm{c}}$ (control) by using $12 \mathrm{~F} 10$ antibody. The highest band depicts diglycosylated, the middle band monoglycosylated and the lowest band unglycosylated form of $\mathrm{PrP}^{\mathrm{c}}$. Note high $\mathrm{PrP}^{\mathrm{c}}$ expression in $\mathrm{SH}-\mathrm{SY} 5 \mathrm{Y}$ cells transfected with pClneoPRNP vector and low, faintly visible, expression of endogenous $\mathrm{PrP}^{\mathrm{c}}$ in parental cells. Recombinant $\mathrm{PrP}^{\mathrm{c}}$ was used as a positive control $(2 \mathrm{ng})$. The displayed Western blot is representative of four independent experiments. (D) ELISA analysis of $\mathrm{PrP}^{\mathrm{c}}$ levels in SH-SY5Y cells stably transfected with pClneoPRNP vector. PrPc levels in stably transfected SH-SY5Y cells are expressed relatively to control PrPc levels observed in parental SH-SY5Y cells. Note markedly higher PrPc expression in pCIneoPRNP transfected cells vs. parental cells. PrPc concentration was measured in $50 \mu \mathrm{g}$ of proteins. Values represent the mean $\pm \mathrm{SD}$ of four independent experiments (two-sided unpaired Student's $t$-test ${ }^{* *} P<0.001$ )

sulfate (SDS), $30 \%$ glycerol, $2 \%$ DTT, and $0.375 \mathrm{M}$ Tris- $-\mathrm{HCl}(\mathrm{pH}$ 8.8 ) and later alkylated in the same buffer supplemented with $2.5 \%$ iodoacetamide instead of DTT for further $25 \mathrm{~min}$. Equilibrated strips were placed on top of vertical $12 \%$ polyacrylamide gels and electrophoresis was carried out at $100 \mathrm{~V}$ overnight (Protean xi 2-D Cell) at $+4{ }^{\circ} \mathrm{C}$. After second dimensional separation on SDS-PAGE the gels were silver stained and scanned using the ScanMaker 4. Densitometric analyses were carried out using the Delta 2D v3.6 (Decodon, Greifswald, Germany) software. For each condition analyzed, four gels were prepared from four different protein extractions. Differences in spot abundance detected by densitometric software were statistically evaluated using twosided unpaired Student's $t$-test. Means and standard deviations (SD) were calculated from four independent sets of experiments. The differences in protein expression with $P$-values $<0.05$ were considered significant.

\section{Identification of protein/peptide sequence analysis}

In-gel digestion was carried out according to a modified published protocol (Shevchenko et al., 1996). Spots of interest were excised from the silver stained gel into $1-2 \mathrm{~mm}^{2}$ slices, destained with 15 $\mathrm{mM}$ potassium ferricyanide/50 $\mathrm{mM}$ sodium thiosulfate (SigmaAldrich, Steinheim, Germany) and then equilibrated with $50 \mathrm{mM}$ ammonium bicarbonate/50\% acetonitrile (ACN) (Sigma-Aldrich). Samples were dried for $15 \mathrm{~min}$ using the SpeedVac SVC100
(Savant Instruments, Farmingdale, NY, USA) vacuum concentrator. Dried spots were rehydrated on ice with 10-20 $\mu$ l of trypsin digestion solution (Promega, Madison, WI, USA) for $45 \mathrm{~min}$ followed by an overnight incubation at $37{ }^{\circ} \mathrm{C}$ in digestion solution without trypsin. The peptides were first extracted with $0.1 \%$ trifluoracetic acid (TFA) for $30 \mathrm{~min}$ in the sonicating water bath Transsonic $310 / \mathrm{H}$ (Elma ${ }^{\circledR}$, Pforzheim, Germany) followed by extraction with $30 \% \mathrm{ACN}$ in $0.1 \%$ TFA and $60 \% \mathrm{ACN}$ in $0.1 \%$ TFA. The eluate was collected in Eppendorf tubes and dried with the SpeedVac. The extracted peptides were dissolved in $0.1 \%$ formic acid and one microliter of each sample was introduced using a CapLC auto sampler (Waters) onto a $\mu$-precolumn ${ }^{\mathrm{TM}}$ cartridge $\mathrm{C} 18$ pepMap (300 $\mu \mathrm{m} \times 5 \mathrm{~mm} ; 5 \mu \mathrm{m}$ partical size) and further separated through a C18 pepMap100 nano Series ${ }^{\mathrm{TM}}(75 \mu \mathrm{m} \times 15 \mathrm{~cm}$; $3 \mu \mathrm{m}$ partical size) analytical column (LC Packings). The single sample run time was set for $60 \mathrm{~min}$. The chromatographically separated peptides were analyzed on a Q-TOF Ultima Global (Micromass, Manchester, UK) mass spectrometer equipped with a nanoflow ESI Z-spray source in positive ion mode. The data acquisition was performed using MassLynx (v 4.0) software on a Windows NT PC and data were further processed on ProteinLynx-Global-Server (v 2.2), (Micromass, Manchester, UK). Processed data were searched against MSDB and Swiss-Prot databases through the Mascot search engine using a peptide mass tolerance and fragment mass tolerance of $0.5 \mathrm{Da}$. The search 
criteria were set with one missed cleavage by trypsin allowed and protein modifications set to methionine oxidation and carbamidomethylcysteine when appropriate.

\section{ELISA}

ELISA (enzyme-linked-immunosorbent assay) was carried out using commercially available BetaPrion BSE EIA Test Kit according to supplier's recommendations (Roboscreen, Leipzig, Germany).

\section{RESULTS}

Differential proteome analysis of human neuroblastoma SH-SY5Y cells stably overexpressing human $\operatorname{PrP}^{c}$ and parental SH-SY5Y cells expressing only endogenous $\mathrm{PrP}^{\mathrm{c}}$ was done to study protein expression changes occurring due to permanent overexpression of $\operatorname{PrP}^{\mathrm{c}}$. Western blot analysis confirmed markedly higher $\mathrm{PrP}^{\mathrm{c}}$ expression in SH-SY5Y cells stably overexpressing $\mathrm{PrP}^{\mathrm{c}}$ as compared to control cells (Fig. $1 \mathrm{C}$ ). $\mathrm{PrP}^{\mathrm{c}}$ level was further quantified by ELISA in each cell lysate before proceeding to 2-DE. In average, $\mathrm{PrP}^{\mathrm{c}}$ expression level was nearly 16-fold higher $(P<0.001)$ in $\mathrm{PrP}^{\mathrm{C}}$ overexpressing as compared to parental cells (Fig. 1D).

Densitometric analysis of silver stained 2-DE gels revealed a total of 18 differentially regulated protein spots between $\mathrm{SH}-\mathrm{SY} 5 \mathrm{Y}$ cells overexpressing $\mathrm{PrP}^{\mathrm{c}}$ and control cells (Table 1). Threshold for identification of up-/downregulated proteins was set to at least 1.5 fold change. According to this criterion 13 proteins were up- and five proteins were down-regulated following $\mathrm{PrP}^{\mathrm{c}}$ overexpression in SH-SY5Y cells with respect to the control group. Nine out of 18 differentially regulated proteins showed a two-fold or higher regulation. The map of significantly reg- ulated protein spots following 2-DE is shown in Fig. 2. In this study an overexpression of $\mathrm{PrP}^{\mathrm{c}}$ influenced various biological processes, especially, signal transduction, cytoskeleton organization and protein folding (Fig. 3). The proteins directly or indirectly involved in signal transduction displayed $\mathrm{PrP}^{\mathrm{C}}$-induced up-regulation in $\mathrm{SH}-\mathrm{SY} 5 \mathrm{Y}$ cells: 14-3-3 gamma (1433G), growth factor receptor bound protein 2 (GRB2), Rho GTP-ase activating protein 1 (RHG01) and platelet-activating factor acetylhydrolase IB subunit gamma (PA1B3). Likewise, three proteins implied in cytoskeleton organization: transgelin 2 (TAGL2), translationally-controlled tumor protein (TCTP) and RHG01were upregulated. Only one protein, UPF0027 (CV028), which appears indirectly involved in cytoskeleton organization was down-regulated in $\mathrm{PrP}^{\mathrm{c}}$ overexpressing neuroblastoma cells. Among three proteins assisting in protein folding two were down-regulated: $40 \mathrm{kDa}$ peptidyl-prolyl cistrans isomerase (PPID) and FK506-binding protein 4 (FKBP4) whereas protein disulfide isomerase precursor (PDIA1) was up-regulated by $\operatorname{PrP}^{c}$. Six out of eight remaining proteins that participate in various biological processes were up-regulated by $\operatorname{PrP}^{\mathrm{c}}$ : calcium and phospholipid binding protein, annexin $\mathrm{V}$ (ANXA5); polyglutamine binding protein-1 (PQBP1) involved in induction of neuronal cell death; oxidative stress protein, glutathione S-transferase omega-1 (GSTO1); UV excision repair protein RAD23 homolog B (RD23B) participating in DNA repair; alcohol dehydrogenase class III (ADHX) with yet undefined physiological function in brain and mitochondrial protein, fumarate hydratase (FUMH), implied in energy metabolism. On the contrary, only two out of eight proteins categorized as having other biological functions were down-regulated:

Table 1. List of proteins identified from 2-DE gels of SH-SY5Y cells. Eighteen different proteins were identified from 2-DE gels of parental and SH-SY5Y cells stably transfected with pCIneoPRNP vector. The number of the spots corresponds to their location on the gel (Fig. 2). Number of peptides matched, ion score, state change, fold change, significance (two-sided unpaired Student's $t$-test), protein identification, abbreviations and Swiss-Prot accession numbers have been given for each spot

\begin{tabular}{|c|c|c|c|c|c|c|c|c|}
\hline $\begin{array}{l}\text { Spot } \\
\text { no. }\end{array}$ & $\begin{array}{l}\text { Peptides } \\
\text { matched }\end{array}$ & Score & $\begin{array}{l}\text { State } \\
\text { change }\end{array}$ & $\begin{array}{l}\text { Fold } \\
\text { change }\end{array}$ & $P$ value & Protein ID & Abbr. & Acc. no. \\
\hline 43 & 6 & 95 & $\uparrow$ & 4.23 & 0.049 & Polyglutamine-binding protein 1 & PQBP1 & Q4VY36 \\
\hline 115 & 8 & 134 & $\uparrow$ & 2.52 & 0.005 & Transgelin-2 & TAGL2 & P37802 \\
\hline 131 & 15 & 259 & $\uparrow$ & 1.69 & 0.007 & Translationally-controlled tumor protein-human & TCTP & P13693 \\
\hline 166 & 4 & 81 & $\uparrow$ & 1.62 & 0.02 & $14-3-3$ protein gamma & $1433 G$ & P61981 \\
\hline 216 & 14 & 185 & $\uparrow$ & 1.67 & 0.03 & Glutathione transferase omega-1 & GSTO1 & P78417 \\
\hline 229 & 11 & 165 & $\uparrow$ & 2.93 & 0.002 & Annexin A5 & ANXA5 & P08758 \\
\hline 412 & 6 & 150 & $\uparrow$ & 1.70 & 0.03 & Protein disulfide-isomerase precursor & PDIA1 & P07237 \\
\hline 451 & 8 & 112 & $\uparrow$ & 2.12 & 0.002 & Rho GTPase-activating protein 1 & RHG01 & Q07960 \\
\hline 486 & 2 & 73 & $\uparrow$ & 1.53 & 0.04 & Fumarate hydratase, mitochondrial precursor & FUMH & P07954 \\
\hline 504 & 15 & 127 & $\uparrow$ & 2.16 & 0.034 & Growth factor receptor-bound protein 2 & GRB2 & P62993 \\
\hline 510 & 7 & 67 & $\uparrow$ & 2.01 & 0.05 & Alcohol dehydrogenase class- 3 & $\mathrm{ADHX}$ & P11766 \\
\hline 569 & 3 & 36 & $\uparrow$ & 1.73 & 0.02 & Platelet-activating factor acetylhydrolase IB subunit gamma & PA1B3 & Q15102 \\
\hline 597 & 11 & 159 & $\uparrow$ & 1.70 & 0.043 & UV excision repair protein RAD23 homolog B & RD23B & P54727 \\
\hline 73 & 6 & 77 & $\downarrow$ & 0.52 & 0.035 & $\begin{array}{l}\text { Bifunctional methylenetetrahydrofolate dehydogenase/ } \\
\text { cyclohydrolase, mitochondrial precursor }\end{array}$ & MTDC & P13995 \\
\hline 251 & 6 & 54 & $\downarrow$ & 0.55 & 0.012 & Spermine synthase & SPSY & P52788 \\
\hline 403 & 16 & 206 & $\downarrow$ & 0.43 & 0.003 & UPF0027 protein C22orf28 & CV028 & Q9Y310 \\
\hline 446 & 3 & 58 & $\downarrow$ & 0.45 & 0.009 & FK506-binding protein 4 & FKBP4 & Q02790 \\
\hline 513 & 14 & 151 & $\downarrow$ & 0.40 & 0.018 & $40 \mathrm{kDa}$ peptidyl-prolyl cis-trans isomerase & PPID & Q08752 \\
\hline
\end{tabular}

Abbr., Abbreviation; Acc., Accession. 


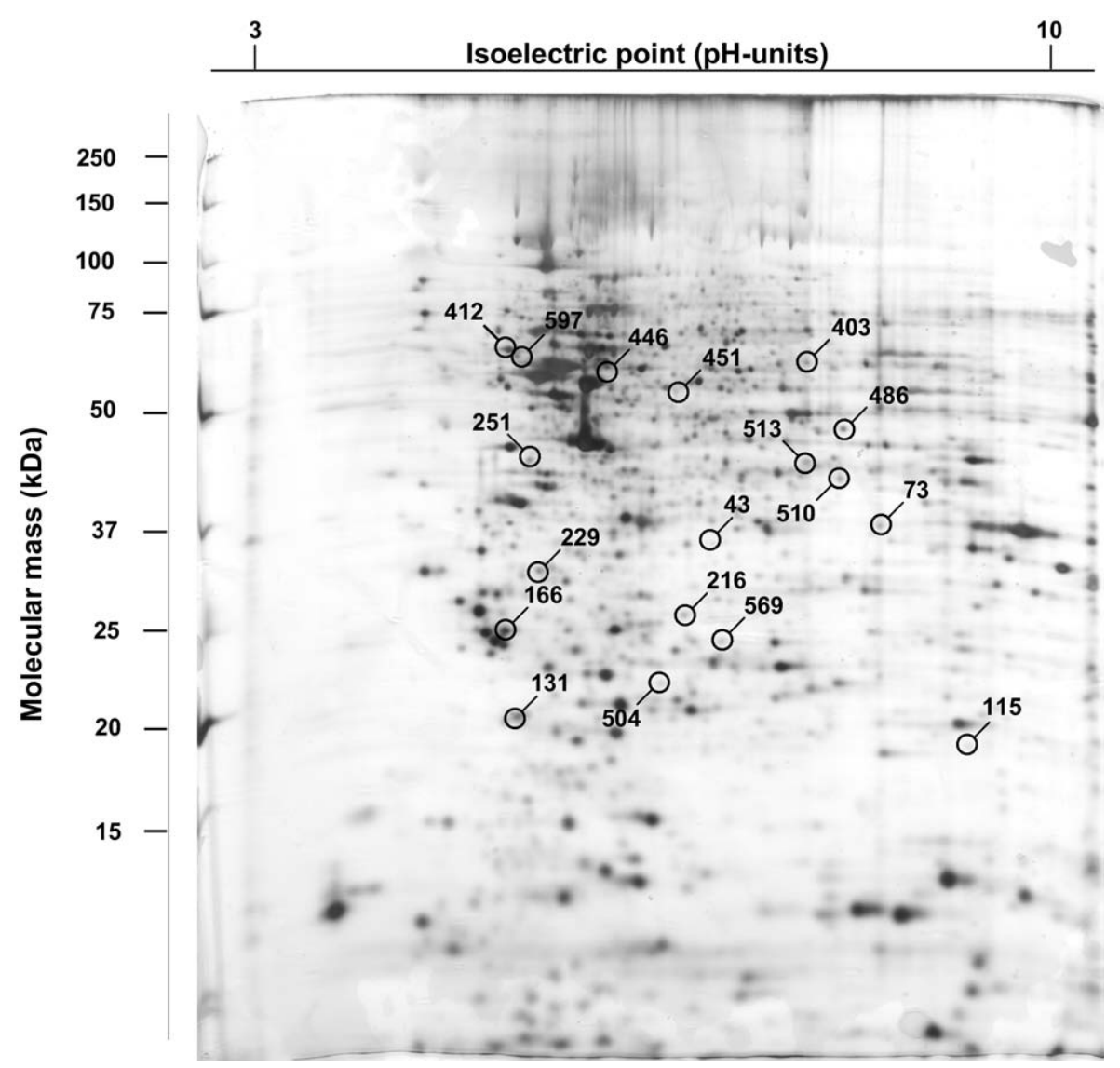

Fig. 2. Silver stained 2-DE gel of SH-SY5Y cells stably overexpressing $\mathrm{PrP}^{\mathrm{c}}$. Linear $17 \mathrm{~cm} \mathrm{IPG}$ strips (pH 3-10) were loaded with $130 \mu \mathrm{g}$ of proteins. Labelling on the gel represents the location of the relevant spots. The protein identity of the spots is listed in Table 1.

spermine synthase (SPSY), an enzyme which catalyzes production of a free radical scavenger spermine and mitochondrial protein, bifunctional methylenetetrahydrofolate dehydogenase/cyclohydrolase (MTDC) that is most probably involved in folate metabolism.

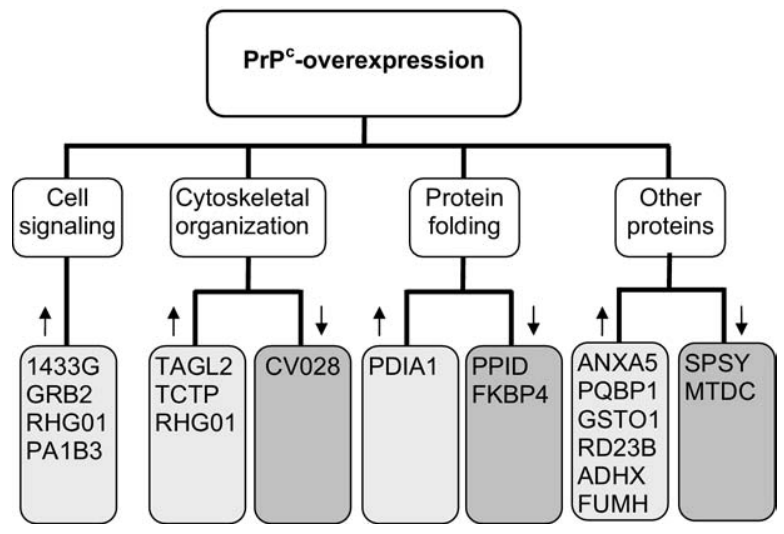

Fig. 3. Schematic depiction of up-/down-regulated proteins following stable overexpression of human $\mathrm{PrP}^{\mathrm{c}}$ in human neuroblastoma $\mathrm{SH}-$ SY5Y cells. All $18 \mathrm{PrP}^{\mathrm{c}}$-regulated proteins are distributed into four groups based on their biological function. Only RHG01 could be simultaneously categorized into two groups. Light grey colour indicates up-regulated whereas dark grey colour indicates down-regulated proteins. Short abbreviations given for each protein are explained in Table 1.
To reinforce the results obtained by densitometric analysis of 2-DE, the expression of ANXA5, TAGL2 and 1433G was additionally confirmed by Western blotting (Fig. 4AC). $\operatorname{PrP}^{\mathrm{c}}$ overexpression induced nearly 4 -fold $(P<0.01)$ up-regulation of ANXA5 in SH-SY5Y cells, as inferred from densitometric analysis of Western blot, although densitometric analysis of 2-DE showed 3-fold up-regulation. In order to further verify our data in an independent set of experiments we performed densitometric analyses of Western blots following transient overexpression of $\operatorname{PrP}^{\mathrm{c}}$ in mouse neuroblastoma N2a and alternative human neuroblastoma SK-N-LO cells which resulted in 2-fold $(P<0.001)$ and 1.8-fold $(P<0.01)$ higher expression of ANXA5 in PrPc overexpressing as compared to control vector transfected cells (Fig. 5A-D).

Western blot analysis revealed more than 260-fold up-regulation of TAGL2 by $\operatorname{PrP}^{\mathrm{c}}(P<0.001)$ in $\mathrm{SH}-\mathrm{SY} 5 \mathrm{Y}$ cells as compared to 2.5 -fold up-regulation observed by 2-DE. We were not able to reproduce this result in two additional cell lines (N2a and SK-N-LO), following transient overexpression of $\operatorname{PrP}^{\mathrm{c}}$, due to the complete lack of the signal with two different TAGL2 antibodies.

An up-regulation of $1433 \mathrm{G}$ by $\mathrm{PrP}^{\mathrm{c}}$ in SH-SY5Y cells was 1.6-fold following 2-DE analysis and was confirmed by Western blotting as being 1.4-fold $(P<0.01)$. The other two cell lines used in this study did not show 


\section{A ANXA5}

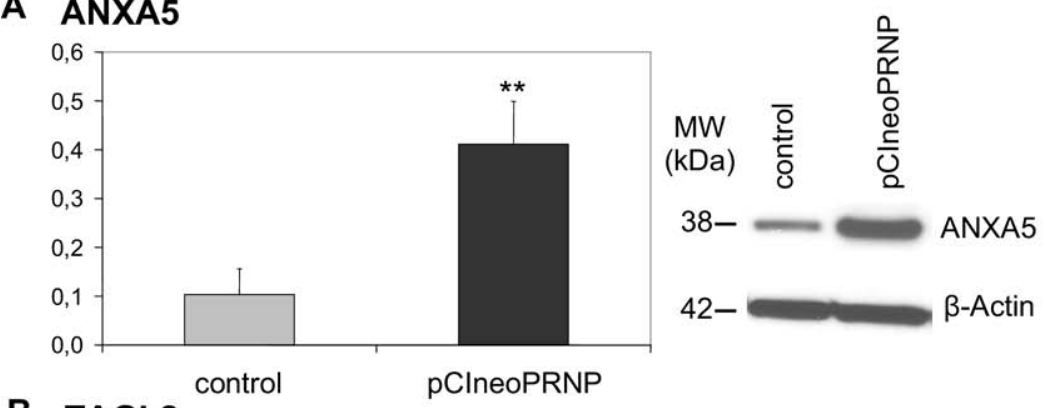

B TAGL2

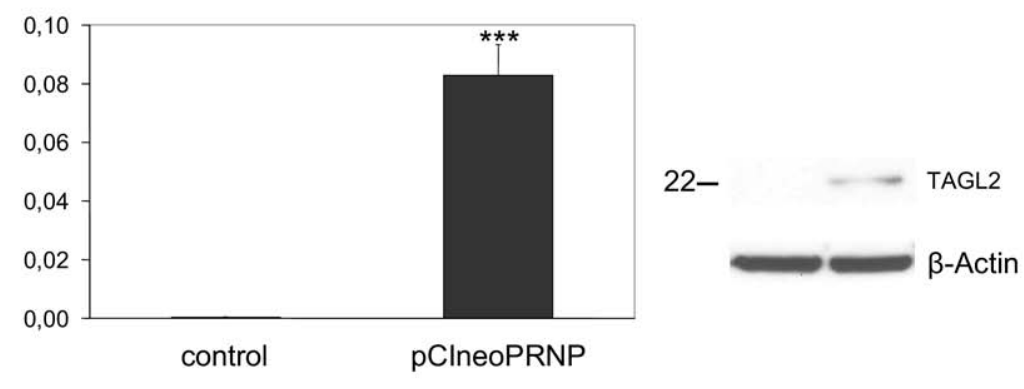

\section{C $1433 G$}

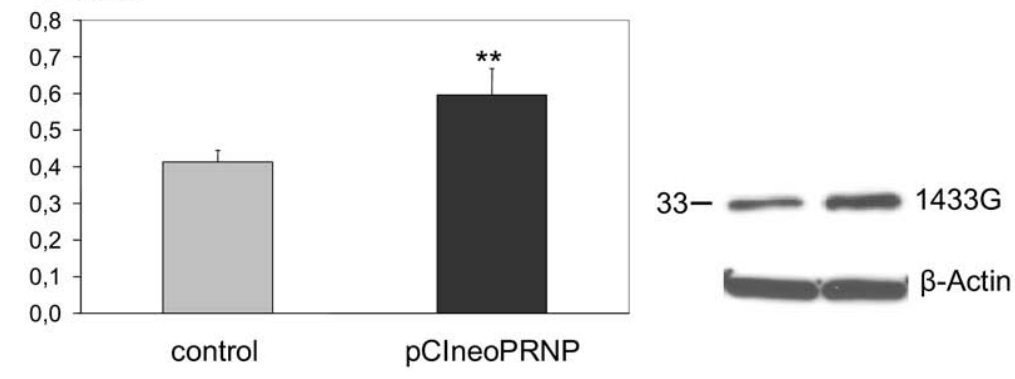

Fig. 4. (A-C) Annexin $V$, transgelin 2 and 14-3-3 gamma are up-regulated following PrPc overexpression in SH-SY5Y cells. Western blot analysis showing PrPc-mediated marked up-regulation of annexin V, ANXA5 (A), transgelin 2, TAGL2 (B) and 14-3-3 gamma, 1433G (C) in cells overexpressing $\mathrm{PrP}^{\mathrm{c}}$ ( $\mathrm{pCIneoPRNP)}$ as compared to parental SH-SY5Y cells (control). $\beta$-actin expression below each Western blot is given as a control for an equal protein load. The displayed Western blots are representatives of four independent experiments. Expression level of each protein displayed by Western blot was quantified by densitometric analysis and is shown as a diagram. Data were normalized against $\beta$-actin and are given as a ratio of each protein/ $\beta$-actin \pm SD ** $P<0.01$; ${ }^{* * *} P<0.001$.

$1433 \mathrm{G}$ regulation following transient overexpression of $\mathrm{PrP}^{\mathrm{c}}$.

Although tumor suppressor oncogene p53 was not detected as differentially regulated by $\mathrm{PrP}^{\mathrm{c}}$ overexpression in $\mathrm{SH}-\mathrm{SY} 5 Y$ cells by 2-DE, we performed additional Western blot analysis showing that its expression indeed remains unchanged between $\mathrm{PrP}^{\mathrm{c}}$-overexpressing and control cells (Fig. 6). The reason to verify p53 expression by additional Western blot analysis was that an increase in p53 expression was already demonstrated in different cell lines overexpressing $\operatorname{PrP}^{c}$. However, we did not detect enhanced p53 expression following $\mathrm{PrP}^{\mathrm{c}}$ overexpression in our cell model.

\section{DISCUSSION}

\section{Proteins involved in cell signaling}

As proof of principle the 14-3-3 gamma protein (1433G), a well known cerebrospinal marker used for distinguishing sporadic Creutzfeldt-Jakob disease (sCJD) from other dementias (Van Everbroeck et al., 2005), exhibited $\mathrm{PrP}^{\mathrm{c}}$ induced up-regulation in SH-SY5Y cells. Proteins belonging to the 14-3-3 family have significant influence on diverse signal transduction pathways, regulation of cell cycle progression and apoptosis (Fu et al., 2000). The finding that $1433 \mathrm{G}$ knock-out mice following intracerebral or intraperitoneal inoculation with the Rocky Mountain strain of scrapie do not show changes in survival rates as compared to wild-type mice (Steinacker et al., 2005), does not exclude the importance that $1433 \mathrm{G}$ might have for the physiological function of $\operatorname{PrP}^{\mathrm{c}}$.

Besides 1433G, GRB2 was another signaling protein found to be up-regulated following overexpression of $\operatorname{PrP}^{\mathrm{c}}$ in the present study. A previous report demonstrated an interaction between GRB2 and $\mathrm{PrP}^{\mathrm{c}}$ in yeast two-hybrid system and co-purification in neuronal microsomal vesicles (Spielhaupter and Schätzl, 2001). This adaptor protein connects the signals from extracellular/transmembrane re- 

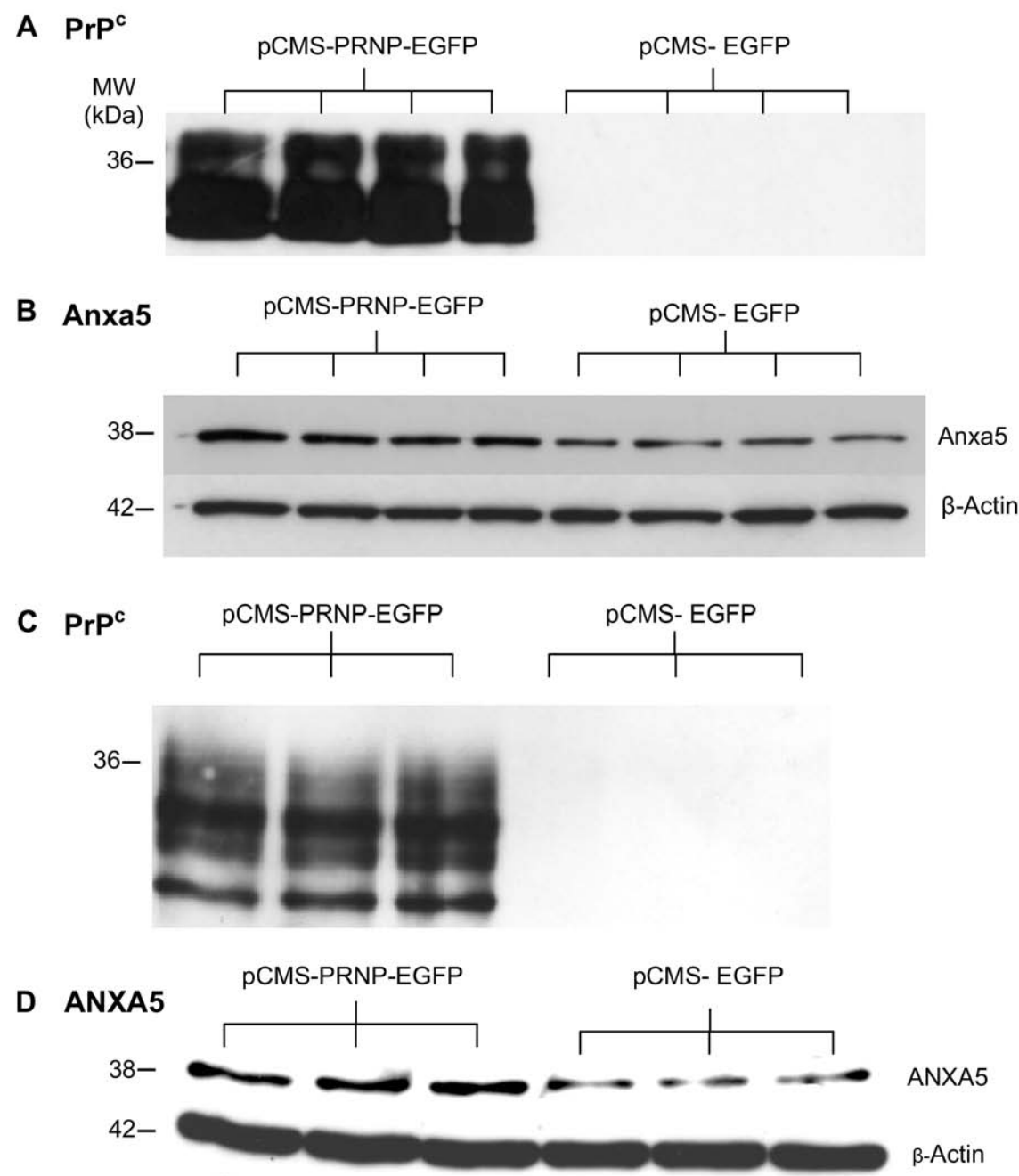

Fig. 5. (A-D) Western blot analyses of $\mathrm{PrP}^{\mathrm{c}}$ and annexin $\mathrm{V}$ expression in mouse neuroblastoma N2a and human neuroblastoma SK-N-LO cells. PrPc and annexin $V$ expression was determined in $20 \mu \mathrm{g}$ of proteins from the total cell lysates of N2a (Panels A, B) and SK-N-LO (Panels C, D) cells. Note high $\mathrm{PrP}^{\mathrm{c}}$ expression in $\mathrm{pCMS}$-PRNP-EGFP-transfected cells of both cell lines as compared to control (pCMS-EGFP) transfected cells (Panels A, C). Panel (B) displays markedly higher annexin (Anxa5) expression in PrPc-overexpressing N2a cells than in the control cells $(P<0.001)$. Panel (D) shows likewise significant up-regulation of annexin (ANXA5) in PrPc-overexpressing SK-N-LO cells as compared to control cells $(P<0.01)$. The displayed Western blots are representatives of four (N2a) and three (SK-N-LO) independent experiments and were reproduced three times. $\beta$-actin expression below each blot demonstrates an equal protein load.

ceptors to intracellular signaling molecules and is essential for the formation of signaling complexes.

RHG01 which also showed an enhanced expression by $\mathrm{PrP}^{\mathrm{c}}$-overexpressing cells belongs to small GTP-ases of the Ras superfamily implied in the control of c-Jun $\mathrm{N}$-terminal kinase and p38 mitogen activated protein kinase signaling cascades (Coso et al., 1995; Minden et al., 1995). A recent analysis of protein microarray data revealed that Rho GTP-ase activating protein 15 represents one of the $\mathrm{PrP}^{\mathrm{c}}$ interacting proteins (Satoh et al., 2009).

PA1B3, which was likewise up-regulated by $\operatorname{PrP}^{\mathrm{c}}$, belongs to platelet-activating factor acetylhydrolases (PAFAH). PAF-AH are not themselves signaling molecules but after the cleavage of the acyl group at the $s n-2$ position they inactivate platelet-activating factor (PAF) which is one of the most effective lipid messengers (Prescott et al., 2000). Identification of specific binding sites for PAF in subcellular fractions of gerbil brain and rat cerebral cortex suggests its physiological role in the brain (Domingo et al., 1988; Marcheselli et al., 1990). Interestingly, the intracellular PAF-AH can hydrolyze some oxidatively modified phospholipids and take part in their removal (Hattori et al., 1993). Thus, an up-regulation of PA1B3 by $\operatorname{PrP}^{c}$ may indicate an increased level of oxidized phospholipids in $\mathrm{PrP}^{\mathrm{c}}$ overexpressing $\mathrm{SH}-\mathrm{SY} 5 \mathrm{Y}$ cells.

\section{Proteins involved in cytoskeletal organization}

The ability of $\mathrm{PrP}^{\mathrm{c}}$ to regulate microtubule dynamics and to reorganise actin cytoskeleton is well documented (Dong et al., 2008; Málaga-Trillo et al., 2009). TAGL2, a protein involved in the organization and stability of the actin cytoskeleton (Goodman et al., 2003) displayed striking, by Western blot validated, 260-fold up-regulation in $\mathrm{PrP}^{\mathrm{c}}$ - 


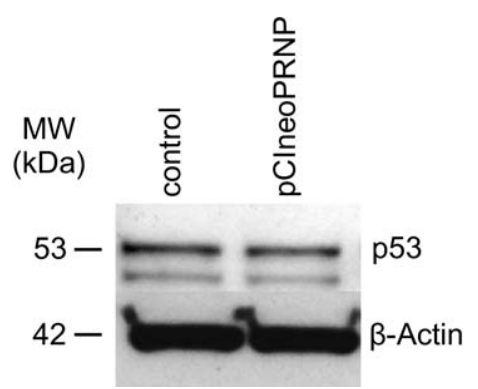

Fig. 6. p53 immunoreactivity after $\operatorname{PrP}^{c}$ overexpression in SH-SY5Y cells. Western blot analysis displays no difference in the expression of p53 between SH-SY5Y cells stably overexpressing $\mathrm{PrP}^{\mathrm{c}}$ (pClneoPRNP) and parental cells expressing only endogenous $\operatorname{PrP}^{c}$ (control). This Western blot is representative of four independent experiments. $\beta$-actin expression demonstrates an equal protein load.

overexpressing cells as compared to control cells. Deletion of the gene Scp1p encoding actin-bundling protein (vertebrate SM22/transgelin) in budding yeast is characterized by reduced production of reactive oxygen species and highly significant increase in longevity (Gourlay et al., 2004). Interestingly, transcriptome analysis following induction of amyloid precursor protein intracellular domain expression in human neuronal cell culture system revealed increased transgelin gene synthesis. Moreover, transgelin was significantly higher expressed in the frontal cortex of Alzheimer disease patients as compared to their agematched controls (Müller et al., 2007). Transgelin can also suppress the expression of the metallo-matrix proteinase MMP-9 (Nair et al., 2006) which is involved in the extracellular matrix remodelling. Perhaps, recently reported $\mathrm{PrP}^{\mathrm{c}}$-dependent down-regulation of MMP-9 transcript in neuronal cells (Pradines et al., 2008) may be additionally linked to an increase in transgelin expression. To our knowledge this is the first time evidence for $\operatorname{PrP}^{\mathrm{C}}$-induced regulation of transgelin.

TCTP which exhibits properties of a tubulin binding protein that associates with microtubules in a cell cycledependent manner (Gachet et al., 1999), showed an upregulation by $\mathrm{PrP}^{\mathrm{c}}$ overexpression. Elevated levels of TCTP lead to microtubule rearrangements (Gachet et al., 1999). Noticeably, recombinant prion protein induces tubulin oligomerization and thereby inhibits microtubule assembly (Nieznanski et al., 2006). Furthermore, TCTP interacts with the third cytoplasmic domain of $\mathrm{Na}^{+} / \mathrm{K}^{+}$ATPase alpha subunit in yeast two-hybrid system and inhibits it in a dose-dependent manner (Jung et al., 2004). An overexpression of TCTP in vivo leads to inhibition of $\mathrm{Na}^{+}$/ $\mathrm{K}^{+}$-ATP-ase activity and intracellular $\mathrm{Ca}^{2+}$ mobilization (Kim et al., 2008). Interestingly, third cytoplasmic domain of $\mathrm{Na}^{+} / \mathrm{K}^{+}$-ATP-ase alpha subunit was identified as a $\mathrm{PrP}^{\mathrm{c}}$ interacting protein (Petrakis and Sklaviadis, 2006).

RHG01 besides its role as a signaling protein (see Proteins involved in cell signaling) is also involved in the regulation and assembly of actin cytoskeleton (Hall, 1998).

UPF0027 protein (CV028), more than a two-fold downregulated by $\mathrm{PrP}^{\mathrm{c}}$ in the present study, has so far unknown function except that it interacts with vinculin (inferred from physical interaction from http://www.expasy.org/uniprot/ Q9Y3I0), an actin filament binding protein that localizes in focal adhesions (Le Clainche and Carlier, 2008).

\section{Proteins involved in protein folding}

Influence of $\mathrm{PrP}^{\mathrm{c}}$ overexpression on proteins involved in protein folding is of special interest due to the fact that prion diseases are triggered by the accumulation of misfolded prion protein. Our study documented a $\operatorname{PrP}^{\mathrm{c}}$-induced up-regulation of protein disulfide isomerase (PDI) precursor (PDIA1), an endoplasmic reticulum (ER)-resident protein that functions as a chaperone catalyzing the isomerization of intra- and intermolecular disulfide bonds. An overexpression of PDIA1 could indicate a response to disrupted ER homeostasis. Importantly, an overexpression of PDI in brains of SCJD patients has also been reported (Yoo et al., 2002).

Conversely, another protein exhibiting chaperone activity, PPID, or cyclophilin 40 showed pronounced downregulation upon $\mathrm{PrP}^{\mathrm{c}}$ overexpression. The results of Cohen and Taraboulos (2003) are indicative of the role of cyclophilins in the normal metabolism of $\mathrm{PrP}^{\mathrm{c}}$. In detail, an addition of the immunosuppressant cyclosporine $A$ inhibited the cyclophylin family of peptidyl-prolyl isomerases (PPlases) in cultured cells which led to the accumulation of proteasome-resistant "prion like" PrP species. The authors also suggested that the possible weakening of PPlase activity during aging may contribute to development of sporadic prion diseases.

In analogy, FK506-binding protein 4 (FKBP4) which exhibited more than a two-fold down-regulation by $\operatorname{PrP}^{\mathrm{c}}$ in this study, belongs to a highly conserved family of chaperone proteins that bind immunosuppressive drugs and have PPlase activity. FKBP4 is a part of the steroid receptor complexes to which it is linked via $90 \mathrm{kDa} H \mathrm{Hp}$ (Sanchez, 1990). Of interest, a microarray study revealed more than a two-fold down-regulation of another member of this family, FK506 binding protein $1 \mathrm{~B}$, in the frontal cortex of sCJD (Xiang et al., 2005).

\section{Proteins involved in other biological processes}

ANXA5 belongs to the annexin family of calcium and phospholipid-binding proteins with poorly understood physiological role. ANXA5 was the only protein that displayed a several fold up-regulation in human neuroblastoma $\mathrm{SH}$ SY5Y cell line stably overexpressing $\mathrm{PrP}^{\mathrm{c}}$, in mouse $\mathrm{N} 2 \mathrm{a}$ and human SK-N-LO neuroblastoma cells, transiently overexpressing $\mathrm{PrP}^{\mathrm{c}}$, and in the previous study where $\mathrm{PrP}^{\mathrm{c}}$ was likewise transiently overexpressed in HEK 293 cells (Ramljak et al., 2008). Hence, PrP $^{\mathrm{c}}$-mediated ANXA5 regulation appears neither cell type specific, vector specific nor dependent on transfection procedure (stable vs. transient). It was reported that ANXA5 knock-out DT-40 cells exhibit defect in cytosolic $\mathrm{Ca}^{2+}$ signaling and are therefore resistant to certain apoptotic agents which induce apoptosis via a $\mathrm{Ca}^{2+}$-dependent pathway, such as staurosporine (Hawkins et al., 2002). Conversely, an overexpression of ANXA5 stimulates apoptotic events (Wang and Kirsch, 2006). Interestingly, it was repeatedly demonstrated that 
$\mathrm{PrP}^{\mathrm{c}}$ overexpression in different cell lines leads to an increased staurosporine-evoked cell death via a p53 pathway (Paitel et al., 2002, 2003, 2004). In the present study we did not observe p53 regulation upon $\mathrm{PrP}^{\mathrm{c}}$ overexpression on 2-DE. Moreover, Western blot analysis confirmed that the level of p53 expression indeed remains unchanged indicating that the sole $\operatorname{PrP}^{\mathrm{c}}$ overproduction in SH-SY5Y cells under basal conditions (no apoptotic agent added) may not be enough to activate p53 pathway. Nevertheless, it is tempting to speculate that there might be a functional link between earlier reported higher responsiveness of $\mathrm{PrP}^{\mathrm{c}}$-overexpressing cells to staurosporine and an up-regulation of ANXA5. Moreover, gene expression profiling in the frontal cortex of SCJD patients detected an up-regulation of ANXA5 (Xiang et al., 2005) suggesting a possible role for this protein in the pathophysiology of CJD.

Expression of PQBP1 was prominently enhanced after $\mathrm{PrP}^{\mathrm{c}}$-overexpression in SH-SY5Y cells as compared to parental cells. PQBP-1 is a nuclear, ubiquitously expressed protein found primarily in neurons of central nervous system with abundant levels registered in cerebellar cortex, hippocampus and olfactory bulb (Waragai et al., 1999). In vitro overexpression of PQBP-1 suppresses cell growth and enhances cell susceptibility to a variety of stress conditions (Waragai et al., 1999). Similarly, PQBP-1 overexpression in vivo results in late-onset neuronal reduction in CNS (Okuda et al., 2003). Induction of neuronal cell death by PQBP-1 seems to occur via mitochondrial stress, a key molecular event shared among distinct neurodegenerative disorders (Marubuchi et al., 2005). An upregulation of $\mathrm{PQBP}-1$ by $\mathrm{PrP}^{\mathrm{c}}$ let us assume that overexpression of $\mathrm{PrP}^{\mathrm{c}}$ in $\mathrm{SH}-\mathrm{SY} 5 \mathrm{Y}$ cells indeed disturbs cellular balance.

GSTO1 is a member of glutathione S-transferase family of enzymes that plays an important role in detoxification processes by conjugating xenobiotic compounds with reduced glutathione. An up-regulation of GSTO1 in $\mathrm{PrP}^{\mathrm{c}}$ overexpressing SH-SY5Y cells indicates an increased oxidative stress. Likewise, we reported an up-regulation of glutathione S-transferase $\mathrm{P}$ by moderate level of $\mathrm{PrP}^{\mathrm{c}}$ overexpression in HEK 293 cells (Ramljak et al., 2008).

SPSY is an enzyme classified to a family of aminopropyltransferases which catalyzes the addition of an aminopropyl group to polyamine spermidine in order to form spermine. The expression of SPSY was down-regulated in $\mathrm{PrP}^{\mathrm{c}}$-overexpressing cells. Natural polyamines including spermine are ubiquitously distributed in mammalian tissues and are essential for cellular growth and differentiation (Pegg and McCann, 1982). Spermine can act directly as a free radical scavenger and can protect DNA from free radical-induced oxidative damage ( $\mathrm{Ha}$ et al., 1998). Further, biological polyamines like spermine not only inhibit nucleic acid-induced polymerization of prion protein (Bera and Nandi, 2007) but their membrane targeting leads to inhibition of $\mathrm{PrP}^{\mathrm{sc}}$ propagation and offers a possibility to degrade pre-existing $\mathrm{PrP}^{\mathrm{sc}}$ aggregates in living cells (Winklhofer and Tatzelt, 2000). Down-regulation of spermine synthase would obviously negatively interfere with the process.
Interestingly, UV excision repair protein RAD23 homolog $B$ (RD23B) exhibited nearly two-fold up-regulation in $\mathrm{SH}-\mathrm{SY} 5 \mathrm{Y}$ cells overexpressing $\mathrm{PrP}^{\mathrm{c}}$. RAD23 proteins have a role in both DNA repair and regulation of protein stability (Glockzin et al., 2003; Brignone et al., 2004). A role for $\mathrm{RD} 23 \mathrm{~B}$ in the nucleotide excision repair, one of the most important DNA repair pathways which eliminates wide variety of base lesions, was suggested (Sugasawa et al., 1996). Therefore, the finding that decrease in SPSY expression by $\mathrm{PrP}^{\mathrm{c}}$ was accompanied by an increase in $\mathrm{RD} 23 \mathrm{~B}$ expression might indicate enhanced susceptibility of $\mathrm{PrP}^{\mathrm{c}}$-overexpressing $\mathrm{SH}-\mathrm{SY} 5 \mathrm{Y}$ cells to DNA damage.

$\mathrm{ADHX}$, two-fold up-regulated in $\mathrm{PrP}^{\mathrm{c}}$-overexpressing cells is the only class of these enzymes that is expressed in adult human brain and whose primary function is not ethanol oxidation. A possible explanation for an up-regulation of this enzyme by $\mathrm{PrP}^{\mathrm{c}}$ is still to be elucidated.

FUMH, an enzyme of tricarboxylic acid cycle which converts fumarate to malate, was up-regulated by $\mathrm{PrP}^{\mathrm{c}}$ overexpression. Another mitochondrial enzyme MTDC with unclear physiological function was down-regulated by $\mathrm{PrP}^{\mathrm{c}}$ overproduction. Nevertheless, MTDC knock-out mice die in utero suggesting its essential role during embryonic development possibly related to mitochondrial folate-metabolism (Di Pietro et al., 2002).

\section{CONCLUSION}

In summary, stable overexpression of $\mathrm{PrP}^{\mathrm{c}}$ in $\mathrm{SH}-\mathrm{SY} 5 \mathrm{Y}$ human neuroblastoma cells regulates expression of proteins involved in different cellular activities. The majority of $\mathrm{PrP}^{\mathrm{c}}$-regulated proteins is associated with cell signaling, cytoskeletal organization and protein folding. Interplay between these protein groups governed by $\operatorname{PrP}^{\mathrm{c}}$ might hold the key to $\operatorname{PrP}^{\mathrm{c}}$ cellular function. An up-regulation of TAGL2, PQBP-1, PDIA1, GSTO1, ANXA5 as well as down-regulation of PPID, FKBP4 and SPSY suggests disturbed cellular homeostasis in $\mathrm{PrP}^{\mathrm{c}}$-overexpressing $\mathrm{SH}$ SY5Y cells, but sole overexpression of $\mathrm{PrP}^{\mathrm{c}}$ is not enough to alter p53 expression and to possibly activate a p53dependent apoptotic pathway in SH-SY5Y cells.

In the future experiments we intend to reveal the effects of staurosporine treatment on protein expression changes and phosphorylation patterns in SH-SY5Y cells overexpressing $\mathrm{PrP}^{\mathrm{c}}$. The reason is repeatedly demonstrated higher susceptibility of $\mathrm{PrP}^{\mathrm{c}}$-overexpressing cells to apoptotic agents such as staurosporine. Although it is known that a pro-apoptotic phenotype of $\mathrm{PrP}^{\mathrm{c}}$-overexpressing cells following the treatment with staurosporine is controlled through a p53 pathway, other proteins involved in the process as well as their phosphorylation patterns are widely unknown.

An important issue of this and similar studies is the comparison of data obtained either by proteomics or transcriptome analysis in different experimental models. This is mandatory in order to filter candidate proteins that might play a decisive role in executing $\mathrm{PrP}^{\mathrm{c}}$ physiological function. In our opinion, ANXA5 could be one of the candidates considering its up-regulation by $\operatorname{PrP}^{\mathrm{c}}$ in this study, using 
three different cell lines, two different vectors and two different transfection procedures, in our previous study (Ramljak et al., 2008) and after gene expression profiling in the frontal cortex of SCJD patients (Xiang et al., 2005).

Acknowledgments-We thank Dr. Andreas W. Stuke for critically reading the manuscript. The excellent technical assistance of Monika Bodemer, Christina Wiese and Christa Scholz is greatly appreciated. We would also like to thank two anonymous reviewers for the comments on an earlier draft which improved the quality of the manuscript. This study was supported by the Association for support of research and teaching at the Neurology Clinic Göttingen (Verein zur Förderung der Forschung und Lehre an der Neurologischen Klinik in Göttingen e.V.).

This study is dedicated to the memory of Prof. Dr. Victor W. Armstrong an outstanding scientist and a dear colleague.

\section{REFERENCES}

Bera A, Nandi PK (2007) Biological polyamines inhibit nucleic-acidinduced polymerisation of prion protein. Arch Virol 152:655-668.

Bounhar Y, Zhang Y, Goodyer CG, LeBlanc A (2001) Prion protein protects human neurons against Bax-mediated apoptosis. J Biol Chem 276:39145-39149.

Brignone C, Bradley KE, Kisselev AF, Grossman SR (2004) A postubiquitination role for MDM2 and hHR23A in the p53 degradation pathway. Oncogene 23:4121-4129.

Brown DR, Besinger A (1998) Prion protein expression and superoxide dismutase activity. Biochem J 334:423-429.

Chen S, Mangé A, Dong L, Lehmann S, Schachner M (2003) Prion protein as trans-interacting partner for neurons is involved in neurite outgrowth and neuronal survival. Mol Cell Neurosci 22:227233.

Chiesa R, Piccardo P, Biasini E, Ghetti B, Harris DA (2008) Aggregated, wild type prion protein causes neurological dysfunction and synaptic abnormalities. J Neurosci 28:13258-13267.

Cohen E, Taraboulos A (2003) Scrapie-like protein accumulates in aggresomes of cyclosporine A-treated cells. EMBO J 22:404-417.

Collinge J, Whittington MA, Sidle KC, Smith CJ, Palmer MS, Clarke AR, Jefferys JG (1994) Prion protein is necessary for normal synaptic function. Nature 370:295-297.

Coso OA, Chiariello M, Yu JC, Teramoto H, Crespo P, Xu N, Miki T, Gutkind JS (1995) The small GTP-binding proteins Rac1 and Cdc42 regulate the activity of the JNK/SAPK signaling pathway. Cell 81:1137-1146.

Di Pietro E, Sirois J, Tremblay ML, MacKenzie RE (2002) Mitochondrial NAD-dependent methylenetetrahydrofolate dehydrogenasemethenyltetrahydrofolate cyclohydrolase is essential for embryonic development. Mol Cell Biol 22:4158-4166.

Domingo MT, Spinnewyn B, Chabrier PE, Braquet P (1988) Presence of specific binding sites for platelet-activating factor (PAF) in brain. Biochem Biophys Res Commun 151:730-736.

Dong CF, Shi S, Wang XF, An R, Li P, Chen JM, Wang X, Wang GR, Shan B, Zhang BY, Han J, Dong XP (2008) The N-terminus of PrP is responsible for interacting with tubulin and fCJD related PrP mutants possess stronger inhibitive effect on microtubule assembly in vitro. Arch Biochem Biophys 470: 83-92.

Dupiereux I, Zorzi W, Rachidi W, Zorzi D, Pierard O, Lhereux B, Heinen E, Elmoualij B (2006) Study on the toxic mechanism of prion protein peptide 106-126 in neuronal and non neuronal cells. J Neurosci Res 84:637-646.

Fu H, Subramanian RR, Masters SC (2000) 14-3-3 proteins: structure, function and regulation. Annu Rev Pharmacol Toxicol 40:617-647.

Gachet Y, Tournier S, Lee M, Lazaris-Karatzas A, Poulton T, Bommer UA (1999) The growth-related, translationally controlled protein P23 has properties of a tubulin finding protein and associates transiently with microtubules during the cell cycle. J Cell Sci 112: 1257-1271.

Glockzin S, Ogi FX, Hengstermann A, Scheffner M, Blattner C (2003) Involvement of the DNA repair protein hHR23 in p53 degradation. Mol Cell Biol 23:8960-8969.

Goodman A, Goode BL, Matsudaira P, Fink GR (2003) The Saccharomyces cerevisiae calponin/transgelin homolog Scp1 functions with fimbrin to regulate stability and organization of the actin cytoskeleton. Mol Biol Cell 14:2617-2629.

Gourlay CW, Carpp LN, Timpson P, Winder SJ, Ayscough KR (2004) A role for the actin cytoskeleton in cell death and aging in yeast. J Cell Biol 164:803-809.

Ha HC, Sirisoma NS, Kuppusamy P, Zweier JL, Woster PM, Casero RA Jr (1998) The natural polyamine spermine functions directly as a free radical scavenger. Proc Natl Acad Sci U S A 95:1114011145.

Hall A (1998) Rho GTPases and the actin cytoskeleton. Science 279:509-514.

Hattori M, Arai H, Inoue K (1993) Purification and characterization of bovine brain platelet-activating factor acetylhydrolase. J Biol Chem 268:18748-18753.

Hawkins TE, Das D, Young B, Moss SE (2002) DT40 cells lacking the $\mathrm{Ca}^{2+}$-binding protein annexin 5 are resistant to $\mathrm{Ca}^{2+}$-dependent apoptosis. Proc Natl Acad Sci U S A 99:8054-8059.

Huang S, Liang J, Zheng M, Li X, Wang M, Wang P, Vanegas D, Wu D, Chakraborty B, Hays AP, Chen K, Chen SG, Booth S, Cohen M, Gambetti P, Kong Q (2007) Inducible overexpression of wild-type prion protein in the muscles leads to a primary myopathy in transgenic mice. Proc Natl Acad Sci U S A 104:6800-6805.

Jung J, Kim M, Kim MJ, Kim J, Moon J, Lim JS, Kim M, Lee K (2004) Translationally controlled tumor protein interacts with the third cytoplasmic domain of Na,K-ATPase alpha subunit and inhibits the pump activity in HeLa cells. J Biol Chem 279:49868-49875.

Kim MJ, Kwon JS, Suh SH, Suh JK, Jung J, Lee SN, Kim YH, Cho MC, Oh GT, Lee K (2008) Transgenic overexpression of translationally controlled tumor protein induces systemic hypertension via repression of $\mathrm{Na}+, \mathrm{K}+-$ ATPase. J Mol Cell Cardiol 44:151-159.

Kramer ML, Kratzin HD, Schmidt B, Römer A, Windl O, Liemann S, Hornemann S, Kretzschmar H (2001) Prion protein binds copper within the physiological concentration range. J Biol Chem 276: 16711-16719.

Krasemann S, Jürgens T, Bodemer W (1999) Generation of monoclonal antibodies against prion proteins with an unconventional nucleic acid-based immunization strategy. J Biotechnol 73:119-129.

Kuwahara C, Takeuchi AM, Nishimura T, Haraguchi K, Kubosaki A, Matsumoto Y, Saeki K, Yokoyama T, Itohara S, Onodera T (1999) Prions prevent neuronal cell-line death. Nature 400:225-226.

Le Clainche C, Carlier MF (2008) Regulation of actin assembly associated with protrusion and adhesion in cell migration. Physiol Rev 88:489-513.

Liang J, Parchaliuk D, Medina S, Sorensen G, Landry L, Huang S, Wang M, Kong Q, Booth SA (2009) Activation of p53-regulated pro-apoptotic pathways in PrP-mediated myopathy. BMC Genomics 10:201.

Málaga-Trillo E, Solis GP, Schrock Y, Geiss C, Luncz L, Thomanetz V, Stuermer CA (2009) Regulation of embryonic cell adhesion by the prion protein. PLoS Biol 7:e55.

Marcheselli VL, Rossowska MJ, Domingo MT, Braquet P, Bazan NG (1990) Distinct platelet-activating factor binding sites in synaptic endings and in intracellular membranes of rat cerebral cortex. J Biol Chem 265:9140-9145.

Martínez T, Pascual A (2007) Identification of genes differentially expressed in SH-SY5Y neuroblastoma cells exposed to the prion peptide 106-126. Eur J Neurosci 26:51-59.

Marubuchi S, Wada Y, Okuda T, Hara Y, Qi ML, Hoshino M, Nakagawa M, Kanazawa I, Okazawa H (2005) Polyglutamine tractbinding protein-1 dysfunction induces cell death of neurons through mitochondrial stress. J Neurochem 95:858-870. 
Minden A, Lin A, Claret FX, Abo A, Karin M (1995) Selective activation of the JNK signalling cascade and c-Jun transcriptional activity by the small GTPases Rac and Cdc42Hs. Cell 81:1147-1157.

Mouillet-Richard S, Ermonval M, Chebassier C, Laplanche JL, Lehmann S, Launay JM, Kellermann O (2000) Signal transduction through prion protein. Science 289:1925-1928.

Müller T, Concannon CG, Ward MW, Walsh CM, Tirniceriu AL, Tribl F, Kögel D, Prehn JH, Egensperger R (2007) Modulation of gene expression and cytoskeletal dynamics by the amyloid precursor protein intracellular domain (AICD). Mol Biol Cell 18:201-210.

Nair RR, Solway J, Boyd DD (2006) Expression cloning identifies transgelin (SM22) as a novel repressor of 92-kDa type IV collagenase (MMP-9) expression. J Biol Chem 281:26424-26436.

Nieznanski K, Podlubnaya ZA, Nieznanska H (2006) Prion protein inhibits microtubule assembly by inducing tubulin oligomerization. Biochem Biophys Res Commun 349:391-399.

Okuda T, Hattori H, Takeuchi S, Shimizu J, Ueda H, Palvimo JJ, Kanazawa I, Kawano H, Nakagawa M, Okazawa H (2003) PQBP-1 transgenic mice show a late-onset motor neuron disease-like phenotype. Hum Mol Genet 12:711-725.

Paitel E, Alves da Costa C, Vilette D, Grassi J, Checler F (2002) Overexpression of $\mathrm{PrP}^{\mathrm{C}}$ triggers caspase 3 activation: potentiation by proteasome inhibitors and blockade by anti-PrP antibodies. J Neurochem 83:1208-1214.

Paitel E, Fahraeus R, Checler F (2003) Cellular prion protein sensitizes neurons to apoptotic stimuli through Mdm2-regulated and p53-dependent caspase 3-like activation. J Biol Chem 278:1006110066.

Paitel E, Sunyach C, Alves da Costa C, Bourdon JC, Vincent B, Checler F (2004) Primary cultured neurons devoid of cellular prion display lower responsiveness to staurosporine through the control of p53 at both transcriptional and post-transcriptional levels. J Biol Chem 279:612-618.

Pauly PC, Harris DA (1998) Copper stimulates endocytosis of the prion protein. J Biol Chem 273:33107-33110.

Pegg AE, McCann PP (1982) Polyamine metabolism and function. Am J Physiol 243:C212-C221.

Petrakis S, Sklaviadis T (2006) Identification of proteins with high affinity for refolded and native $\operatorname{PrP}^{\mathrm{c}}$. Proteomics 6:6476-6484

Pradines E, Loubet D, Schneider B, Launay JM, Kellermann O, Mouillet-Richard S (2008) CREB-dependent gene regulation by prion protein: impact on MMP-9 and beta-dystroglycan. Cell Signal 20:2050-2058.

Prescott SM, Zimmerman GA, Stafforini DM, McIntyre TM (2000) Platelet-activating factor and related lipid mediators. Annu Rev Biochem 69:419-445.

Ramljak S, Asif AR, Armstrong VW, Wrede A, Groschup MH, Buschmann A, Schulz-Schaeffer W, Bodemer W, Zerr I (2008) Physiological role of the cellular prion protein $\left(\mathrm{PrP}^{\mathrm{c}}\right)$ : protein profiling study in two cell culture systems. J Proteome Res 7:2681-2695.

Sanchez ER (1990) Hsp56: a novel heat shock protein associated with untransformed steroid receptor complexes. J Biol Chem 265: 22067-22070.

Satoh J, Obayashi S, Misawa T, Sumiyoshi K, Oosumi K, Tabunoki H (2009) Protein microarray analysis identifies human cellular prion protein interactors. Neuropathol Appl Neurobiol 35:16-35.

Shevchenko A, Wilm M, Vorm O, Mann M (1996) Mass spectrometric sequencing of proteins silver-stained polyacrylamide gels. Anal Chem 68:850-858.
Spielhaupter C, Schätzl HM (2001) $\operatorname{PrP}^{c}$ directly interacts with proteins involved in signaling pathways. J Biol Chem 276:44604-44612.

Steinacker $\mathrm{P}$, Schwarz $\mathrm{P}$, Reim K, Brechlin $\mathrm{P}$, Jahn O, Kratzin $\mathrm{H}$, Aitken A, Wiltfang J, Aguzzi A, Bahn E, Baxter HC, Brose N, Otto M (2005) Unchanged survival rates of 14-3-3gamma knockout mice after inoculation with pathological prion protein. Mol Cell Biol 25:1339-1346.

Sugasawa K, Masutani C, Uchida A, Maekawa T, van der Spek PJ, Bootsma D, Hoeijmakers JH, Hanaoka F (1996) HHR23B, a human Rad23 homolog, stimulates XPC protein in nucleotide excision repair in vitro. Mol Cell Biol 16:4852-4861.

Sunyach C, Cisse MA, da Costa CA, Vincent B, Checler F (2007) The $\mathrm{C}$-terminal products of cellular prion protein processing, $\mathrm{C} 1$ and C2, exert distinct influence on p53-dependent staurosporine-induced caspase-3 activation. J Biol Chem 282:1956-1963.

Van Everbroeck BR, Boons J, Cras P (2005) 14-3-3 \{gamma\}-isoform detection distinguishes sporadic Creutzfeldt-Jakob disease from other dementias. J Neurol Neurosurg Psychiatry 76:100-102.

Vassallo N, Herms J, Behrens C, Krebs B, Saeki K, Onodera T, Windl O, Kretzschmar HA (2005) Activation of phosphatidylinositol 3-kinase by cellular prion protein and its role in cell survival. Biochem Biophys Res Commun 332:75-82.

Walz R, Amaral OB, Rockenbach IC, Roesler R, Izquierdo I, Cavalheiro EA, Martins VR, Brentani RR (1999) Increased sensitivity to seizures in mice lacking cellular prion protein. Epilepsia 40:1679_ 1682.

Wang W, Kirsch T (2006) Annexin V/beta 5 integrin interactions regulate apoptosis of growth plate chondrocytes. J Biol Chem 281 30848-30856.

Waragai M, Lammers $\mathrm{CH}$, Takeuchi S, Imafuku I, Udagawa Y, Kanazawa I, Kawabata M, Mouradian MM, Okazawa H (1999) PQBP-1, a novel polyglutamine tract-binding protein, inhibits transcription activation by Brn-2 and affects cell survival. Hum Mol Genet 8:977-987.

Watt NT, Routledge MN, Wild CP, Hooper NM (2007) Cellular prion protein protects against reactive-oxygen-species-induced DNA damage. Free Radic Biol Med 43:959-967.

Weise J, Crome O, Sandau R, Schulz-Schaeffer W, Bähr M, Zerr I (2004) Upregulation of cellular prion protein $\left(\mathrm{PrP}^{\mathrm{c}}\right)$ after focal cerebral ischemia and influence of lesion severity. Neurosci Lett 372:146-150.

Westaway D, DeArmond SJ, Cayetano-Canlas J, Groth D, Foster D, Yang SL, Torchia M, Carlson GA, Prusiner SB (1994) Degeneration of skeletal muscle, peripheral nerves, and the central nervous system in transgenic mice overexpressing wild-type prion proteins. Cell 76:117-129.

Winklhofer KF, Tatzelt J (2000) Cationic lipopolyamines induce degradation of $\mathrm{PrP}^{\mathrm{sc}}$ in scrapie-infected mouse neuroblastoma cells. Biol Chem 381:463-469.

Wong BS, Liu T, Li R, Pan T, Petersen RB, Smith MA, Gambetti P, Perry G, Manson JC, Brown DR, Sy MS (2001) Increased levels of oxidative stress markers detected in the brains of mice devoid of prion protein. J Neurochem 76:565-572.

Xiang W, Windl O, Westner IM, Neumann M, Zerr I, Lederer RM, Kretzschmar HA (2005) Cerebral gene expression profiles in sporadic Creutzfeldt-Jakob disease. Ann Neurol 58:242-257.

Yoo BC, Krapfenbauer K, Cairns N, Belay G, Bajo M, Lubec G (2002) Overexpressed protein disulfide isomerase in brains of patients with sporadic Creutzfeldt-Jakob disease. Neurosci Lett 334:196 200. 


\section{DISCUSSION}

\subsection{Codon 129 polymorphism specific CSF proteome pattern in SCJD}

Disease phenotype of SCJD is mainly influenced by the methionine/valine (M/V) polymorphism at codon 129 in the human prion protein gene (PRNP gene) and by the presence of two major types of pathological, protease-resistant forms of the prion protein $\left(\mathrm{PrP}^{\mathrm{Sc}}\right.$ ) leading to 2 different profiles in Western blot (type 1 and type 2 ). The clinical and pathological characteristics of these molecular subtypes markedly differ with respect to symptoms at onset, localisation and type of the pathological changes as well as $\mathrm{PrP}^{\mathrm{Sc}}$ deposition pattern (Parchi et al., 1999; Gambetti et al., 2003). This might suggest the involvement of different molecular pathways in SCJD pathogenesis.

At the molecular level, TSEs are caused by the conversion of a host cellular glycoprotein, the prion protein $\left(\operatorname{PrP}^{\mathrm{C}}\right)$ into a pathological conformer called scrapie prion protein $\left(\mathrm{PrP}^{\mathrm{Sc}}\right)$, which tends to aggregate and accumulate in the brain tissue. The presence of the pathological form of PrP may induce brain proteome changes. In turn, these alterations may also be reflected in CSF.

However, due to a high dynamic range of protein abundance in CSF spanning twelve orders of magnitude (Anderson et al., 1998) and the fact that around 10 very well known proteins (e.g. albumin, immunoglobulins, transferrin and haptoglobin) comprise up to $90-95 \%$ of the total protein contents, depletion of the high abundant proteins is indispensible for in-depth exploration of SCJD-associated alterations in CSF proteome.

The densitometric and statistical analysis of CSF 2D maps showed up-regulation of 27 and down-regulation of 3 proteins in MM-sCJD as well as up-regulation of 24 proteins in VVsCJD in comparison to non-demented neurological controls. Twenty one proteins showed common up-regulation for both codon 129 polymorphism in SCJD. For instance, the leucinerich alpha-2-glycoprotein (LRG), complement $\mathrm{C} 4$ and superoxide dismutase [Cu-Zn] (SOD1), which belong to the group of MM-sCJD dysregulated proteins, were already shown to be implicated in the pathobiology of PrP (Milhavet et al., 2002; Milhavet et al., 2000; Mabbott et al., 2004; Xiang et al., 2004). The group of VV-sCJD specifically regulated proteins includes DJ-1 protein, fibrinogen alpha chain (FGA) and angiotensinogen (ANGT). The detection of regulated proteins specific for codon 129 genotype may confirm the hypothesis which assumes the involvement of different molecular pathways in SCJD pathogenesis depending on $\mathrm{PrP}^{\mathrm{Sc}}$ strain. Moreover, the dominant up-regulation of proteins in CSF from sCJD-affected 
patients may occur due to release or secretion mechanisms of the protein content from impaired neural cells into the extracellular space and then eventually into CSF. However, this far-reaching hypothesis has to be proved by further investigations.

\subsection{Implication of glycolytic enzymes in SCJD pathology}

Almost $40 \%$ of sCJD specific regulated proteins in CSF are involved in glucose metabolism, thus in energy metabolism. All these enzymes displayed up-regulation in sCJD regardless of codon 129 polymorphism. The increase in CSF level of glucose-6-phosphate isomerase (G6PI), lactate dehydrogenase (LDH) and fructose-bisphosphate aldolase A (ALDOA) was confirmed on a larger group of SCJD patients including three possible codon 129 polymorphisms as well as on three different types of controls consisting of non-demented neurological controls (NDC), patients with vascular dementia (VD) and Alzheimer's disease (AD). Subsequently, abundance of glycolytic enzymes in the brain as well as their cellular localization was determined.

Additionally to the increased level of G6PI in CSF, its decreased level was found in the brain of MM1-sCJD subtype. Moreover, in NDC and AD control groups, G6PI is predominantly localized in neurons, while in SCJD a shift in cellular distribution is occurring and G6PI is mostly present in reactive astrocytes. With these data we demonstrate for the first time the involvement of G6PI in prion-induced pathological process. Furthermore, different regulation of G6PI in the brain could suggest that its expression and/or secretion may be modulated in a $\operatorname{PrP}^{\mathrm{Sc}}$ strain-dependent manner.

For ALDOA and LDH increase in CSF level did not correlate with unchanged level in the brain when compared to age-matched control group. Moreover, partial shift in ALDOA cellular distribution was observed in the sCJD. Diffuse ALDOA immunostaining was predominantly found in neurons in the grey matter and in astrocytes in the white matter of NDC and AD, whereas, the ALDOA immunoreactivity in the SCJD was mostly detected in neuronal cell bodies.

Beside their glycolytic function, all three investigated enzymes play other role in cellular physiology. For instance, G6PI possesses an activity of extracellular cytokine and acts as a growth factor promoting the survival and neurite outgrowth of motor and sensory neurons, as well as an autocrine motility factor inducing cell motility (Gurney et al., 1986; Niinaka et al., 1998; Watanabe et al., 1996). Furthermore, it has been shown that the inhibition of G6PI expression caused an increased susceptibility to caspase-dependent apoptosis in PC12 neuronal cells as well as its overexpression and subsequent secretion of G6PI protected NIH- 
3 T3 fibroblasts against PI3K/Akt mediated apoptosis (Romagnoli et al., 2003; Tsutsumi et al., 2003). This finding indicates anti-apoptotic properties of G6PI. Moreover, the positive G6PI immunostaining in astrocytes occurred two weeks after mechanical injury of murine cerebral cortex and its expression was shown to be elevated in the later stage of the brain infection with rabies virus in $\mathrm{C} 3 \mathrm{H}$ mice model (Decourt et al., 2005; Prosniak et al., 2003). This may suggest that expression of G6PI in astrocytes can be a response to signals coming from impaired neurons to increase their metabolism and prolong survival. Taken together, the same motion of G6PI action might occur in sCJD-affected brain, but might be differentially modulated by different $\mathrm{PrP}^{\mathrm{Sc}}$ strains.

$\mathrm{LDH}$ is an interaction partner of $\operatorname{PrP}^{\mathrm{C}}$ and its expression was found to be up-regulated when $\mathrm{PrP}^{\mathrm{C}}$ was introduced into Prnp ${ }^{0 / 0}$ cells (Ramljak et al., 2008; Rutishauser et al., 2009; Watts et al., 2009). Moreover, $\operatorname{PrP}^{\mathrm{C}}$ deficiency in astrocytes leads to glutamate-independent elevation of lactate transport (Kleene et al., 2007). Therefore, it should be considered that LDH is possibly not only a marker of cellular damage, but could play a more specific role in prioninduced pathological processes. We hypothesize that a loss or gain of PrP function in astrocytes of CJD-affected brain may result in elevated level of extracellular lactate leading to acidosis-induced damage in neurons.

It has been shown, that glyceraldehyde-3-phosphate, an enzymatic product of ALDOA, is implied in the protection of cells against apoptosis via the inhibition of caspase-3 activity (Jang et al., 2009). Moreover, neurotoxicity of doppel (Dpl), $\operatorname{PrP}^{\mathrm{C}}$ homolog, in Purkinje cells of the Ngsk Prnp ${ }^{0 / 0}$ mouse model varies according to aldolase $\mathrm{C}$ expression. The higher sensitivity to Dpl-induced neurotoxicity and subsequent increased cell loss, is characteristic for Purkinje cells from aldolase C-negative compartments of the cerebellum (Heitz et al., 2008). Therefore, the presence of ALDOA in impaired neurons and its secretion might play an anti-apoptotic role in SCJD.

Both, glycolysis and apoptosis are highly conserved and finely regulated multi-step processes maintaining cellular homeostasis. The activation of apoptotic pathway is dependent on energy status and, hence, apoptosis might be dependent on glucose metabolism. Based on numerous studies demonstrating that glucose metabolism is involved in cell death and survival, it is reasonable to speculate that these two crucial processes are linked. However, precise mechanisms underlying the regulation of glucose metabolism and the implication of glycolytic enzymes in apoptosis remain to be elucidated. 


\subsection{Disturbances in cellular homeostasis upon stably $\operatorname{PrP}^{\mathrm{C}}$-overexpression in human neuroblastoma SH-SY5Y cells}

Differential proteome analysis of human neuroblastoma SH-SY5Y cells stably overexpressing human $\operatorname{PrP}^{\mathrm{C}}$ was performed to study protein expression changes upon permanent overproduction of $\operatorname{PrP}^{\mathrm{C}}$.

Densitometric analysis of silver stained 2D gels showed 18 differentially regulated proteins in SH-SY5Y cells overexpressing human $\mathrm{PrP}^{\mathrm{C}}$. Between them, 13 proteins were up- and 5 down-regulated. Few biological processes, especially, signal transduction, cytoskeleton organization and protein folding are influenced by overproduction of $\mathrm{PrP}^{\mathrm{C}}$ in SH-SY5Y cells. To reinforce obtained results, the changes in expression were confirmed by Western blot for three selected proteins: annexin A5 (ANXA5), transgelin-2 (TAGL2) and 14-3-3 protein gamma (1433G). Additionally, in order to further verify our data, densitometric analysis of Western blots following transient overexpression of $\operatorname{PrP}^{\mathrm{C}}$ in mouse neuroblastoma $\mathrm{N} 2 \mathrm{a}$ and alternative human neuroblastoma SK-N-LO cells was performed. In both cell lines upregulation of ANXA5 was found as compared to cells transfected with control vector. For two remaining proteins, TAGL2 and 1433G, changes of their expression were reproduced neither in N2a nor in SK-N-LO cells.

In different cell lines, $\operatorname{PrP}^{\mathrm{C}}$-overproduction was shown to increase expression of the tumor suppressor oncogene p53 (Paitel et al., 2002; Paitel et al., 2003). Therefore, supplemental Western blot analysis was performed in order to verify p53 expression in stably $\operatorname{PrP}^{\mathrm{C}}$ overexpressing SH-SY5Y cells. However, no enhancement in p53 production following stable $\operatorname{PrP}^{\mathrm{C}}$ overexpression was detected.

To the proteins involved in signal transduction which expression was modulated by stable $\operatorname{PrP}^{\mathrm{C}}$ overexpression in SH-SY5Y cells belong: 14-3-3 protein gamma (1433G), growth factor receptor bound protein 2 (GRB2), Rho GTP-ase activating protein 1 (RHG01), and plateletactivating factor acetylhydrolase IB subunit gamma (PA1B3).

Proteins belonging to the 14-3-3 family modulate diverse signal transduction pathways regulating cell cycle progression and apoptosis (Fu et al., 2000). The 14-3-3 protein gamma is a well known as CSF diagnostic marker for differential diagnosis of CJD (Van Everbroeck et al., 2005; Zerr et al., 1996) and expression of other 14-3-3 proteins (beta, eta and zeta isoform) was found to be decreased in SCJD-affected brain (Xiang et al., 2005). Moreover, 14-3-3 proteins are interaction partners forming molecular complexes with $\operatorname{PrP}^{\mathrm{C}}$ (Satoh et al., 2006; Watts et al., 2009). Therefore, 14-3-3 proteins may have an impact on the physiological function of $\operatorname{PrP}^{\mathrm{C}}$. 
Growth factor receptor-bound protein 2 (GRB2) is another signaling protein which was found to be up-regulated in stable $\operatorname{PrP}^{\mathrm{C}}$ overexpressing SH-SY5Y cells. This protein connects signals from extracellular/transmembrane receptors with intracellular signaling molecules and is crucial for the formation of signaling complexes. Furthermore, yeast two hybrid system and co-precipitation in neuronal microsomal vesicles showed that GRB2 directly interact with $\operatorname{PrP}^{\mathrm{C}}$ (Spielhaupter and Schatzl, 2001).

To the proteins involved in cytoskeleton organization and dysregulated through $\operatorname{Pr} \mathrm{P}^{\mathrm{C}}$ overexpression, belong: transgelin 2 (TAGL2), translationally-controlled tumor protein (TCTP) and Rho GTP-ase activating protein 1 (RHG01).

The involvement of $\mathrm{PrP}^{\mathrm{C}}$ in the regulation of microtubule dynamics and reorganization of actin cytoskeleton has been already reported (Dong et al., 2008; Málaga-Trillo et al., 2009). TAGL2, which displayed enormous up-regulation in Western blot analysis, is involved in the organization and stability of the actin cytoskeleton (Goodman et al., 2003). Interestingly, transcriptome studies following induction of amyloid precursor protein intracellular domain expression in human neuronal cells revealed increased expression of the gene encoding TAGL. Moreover, TAGL was significantly higher expressed in AD brain as compared to agematched controls (Müller et al., 2007). These findings suggest that TAGL2 might play some role in PrP pathophysiology.

TCTP, which exhibits properties of tubulin-binding protein and is associated with microtubules in cell cycle-dependent manner, showed up-regulation induced by $\operatorname{PrP}^{\mathrm{C}}$ overexpression in SH-SY5Y cells. Its elevated level leads to microtubule rearrangements (Gachet et al., 1999). In contrast, recombinant PrP stimulates tubulin oligomerization and thereby inhibits microtubule assembly (Nieznanski et al., 2006). Moreover, TCTP was found to interact with the third cytoplasmic domain of $\mathrm{Na}^{+} / \mathrm{K}^{+}$-ATP-ase alpha subunit in yeast twohybrid system and inhibits it in dose-dependent manner (Jung et al., 2004). Interestingly, the third cytoplasmic domain of $\mathrm{Na}^{+} / \mathrm{K}^{+}$-ATP-ase alpha subunit is also an interaction partner of $\operatorname{PrP}^{\mathrm{C}}$ (Petrakis and Sklaviadis, 2006).

To the proteins involved in the signal transduction which expression was modulated by stable $\mathrm{PrP}^{\mathrm{C}}$ overexpression in SH-SY5Y cells belong: $40 \mathrm{kDa}$ peptidyl-prolyl cis-trans isomerase (PPID), FK506-binding protein 4 (FKBP4), and disulfide isomerase precursor (PDIA1).

Due to the fact that prion diseases are triggered by accumulation of misfolded PrP, the influence of $\mathrm{PrP}^{\mathrm{C}}$ overexpression on proteins involved in protein folding is of special interest. The expression of PDIA1, a chaperone catalyzing the isomerisation of intra- and 
intermolecular disulfide bonds, was up-regulated in the analyzed cell model. Interestingly, an overexpression of PDIA1 was also found in sCJD-affected brain (Yoo et al., 2002).

PPID, also known as cyclophilin 40, showed up-regulation upon $\operatorname{PrP}^{\mathrm{C}}$-overexpression. It has been already shown that cyclophilins play a role in $\operatorname{PrP}^{\mathrm{C}}$ metabolism. The inhibition of the cyclophilin family of peptidyl-propyl isomerases in cultured cells leads to the accumulation of proteasome-resistant scrapie-like PrP aggregates (Sunderland et al., 2003).

\subsection{Annexin A5 as molecular partner for PrP pathobiology}

The ANXA5 is the only protein which was up-regulated upon $\operatorname{PrP}^{\mathrm{C}}$-overexpression in all three different neuroblastoma cells used in our study as well as in a previous work where $\operatorname{PrP}^{\mathrm{C}}$ was transiently overexpressed in HEK 293 cells (Ramljak et al., 2008). Therefore, $\operatorname{PrP}^{\mathrm{C}}$-mediated ANXA5 regulation appears neither cell type specific, vector specific nor dependent on transfection mode. Moreover, up-regulation of ANXA production was found in global gene expression profiling of sCJD-affected brain (Xiang et al., 2005). ANXA5 belongs to the family of calcium-dependent phospholipid-binding proteins, but its physiological role is still poorly understood. In vitro experiments showed that ANXA5 could be involved in apoptosis, blood coagulation as well as calcium singaling and transport (Yoshizaki et al., 1992; Gerke and Moss, 1997; Reutelingsperger et al., 1997). ANXA5 is also vulnerable to form voltagedependent calcium channels in phospholipid bilayer (Huber et al., 1992; Liemann et al., 1996). Additionally to its cytoplasmic localization, ANXA5 can be secreted or can bind to phosphaditylserine on the outer cell surface. The presentation of phosphaditylserines on the cell surface occurs during apoptosis and it is a recognition signal for phagocytes. This process can provoke unnecessary coagulation and inflammatory response. ANXA5 can shield surfaceexposed phosphaditylserines, thus it can inhibit their pro-coagulant and pro-inflammation activity. However, it does not block completely phagocytosis of apoptotic bodies which can still be efficiently utilized (van Engeland et al., 1996; Reutelingsperger et al., 1997). Taken all together, ANXA might play a role in the pathophysiology of PrP.

In conclusion, stable $\mathrm{PrP}^{\mathrm{C}}$ overexpression in $\mathrm{SH}-\mathrm{SY} 5 \mathrm{Y}$ neuroblastoma cells disturbs cellular homeostasis, especially processes associated with cell signaling, cytoskeletal organization and protein folding. However, sole $\mathrm{PrP}^{\mathrm{C}}$-overexpression is not enough to alter p53 expression and possibly activates p53-dependent apoptotic pathway. 
The comparison between data obtained from different proteomic and transcriptomic experimental models allows filtering candidate proteins that might play a decisive role in the physiology and the pathology of $\operatorname{PrP}^{\mathrm{C}}$. In our opinion, ANXA5 could be one of these candidates. 


\section{SUMMARY}

This thesis includes 2 original publications that investigate the physiology and the pathology of the human prion protein.

In our first study, we analyzed CSF proteome alterations in living, symptomatic sCJD patients with two different codon 129 genotypes (MM and VV) using a proteomic approach consisted of 2D Fluorescence Difference Gel Electrophoresis (2D-DIGE) and mass spectrometry analysis.

Densitometric analysis of 2D gels showed the up-regulation of 27 and down-regulation of 3 proteins in the MM-sCJD as well as the up-regulation of 24 proteins in the VV-sCJD when compared to control. Beside proteins showing common regulation for both codon 129 genotypes in SCJD, some proteins seem to be specifically regulated in certain genotype. The detection of these proteins may confirm the hypothesis which assumes the involvement of different molecular pathways in SCJD pathogenesis depending on $\mathrm{PrP}^{\mathrm{Sc}}$ strain.

Almost $40 \%$ of sCJD specifically regulated proteins in CSF are involved in glucose metabolism, regardless of codon 129 polymorphism. The validation phase of selected glycolytic enzymes using Western blot technique confirmed up-regulation of ALDOA, LDH and G6PI when compared to three different control groups (NDC, AD and VD).

Furthermore, the immunolabeling showed that G6PI is present in reactive astrocytes in sCJD affected brain while it is predominantly localized in neurons in age-matched control brain. Additionally, decreased level of G6PI was found in the brain of MM1-sCJD subtype. With these data, we have demonstrated for the first time the implication of G6PI in prion-induced pathology.

The identification of SCJD-regulated proteins in CSF proteome alterations in living, symptomatic sCJD- patients will broaden our knowledge about pathological processes occurring in SCJD, as they are still not fully understood. Moreover, they could serve as protein source to identify novel biomarkers for differential sCJD diagnosis.

In our second study, we also applied a proteomic approach in order to reveal proteins, and thereby biological processes, affected by stable overexpression of human $\operatorname{PrP}^{\mathrm{C}}$ in human neuroblastoma SH-SY5Y cell line.

Densitometric analysis of silver stained 2D gels showed 18 differentially regulated proteins in SH-SY5Y cells overexpressing human $\operatorname{PrP}^{\mathrm{C}}$. Between them, 13 proteins were up- and 5 
down-regulated. The $\mathrm{PrP}^{\mathrm{C}}$ overexpression in SH-SY5Y cells affected mostly few biological processes such as signal transduction, cytoskeleton organization and protein folding.

An increased expression of tumor suppressor oncogene p53 caused by $\operatorname{PrP}^{\mathrm{C}}$ overproduction was already demonstrated in different cell lines (Paitel et al., 2002; Paitel et al., 2003). Therefore, supplemental Western blot analysis was performed to verify p53 expression in SHSY5Y cells. However, no enhancement in its production following stable $\operatorname{PrP}^{\mathrm{C}}$ overexpression was detected.

The ANXA5 is the only one protein which was up-regulated upon $\operatorname{PrP}^{\mathrm{C}}$ overexpression in three different neuroblastoma cells, and in a previous study where $\operatorname{PrP}^{\mathrm{C}}$ was transiently overexpressed in HEK293 cells (Ramljak et al., 2008). Therefore, $\operatorname{PrP}^{\mathrm{C}}$-mediated ANXA5 regulation appears neither cell type specific, vector specific nor dependent on transfection mode. ANXA5 belongs to the family of calcium and phospholipid-binding proteins with poorly understood physiological role. However, ANXA5 up-regulation was found in gene expression profiling of sCJD-affected brain (Xiang et al., 2005) suggesting its possible role in the pathophysiology of sCJD.

In conclusion, stable $\mathrm{PrP}^{\mathrm{C}}$ overexpression in $\mathrm{SH}-\mathrm{SY} 5 \mathrm{Y}$ neuroblastoma cells is disturbing cellular homeostasis, especially processes associated with cell signaling, cytoskeletal organization and protein folding. However, sole $\operatorname{PrP}^{\mathrm{C}}$ overexpression is not enough to alter p53 expression and possibly activate p53-dependent apoptotic pathway.

The comparison between data obtained from different proteomic and transcriptomic experimental models allows filtering candidate proteins that might play a decisive role in the physiology and the pathology of $\operatorname{PrP}^{\mathrm{C}}$. In our opinion, ANXA5 could be one of these candidates.

Proteomics gives a unique opportunity to analyze both physiological and pathological processes at the protein level on a global scale. Proteome analysis of SH-SY5Y human neuroblastoma cells stably overexpressing $\mathrm{PrP}^{\mathrm{C}}$ revealed proteins whose expression is directly modulated through $\operatorname{PrP}^{\mathrm{C}}$ and consequently physiological processes which are influenced by $\mathrm{PrP}^{\mathrm{C}}$ level in cells. On the other hand side, identification of CSF proteome alterations in sCJD provides more information about pathological processes occurring in the brain and caused by presence of $\operatorname{PrP}^{\mathrm{Sc}}$. Both these studies broaden our knowledge about still not fully understood pathobiology of PrP. 


\section{LITERATURE}

Anderson NL, Anderon NG, (1998). Proteome and proteomics: new technologies, new concepts, and new words. Electrophoresis 19, 1853-1861

Anderson RM, Donnelly CA, Ferguson NM, Woolhouse ME, Watt CJ, Udy HJ, MaWhinney S, Dunstan SP, Southwood TR, Wilesmith JW, et al., (1996). Transmission dynamics and epidemiology of BSE in British cattle [published erratum appears in Nature 1997 Mar 20;386(6622):302]. Nature 382, 779-788

Behrens A, Aguzzi A, (2002). Small is not beautiful: antagonizing functions for the prion protein $\operatorname{PrP}(\mathrm{C})$ and its homologue Dpl. Trends Neurosci 25, 150-154

Belay ED, Madox RA, Williams ES, Miller MW, Gambetti P, Schonberger LB, (2004). Chronic wasting disease and potential transmission to humans. Emerg Infect Dis 10, 977-984 Bendheim PE, Brown, HR, Rudelli RD, Scala LJ, Goller NL, Wen GY, Kascsak RJ, Cashman NR, Bolton DC, (1992). Nearly ubiquitous tissue distribution of the scrapie agent precursor protein. Neurology 42, 149-156

Bounhar Y, Zhang Y, Goodyer CG, LeBlanc AC, (2001). Prion protein protects human neurons against Bax-mediated apoptosis. J Biol Chem 276, 39145-39149

Brechlin P, Jahn O, Steinacker P, Cepek L, Kratzin H, Lehnert S, Jesse S, Mollenhauer B, Kretzschmar HA, Wiltfang J, Otto M, (2008). Cerebrospinal fluid-optimized two-dimensional difference gel electrophoresis (2-D DIGE) facilitates the differential diagnosis of CreutzfeldtJakob disease. Proteomics 8, 4357-4366

Brown DR, Nicholas RS, Canevari L, (2002). Lack of prion protein expression results in a neuronal phenotype sensitive to stress. J Neuro Res 67, 211-224

Brown DR, Qin K, Herms JW, Madlung A, Manson J, Strome R, Fraser PE, Kruck T, von Bohlen A, Schulz-Schaeffer WJ, et al., (1997a). The cellular prion protein binds copper in vivo. Nature 390, 684-687

Brown DR, Schuzl-Schaeffer WJ, Schmidt B, Kretzschmar H, (1997b). Prion proteindeficient cells show altered response to oxidative stress due to decreased SOD-1 activity. Exp Neurol 146, 104-112 
Brown P, Preece M, Brandel J-P, Sato T, McShane L, Zerr I, Fletcher A, Will, RG, Pocchiari M, Cashmann NR, et al., (2000). Iatrogenic Creutzfeldt-Jakob disease at the millennium. Neurology 55, 1075-1081

Budka H, Aguzzi A, Brown P, Bruche JM, Bugiani O, Gullotta F, Haltia M, Hauw JJ, Ironside JW, Jellinger K, et al., (1995). Neuropathological diagnostic criteria for CreutzfeltdJakob disease (CJD) and other human spongiform encephalopathies (prion diseases). Brain Pathol 5, 459-466

Büeler H, Aguzzi A, Sailer A, Greiner RA, Autenried P, Aguet M, Weissmann C, (1993). Mice devoid of PrP are resistent to scrapie. Cell 73, 1339-1347

Büeler H, Fischer M, Lang Y, Bluethmann H, Lipp HP, DeArmond SJ, Prusiner SB, Aguet M, Weissmann C, (1992). Normal development and behaviour of mice lacking the neuronal cell-surface PrP protein. Nature 356, 577-582

Bugiani O, Giaccone G, Piccardo P, Morbin M, Tagliavini F, Ghetti B, (2000). Neuropathology of Gerstmann-Sträussler-Scheinker disease. Microsc Res Tech 50, 10-5

Castellani RJ, Colucci M, Xie Z, Zou W, Li C, Parchi P, Capellari S, Pastore M, Rahbar MH, Chen SG, et al., (2004). Sensitivity of 14-3-3 protein test varies in subtypes of sporadic Creutzfeldt-Jakob disease. Neurology 63, 436-442

Chesebro B, Race B, Meade-White K, Lacasse R, Race R, Klingeborn M, Striebel J, Dorward D, McGovern G, Jeffrey M, (2010). Fatal transmissible amyloid encephalopathy: a new type of prion disease associated with lack of prion protein membrane anchoring. PLoS Pathog 6, e1000800

Chesebro B, Trifilo M, Race R, Meade-White K, Teng C, LaCasse R, Raymond L, Favara C, Baron G, Priola S, Caughey B, Masliah E, Oldstone M, (2005). Anchorless prion protein results in infectious amyloid disease without clinical scrapie. Science 308, 1435-1439

Chiarini LB, Freitas AR, Zanata SM, Berntani RR, Martins VR, Linden R, (2002). Cellular prion protein transduces neuroprotective signals. Embo J 13, 3317-3326

Chiesa R, Piccardo P, Quaglio E, Drisaldi B, Si-Hoe SL, Takao M, Ghetti B, Harris DA, (2003). Molecular distinction between pathogenic and infectious properties of the prion protein. J Virol 77, 7611-7612

Choe LH, Green A, Knight RS, Thompson EJ, Lee KH, (2002). Apolipoprotein E and other cerebrospinal fluid proteins differentiate ante mortem variant Creutzfeldt-Jakob disease from ante mortem sporadic Creutzfeldt-Jakob disease. Electrophoresis 23, 2242-2246 
Collinge J, Palmer MS, Sidle KC, Hill AF, Gowland I, Meads, J, Asante E, Bradley R, Doey LJ, Lantos PL, (1995). Unaltered susceptibility to BSE in transgenic mice expressing human prion protein. Nature $378,779-783$

Collinge J, Sidle KC, Meads J, Ironside J, Hill AF, (1996). Molecular analysis of prion strain variation and the aetiology of 'new variant' CJD. Nature 383, 685-690

Collinge J, (1997). Human prion diseases and bovine spongiform encephalopathy (BSE). Hum Mol Genet 6, 1699-1670

Collinge J, (2001). Prion diseases of humans and animals: their causes and molecular basis. Annu Rev Neurosci 24, 519-550

Decourt B, Bouleau Y, Dulon D, Hafidi A, (2005). Expression analysis of neuroleukin, calmodulin, cortactin, and Rho7/Rnd2 in the intact and injured mouse brain. Brain Res Dev Brain Res 159, 36-54

DeKosky ST, Ikonomovic M, Wang X, Farlow M, Wisniewski S, Lopez OL, Becker JT, Saxton J, Klunk WE, Sweet R, Kaufer DI, Kamboh MI, (2003). Plasma and cerebrospinal fluid alpha1-antichymotrypsin levels in Alzheimer's disease: correlation with cognitive impairment. Ann Neurol 53, 81-89

Demeester N, Castro G, Desrumaux C, De Geitere C, Fruchart JC, Santens P, Mulleners E, Engelborghs S, De Deyn PP, Vandekerckhove J, Rosseneu M, Labeur C, (2000). Characterization and functional studies of lipoproteins, lipid transfer proteins, and lecithin:cholesterol acyltransferase in CSF of normal individuals and patients with Alzheimer's disease. J Lipid Res 41, 963-974

Dong CF, Shi S, Wang XF, An R, Li P, Chen JM, Wang X, Wang GR, Shan B, Zhang BY, Han J, Dong XP, (2008). The N-terminus of PrP is responsible for interacting with tubulin and fCJD related PrP mutants possess stronger inhibitive effect on microtubule assembly in vitro. Arch Biochem Biophys 470, 83-89

Ford MJ, Burton LJ, Morris RJ, Hall SM, (2002). Selective expression of prion protein in peripheral tissues of the adult mouse. Neuroscience 113, 177-192

Fu H, Subramanian RR, Masters SC, (2000). 14-3-3 proteins: structure, function, and regulation. Annu Rev Pharmacol Toxicol 40 
Gachet Y, Tournier S, Lee M, Lazaris-Karatzas A, Poulton T, Bommer UA, (1999). The growth-related, translationally controlled protein P23 has properties of a tubulin binding protein and associates transiently with microtubules during the cell cycle. J Cell Sci 112, $1257-1271$

Gambetti P, Kong Q, Zou W, Parchi P, Chen SG, (2003). Sporadic and familial CJD: classification and characterisation. Br Med Bull 66, 213-239

Gerke V, Moss SE, (1997). Annexins and membrane dynamics. Biochim Biophys Acta 1357, $129-154$

Gibbs Jr. C, Asher DM, Kobrine A, Amyx HL, Sulima MP, Gajdusek DC, (1994). Transmission of Creutzfeldt-Jakob disease to a chimpanzee by electrodes contaminated during neurosurgery. J Neurol Neurosurg Psychiatry 57, 757-758

Goldfarb LG, Petersen RB, Tabaton M, Brown P, LeBlanc AC, Montagna P, Cortelli P, Julien J, Vital C, Pendelbury WW, et al., (1992). Fatal familial insomnia and familial CreutzfeldtJakob disease: disease phenotype determined by a DNA polymorphism. Science $258,806-808$ Goodman A, Goode BL, Matsudaira P, Fink GR, (2003). The Saccharomyces cerevisiae calponin/transgelin homolog Scp1 functions with fimbrin to regulate stability and organization of the actin cytoskeleton. Mol Biol Cell 14, 2617-2629

Gurney ME, Heinrich SP, Lee MR, Yin HS, (1986). Molecular cloning and expression of neuroleukin, a neurotrophic factor for spinal and sensory neurons. Science 234, 66-67

Harrington MG, Merril CR, Asher DM, Gajdusek DC, (1986). Abnormal proteins in the cerebrospinal fluid of patients with Creutzfeldt-Jakob disease. N Engl J Med 315, 279-283

Heitz S GV, Lutz Y, Rodeau JL, Zanjani HS, Sugihara I, Bombarde G, Richard F, Fuchs JP, Vogel MW, Mariani J, Bailly Y, (2008). BCL-2 counteracts Doppel-induced apoptosis of prion-protein-deficient Purkinje cells in the Ngsk Prnp(0/0) mouse. Dev Neurobiol 15, 332348

Hill AF, Desbruslais M, Joiner S, Sidle KC, Gowland I, Collinge J, Doey LJ, Lantos P, (1997). The same prion strain causes vCJD and BSE. Nature 389, 448-450

Horrobin DF, Glen AI, Vaddadi K, (1994). The membrane hypothesis of schizophrenia. Schizphr Res 13, 195-120

Hsich G, Kenney K, Gibbs Jr. C, Lee KH, Harrington MG, (1996). The 14-3-3 brain protein in cerebrospinal fluid as a marker for transmissible spongifrom encephalopathies. $\mathrm{N}$ Engl $\mathbf{J}$ Med 335, 924-930 
Huber R, Berendes R, Burger A, Schneider M, Karshikov A, Luecke H, Römisch J, Paques E, (1992). Crystal and molecular structure of human annexin V after refinement. Implications for structure, membrane binding and ion channel formation of the annexin family of proteins. $\mathbf{J}$ Mol Biol 223, 683-704

Huillard d'Aignaux JN, Cousens SN, Maccario J, Costagliola D, Alpers MP, Smith PG, Alperovitch A, (2002). The incubation period of kuru. Epidemiology 13, 402-408

Iqbal K, Grundke-Iqbal I, (1997). Elevated levels of tau and ubiquitin in brain and cerebrospinal fluid in Alzheimer's disease. Int J Geriatr Psychiatry 9 Suppl 1, 289-296

Jang M, Kang HJ, Lee SY, Chung SJ, Kang S, Chi SW, Cho S, Lee SC, Lee CK, Park BC, Bae KH, Park SG, (2009). Glyceraldehyde-3-phosphate, a glycolytic intermediate, plays a key role in controlling cell fate via inhibition of caspase activity. Mol Cells 28, 559-563

Jung J, Kim M, Kim MJ, Kim J, Moon J, Lim JS, Kim M, Lee K, (2004). Translationally controlled tumor protein interacts with the third cytoplasmic domain of Na,K-ATPase alpha subunit and inhibits the pump activity in HeLa cells. J Biol Chem 279, 49868-49875

Kleene R, Loers G, Langer J, Frobert Y, Buck F, Schachner M, (2007). Prion protein regulates glutamate-dependent lactate transport of astrocytes. J Neurosci 27, 12331-12340

Knight R, (1999). The relationship between new variant Creutzfeldt-Jakob disease and bovine spongiform encephalopathy. Vox Sang 76, 203-208

Knight CG, Zitzmann N, Prabhakar S, Antrobus R, Dwek R, Hebestreit H, Rainey PB, (2006). Unraveling adaptive evolution: how a single point mutation affects the protein coregulation network. Nat Genet 38, 1015-1012

Knopman D, Parisi JE, Salviati A, Floriach-Robert M, Boeve BF, Ivnik RJ, Smith GE, Dickson DW, Johnson KA, Petersen LE, McDonald WC, Braak H, Petersen RC, (2003). Neuropathology of cognitively normal elderly. J Neuropathol Exp Neurol 62, 1087-1095

Kuwahara C, Takeuchi AM, Nishimura T, Haraguchi K, Kubosaki A, Matsumoto Y, Saeki K, Yokoyama T, Itohara S, Onodera T, (1999). Prions prevent neuronal cell-line death. Nature $400,225-226$

Lang CJ, Heckmann JG, Neundorfer B, (1998). Creutzfeldt-Jakob disease via dural and corneal transplants. J Neurol Sci 160, 128-139

Liemann S, Benz J, Burger A, Voges D, Hofmann A, Huber R, Göttig P, (1996). Structural and functional characterisation of the voltage sensor in the ion channel human annexin V. J Mol Biol 258, 555-561 
Mahadik SP, Murkherejee S, Correnti EE, Kelkar HS, Wakade CG, Costa RM, Scheffer R, (1994). Plasma membrane phospholipid and cholesterol distribution of skin fibroblasts from drug-naive patients at the onset of psychosis. Schizphr Res 13, 239-247

Málaga-Trillo E, Solis GP, Schrock Y, Geiss C, Luncz L, Thomanetz V, Stuermer CA, (2009). Regulation of embryonic cell adhesion by the prion protein. PLoS Biol 7, e55

Mallucci GR, Ratte S, Asante EA, Linehan J, Gowland I, Jefferys JG, Collinge J, (2002). Post-natal knockout of prion protein alters hippocampal CA1 properties, but does not result in neurodegeneration. EMBO J 21, 202-210

Manson JC, Clarke AR, McBride PA, McConnell I, Hope J, (1994). PrP gene dosage determines the timing but not the final intensity or distribution of lesions in scrapie pathology. Neurodegeneration 3, 331-340

Martins-De-Souza D, WobrockT, Zerr I, Schmitt A, Gawinecka J, Schneider-Axmann T, Falkai P, Turck CW, (2010). Different apolipoprotein E, apolipoprotein A1 and prostaglandin-H2 D-isomerase levels in cerebrospinal fluid of schizophrenia patients and healthy controls. World J Biol Psychiatry 11, 719-728

Martins VR, Grane, E, Garcia-Abreu, J, de Souza SJ, Mercadante AF, Veiga SS, Zanata SM, Neto VM, Brentani RR, (1997). Complementary hydropathy identifies a cellular prion protein receptor. Nat Med 3, 1376-1382

McBride PA, Eikelenboom P, Kraal G, Fraser H, Bruce ME, (1992). PrP protein is associated with follicular dendritic cells of spleens and lymph nodes in uninfected and scrapie-infected mice. J Pathol 168, 413-418

Mclennan NF, Brennan PM, McNeill A, Davies I, Fotheringham A, Rennison KA, Ritchie D, Brannan F, Head MW, Ironside JW, et al., (2004). Prion protein accumulation and neuroprotection in hypoxic brain damage. Am J Pathol 165, 227-235

Meissner B, Kallenberg K, Sanchez-Juan P, Collie D, Summers DM, Almonti S, Collins SJ, Smith P, Cras P, Jansen GH, Brandel JP, Coulthart MB, Roberts H, Van Everbroeck B, Galanaud D, Mellina V, Will RG, Zerr I (2009). MRI lesion profiles in sporadic CreutzfeldtJakob disease. Neurology 72, 1994-2001

Milhavet O, Lehmann S, (2002). Oxidative stress and the prion protein in transmissible spongiform encephalopathies. Brain Res Res Rev 38, 328-339 
Milhavet O, MacMahon HE, Rachidi W, Nishida N, Katamine S, Mangé A, Arlotto M, Casanova D, Riondel J, Favier A, Lehmann S, (2000). Prion infection impairs the cellular response to oxidative stress. Proc Natl Acad Sci U S A 97, 13937-13942

Müller T, Concannon CG, Ward MW, Walsh CM, Tirniceriu AL, Tribl F, Kögel D, Prehn JH, Egensperger R, (2007). Modulation of gene expression and cytoskeletal dynamics by the amyloid precursor protein intracellular domain (AICD). Mol Biol Cell 18, 201-210

Mabbott NA, Burce MR, (2004). Complement component C5 is not involved in scrapie pathogenesis. Immunobiology 209, 545-9

Mead S, (2006). Prion disease genetics. Eur J Hum Genet 14, 273-81

Nazor KE, Kuhn F, Seward T, Green M, Zwald D, Pürro M, Schmid J, Biffiger K, Power AM, Oesch B, Raeber AJ, Telling GC, (2005). Immunodetection of disease-associated mutant PrP, which accelerates disease in GSS transgenic mice. EMBO J 24, 2472-2478

Nieznanski K, Podlubnaya Z, Nieznanska H, (2006). Prion protein inhibits microtubule assembly by inducing tubulin oligomerization. Biochem Biophys Res Commun 349, 391-399 Niinaka Y, Paku S, Haga A, Watanabe H, Raz A, (1998). Expression and secretion of neuroleukin/phosphohexose isomerase/maturation factor as autocrine motility factor by tumor cells. Cancer Res 58, 2667-2674

Paitel E, Alves da Costa C, Vilette D, Grassi J, Checler F, (2002). Overexpression of PrPc triggers caspase 3 activation: potentiation by proteasome inhibitors and blockade by anti-PrP antibodies. J Neurochem 83, 1208-1214

Paitel E, Fahraeus R, Checler F, (2003). Cellular prion protein sensitizes neurons to apoptotic stimuli through Mdm2-regulated and p53-dependent caspase 3-like activation. J Biol Chem 278, 10061-10066

Palmer MS, Dryden AJ, Hughes JT, Collinge J, (1991). Homozygous prion protein genotype predisposes to sporadic Creutzfeldt-Jakob disease [published erratum appears in Nature 1991 Aug 8;352(6335):547] Nature 352, 340-342

Pan KM, Baldwin M, Nguyen J, Gasset M, Serban A, Groth D, Mehlhorn I, Huang Z, Fletterick RJ, Cohen FE, et al., (1993). Conversion of alpha-helices into beta-sheets features in the formation of the scrapie prion proteins. Proc Natl Acad Sci U S A 90, 10962-10966 Parchi P, Capellari, S, Brown P, Sima, A.A.F., Mikol, J., Gray, F., Frosch, M.P., Trojanowski, J.Q., Vital, C., Ghetti, B., et al. (1999a). Molecular and clinico-pathologic phenotypic variability in genetic Creutzfeldt-Jakob disease. Neurology 52 (Suppl 2), A323-324 
Parchi P, Giese A, Capellari S, Brown P, Schulz-Schaeffer W, Windl O, Zerr I, Budka H, Kopp N, Piccardo P, Poser S, Rojiani A, Streichemberger N, Julien J, Vital C, Ghetti B, Gambetti P, Kretzschmar H, (1999). Classification of Sporadic Creutzfeldt-Jakob Disease Based on Molecular and Phenotypic Analysis of 300 Subjects. Ann Neurol 46, 224-233

Pauly PC, Harris DA, (1998). Copper stimulates endocytosis of the prion protein. J Biol Chem 273, 33107-33110

Petersen R, Parisi JE, Dickson DW, Johnson KA, Knopman DS, Boeve BF, Jicha GA, Ivnik RJ, Smith GE, Tangalos EG, Braak H, Kokmen E, (2006). Neuropathologic features of amnestic mild cognitive impairment. Arch Neurol 63, 665-672

Petrakis S, Sklaviadis T, (2006). Identification of proteins with high affinity for refolded and native PrPC. Proteomics 6, 6476-6484

Piubelli C, Fiorini M, Zanusso G, Milli A, Fasoli E, Monaco S, Righetti PG, (2006). Searching for markers of Creutzfeldt-Jakob disease in cerebrospinal fluid by two-dimensional mapping. Proteomics 6 Suppl 1 256-261

Prado MA, Alves-Silva J, Magalhães AC, Prado VF, Linden R, Martins VR, Brentani RR, (2004). PrPc on the road: trafficking of the cellular prion protein. J Neurochem 88, 769-768

Prosniak M, Zborek A, Scott GS, Roy A, Phares TW, Koprowski H, Hooper DC, (2003). Differential expression of growth factors at the cellular level in virus-infected brain. Proc Natl Acad Sci U S A 100, 6765-6770

Prusiner SB, Scott M, Foster D, Pan KM, Groth D, Mirenda C, Torchia M, Yang SL, Serban D, Hoppe PC, et al., (1990). Transgenetic studies implicate interactions between homologous PrP isoforms in scrapie prion replication. Cell 63, 673-686

Puchades M, Hansson SF, Nilsson CL, Andreasen N, Blennpw K, Davidsson P, (2003). Proteomic studies of potential cerebrospinal fluid protein markers for Alzheimer's disease. Brain Res Mol Brain Res 118, 140-146

Ramljak S, Asif AR, Armstrong VW, Wrede A, Groschup MH, Buschmann A, SchulzSchaeffer W, Bodemer W, Zerr I, (2008). Physiological role of the cellular prion protein (PrPc): protein profiling study in two cell culture systems. J Proteome Res 7, 2681-2695

Reutelingsperger CP, van Heerde WL, (1997). Annexin V, the regulator of phosphatidylserine-catalyzed inflammation and coagulation during apoptosis. Cell Mol Life Sci 53, 527-532 
Riek R, Hornemann S, Wider G, Billeter M, Glockshuber R, Wüthrich K, (1996). NMR structure of the mouse prion protein domain PrP(121-321). Nature 382, 180-182

Riek R, Hornemann S, Wider G, Glockshuber R, Wuthrich K, (1997). NMR characterization of the full-length recombinant murine prion protein, $\operatorname{mPrP}(23-231)$. FEBS Lett 413, 282-288

Romagnoli A, Oliverio S, Evangelisti C, Iannicola C, Ippolito G, Piacentini M, (2003). Neuroleukin inhibition sensitises neuronal cells to caspase-dependent apoptosis. Neuroleukin inhibition sensitises neuronal cells to caspase-dependent apoptosis 302, 448-445

Roucou X, Guo Q, Zhang Y, Goodyer CG, LeBlanc AC, (2003). Cytosolic prion protein is not toxic and protects against Bax-mediated cell death in human primary neurons. J Biol Chem 278, 40877-40881

Rutishauser D, Mertz KD, Moos R, Brunner E, Rülicke T, Calella AM, Aguzzi A, (2009). The comprehensive native interactome of a fully functional tagged prion protein. PLoS One 4, e4446

Sakurai-Yamashita Y, Sakaguchi S, Yoshikawa D, Okimura N, Masuda Y, Katamine S, Niwa M, (2005). Female-specific neuroprotection against transient brain ischemia observed in mice devoid of prion protein is abolished by ectopic expression of prion protein-like protein. Neuroscience 136, 281-287

Sanchez-Juan P, Green A, Ladogana A, Cuadrado-Corrales N, Sanchez-Valle R, Mitrova E, Stoeck K, Sklaviadis T, Kulczycki J, Hess K, et al., (2006). Cerebrospinal fluid tests in the differential diagnosis of CJD. Neurology 67, 637-643

Sanchez JC, Guillaume E, Lescuyer P, Allard L, Carrette O, Scherl A, Burgess J, Corthals GL, Burkhard PR, Hochstrasser DF, (2004). Cystatin C as a potential cerebrospinal fluid marker for the diagnosis of Creutzfeldt-Jakob disease. Proteomics 4, 2229-2233

Satoh J, Nanri Y, Yamamura T, (2006). Rapid identification of 14-3-3-binding proteins by protein microarray analysis. J Neurosci Methods 152, 278-288

Schneider B, Mutel V, Pietri M, Ermonval M, Mouillet-Richard S, Kellermann O, (2003). NADPH oxidase and extracellular regulated kinases $1 / 2$ are targets of prion protein signaling in neuronal and nonneuronal cells. Proc Natl Acad Sci U S A 100, 13326-13331

Silveira JR, Raymond GJ, Hughson AG, Race R, Sim VL, Hayes SF, Caughey B, (2005). The most infectious prion protein particles. Nature 437, 257-261 
Solforosi L, Criado JR, McGavern DB, Wirz S, Sánchez-Alavez M, Sugama S, DeGiorgio LA, Volpe BT, Wiseman E, Abalos G, Masliah E, Gilden D, Oldstone MB, Conti B, Williamson RA, (2004). Cross-linking cellular prion protein triggers neuronal apoptosis in vivo. Science $303,1514-1516$

Sparkes RS, Simon M, Cohn VH, Fournier RE, Lem J, Klisak I, Heinzmann C, Blatt C, Lucer, M, Mohandas T, et al., (1986). Assignment of the human and mouse prion protein genes to homologous chromosomes. Proc Natl Acad Sci U S A 83, 7358-7362

Spielhaupter C, Schatzl, HM, (2001). $\operatorname{PrP}^{\mathrm{c}}$ directly interacts with proteins involved in signaling pathways. J Biol Chem 276, 44604-44612

Spudich A, Frigg R, Kilic E, Kilic U, Oesch B, Raeber A, Bassetti CL, Hermann DM, (2005). Aggravation of ischemic brain injury by prion protein deficiency: role of ERK-1/-2 and STAT-1. Neurobiol Dis 20, 442-449

Stuermer CA, Langhorst MF, Wiechers MF, Legler DF, Von Hanwehr SH, Guse AH, Plattner $\mathrm{H}$, (2004). PrPc capping in T cells promotes its association with the lipid raft proteins reggie-1 and reggie-2 and leads to signal transduction. Faseb J 18, 1731-1733

Sunderland T, Linker G, Mirza N, Putnam KT, Friedman DL, Kimmel LH, Bergeson J, Manetti GJ, Zimmermann M, Tang B, et al., (2003). Decreased B-amyloid 1-42 and increased tau levels in cerebrospinal fluid of patients with Alzheimer disease. Journal of the American Medical Association 289, 2094-2103

Telling GC, Scott M, Mastrianni J, Gabizon R, Torchia M, Cohen FE, DeArmond SJ, Prusiner SB, (1995). Prion propagation in mice expressing human and chimeric $\operatorname{PrP}$ transgenes implicates the interaction of cellular PrP with another protein. Cell 83, 79-90

Tsutsumi S, Hogan V, Nabi IR, Raz A, (2003). Overexpression of the autocrine motility factor/phosphoglucose isomerase induces transformation and survival of NIH-3T3 fibroblasts. Cancer Res 63, 242-249

van Engeland M, Ramaekers F, Schutte B, Reutelingsperger CP, (1996). A novel assay to measure loss of plasma membrane asymmetry during apoptosis of adherent cells in culture. Cytometry 24, 131-139

Van Everbroeck BR, Boons J, Cras P, (2005). 14-3-3 gamma-isoform detection distinguishes sporadic Creutzfeldt-Jakob disease from other dementias. J Neurol Neurosurg Psychiatry 76, $100-102$ 
Vassallo N, Herms J, Behrens C, Krebs B, Saeki K, Onodera T, Windl O, Kretzschmar HA, (2005). Activation of phosphatidylinositol 3-kinase by cellular prion protein and its role in cell survival. Biochem Biophys Res Commun 332, 75-82

Watanabe N, Seto H, Shimizu M, Tanii Y, Kim YD, Shibata R, Kawaguchi M, Tsuji S, Morijiri M, Kageyama M, et al., (1996). Brain SPECT of Creutzfeldt-Jakob disease. Clin Nucl Med 21, 236-241

Watts JC, Huo H, Bai Y, Ehsani S, Jeon AH, Shi T, Daude N, Lau A, Young R, Xu L, Carlson GA, Williams D, Westaway D, Schmitt-Ulms G, (2009). Interactome analyses identify ties of PrP and its mammalian paralogs to oligomannosidic N-glycans and endoplasmic reticulum-derived chaperones. PLoS Pathog 5, e100060

Westaway D, DeArmond SJ, Cayetano-Canlas J, Groth D, Foster D, Yang S-L, Torchi, M, Carlson GA, Prusiner SB, (1994). Degeneration of skeletal muscle, peripheral nerves, and the central nervous system in transgenic mice overexpressing wild-type prion proteins. Cell 76, 117-129

Wharton S, Williams GH, Stoeber K, Gelsthorpe CH, Baxter L, Johnson AL, Ince PG, (2005). Expression of Ki67, PCNA and the chromosome replication licensing protein Mcm2 in glial cells of the ageing human hippocampus increases with the burden of Alzheimer-type pathology. Neurosci Lett 383, 33-38

WHO, (1998). Human transmissible spongiform encephalopathies. Wkly Epidemiol Rec 47, $361-365$

Will RG, (2003). Acquired prion disease: iatrogenic CJD, variant CJD, kuru. Br Med Bull 66, 255-265

Will RG, Zeidler, M., Stewart, G.E., Macleod, M.A., Ironside, J.W., Cousens, S.N., Mackenzie, J., Estibeiro, K., Green, AJ, Knight RS, (2000). Diagnosis of new variant Creutzfeldt-Jakob disease. Ann Neurol 47, 575-582

Wong BS, Liu, T, Li R, Pan T, Petersen RB, Smith MA, Gambetti P, Perry G, Manson JC, Brown DR, et al., (2001). Increased levels of oxidative stress markers detected in the brains of mice devoid of prion protein. J Neurochem 76, 565-572

Wopfner F, Weidenhöfer G, Schneider R, von Brunn A, Gilch S, Schwarz TF, Werner T, Schätzl HM, (1999). Analysis of 27 mammalian and 9 avian PrPs reveals high conservation of flexible regions of the prion protein. J Mol Biol 289, 1163-1178 
Xiang W, Hummel M, Mitteregger G, Pace C, Windl O, Mansmann U, Kretzschmar HA, (2007). Transcriptome analysis reveals altered cholesterol metabolism during the neurodegeneration in mouse scrapie model. J Neurochem 102, 834-847

Xiang W, Windl O, Westner IM, Neumann M, Zerr I, Lederer RM, Kretzschmar HA, (2005).

Cerebral gene expression profiles in sporadic Creutzfeldt-Jakob disease. Ann Neurol 58, 242257

Xiang W, Windl O, Wünsch G, Dugas M, Kohlmann A, Dierkes N, Westner IM, Kretzschmar HA, (2004). Identification of differentially expressed genes in scrapie-infected mouse brains by using global gene expression technology. J Virol 78, 11051-11060

Yoo BC, Krapfenbauer K., Cairns N, Belay G, Bajo M, Lubec G, (2002). Overexpressed protein disulfide isomerase in brains of patients with sporadic Creutzfeldt-Jakob disease. Neurosci Lett 34, 196-200

Yoshizaki H, Tanabe S, Arai K, Murakami A, Wada Y, Ohkuchi M, Hashimoto Y, Maki M, (1992). Effects of calphobindin II (annexin VI) on procoagulant and anticoagulant activities of cultured endothelial cells. Chem Pharm Bull (Tokyo) 40, 1860-1863

Zerr I, Bodemer M, Otto M, Poser S, Windl O, Kretzschmar HA, Gefeller O, Weber T, (1996). Diagnosis of Creutzfeldt-Jakob disease by two-dimensional gel electrophoresis of cerebrospinal fluid. Lancet 348, 846-849. 


\section{LIST OF PUBLICATIONS}

1. Gawinecka J, Dieks J, Asif AR, Carimalo J, Heinemann U, Streich JH, Dihazi H, SchulzSchaeffer W, Zerr I. Codon 129 polymorphism specific CSF proteome pattern in sporadic Creutzfeldt-Jakob disease - the implication of glycolytic enzymes in $\mathrm{PrP}^{\mathrm{Sc}}$-induced pathology. J Proteome Res 2010 Sep 27 [Epub ahead print]

2. Weiss E, Ramljak S, Asif AR, Ciesielczyk B, Schmitz M, Gawinecka J, SchulzSchaeffer W, Behrens C, Zerr I. Cellular prion protein overexpression disturbs cellular homeostasis in SH-SY5Y neuroblastoma cells but does not alter p53 expression: a proteomic study. Neuroscience 2010 Sep; 169(49):1640-50

3. Schmitz M, Schlomm M, Hasan B, Beekes M, Mitrova E, Korth C, Breil A, Carimalo J, Gawinecka J, Varges D, Zerr I. Codon 129 polymorphism and the E200K mutation do not affect the cellular prion protein isoform composition in the cerebrospinal fluid from patients with Creutzfeldt-Jakob Disease. Eur J Neurosci 2010 Jun; 31(11):2024-31

4. Martins-De-Souza D, Wobrock T, Zerr I, Schmitt A, Gawinecka J, Schneider-Axmann T, Falkai P, Turck CW. Different apolipoprotein E, apolipoprotein A1 and prostaglandinH2 D-isomerase levels in cerebrospinal fluid of schizophrenia patients and healthy controls. World J Biol Psychiatr. 2010 Aug; 11(5):719-28

5. Gawinecka J, I Zerr. Cerebrospinal fluid biomarkers in human prion diseases, Future Neurology 2010; 5(2):301:316 - review

6. Gmitterová K, Heinemann U, Gawinecka J, Varges D, Ciesielczyk B, Valkovic P, Benetin J, Zerr I. 8-OHdG in Cerebrospinal Fluid as a Marker of Oxidative Stress in Various Neurodegenerative Diseases, Neurodegener Dis 2009 Dec; 6(5-6):263-9

7. Wemheuer WM, Benesrtad SL, Wrede A, Schulze-Strum U, Wemheuer WE, Hahmann U, Gawinecka J, Schütz E, Zerr I, Brening B, Bratberg B, Andreoletti O, SchulzSchäffer WJ. Similarities between forms of sheep scrapie and Creutzfeldt-Jakob disease are encoded by distinct prion types, Am J Pathol 2009 Dec; 175(6):2566-73

8. Ladogana A, Sanchez-Juan P, Mitrová E, Green A, Cuadrado-Corrales N, Sánchez-Valle R, Koscova S, Aguzzi A, Sklaviadis T, Kulczycki J, Gawinecka J, Saiz A, Calero M, van Duijn CM, Pocchiari M, Knight R, Zerr I. Cerebrospinal fluid biomarkers in human genetic Transmissible Spongiform Encephalopathies (TSEs), J Neurol 2009 Oct; 256(10):1620-8 


\section{CURRICULUM VITAE}

\section{Personal data}

Name

Joanna Gawinecka

Date of birth

20.03.1981

Place of birth

Aleksandrow Kujawski, Poland

Nationality

Polish

\section{Education/Experience}

- February 2008-present

Ph.D. Program Molecular Medicine

Georg-August University School of Sciences

Göttingen, Germany

- August 2006-present

Prion Research Group, Department of Neurology

Medical Center Georg-August University

(headed by Prof. Dr. Inga Zerr)

Göttingen, Germany

Graduate studies

- 2000-2006

Gdansk University of Technology

Gdansk, Poland

Master's Degree in Biotechnology

Specialization: Molecular and Pharmaceutical Biotechnology

- July 2005

Department of Medical Microbiology and Clinical Immunology

The Children`s Memorial Health Institute

Warsaw, Poland

Short term laboratory traineeship

- March-November 2004 Biotechnology Development

Novartis Pharma,

Basel, Switzerland

research on expression of recombinant proteins used as

biopharmaceuticals

- July 2002

Laboratory of Medical Microbiology

Powiatowa Stacja Sanitarno-Epidemiologiczna

Alekasandrow Kujawski, Poland

Short term laboratory traineeship

- 1996-2000

X Secondary School

Torun, Poland

High School Final Exam: Mathematics 